Florida International University

FIU Digital Commons

FIU Electronic Theses and Dissertations

University Graduate School

3-24-2014

\title{
The Roles of Microcystin and Sulfide in Physiology and Tactic Responses of Pathogenic and Non- Pathogenic Mat-Forming Cyanobacteria
}

Abigael C. Brownell

Florida International University, abrow093@fiu.edu

DOI: $10.25148 /$ etd.FI14040886

Follow this and additional works at: https://digitalcommons.fiu.edu/etd

Part of the Biology Commons, Environmental Microbiology and Microbial Ecology Commons, Marine Biology Commons, Microbial Physiology Commons, Other Microbiology Commons, and the Pathogenic Microbiology Commons

\section{Recommended Citation}

Brownell, Abigael C., "The Roles of Microcystin and Sulfide in Physiology and Tactic Responses of Pathogenic and Non-Pathogenic Mat-Forming Cyanobacteria" (2014). FIU Electronic Theses and Dissertations. 1364.

https://digitalcommons.fiu.edu/etd/1364

This work is brought to you for free and open access by the University Graduate School at FIU Digital Commons. It has been accepted for inclusion in FIU Electronic Theses and Dissertations by an authorized administrator of FIU Digital Commons. For more information, please contact dcc@fiu.edu. 


\section{FLORIDA INTERNATIONAL UNIVERSITY}

Miami, Florida

\section{THE ROLES OF MICROCYSTIN AND SULFIDE IN PHYSIOLOGY AND TACTIC RESPONSES OF PATHOGENIC AND NON-PATHOGENIC MAT-FORMING CYANOBACTERIA}

A thesis submitted in partial fulfillment of the requirements for the degree of

MASTER OF SCIENCE

in

BIOLOGY

by

Abigael C. Brownell

2014 
To: Dean Kenneth G. Furton

College of Arts and Sciences

This thesis, written by Abigael C. Brownell, and entitled The Roles of Microcystin and Sulfide in Physiology and Tactic Responses of Pathogenic and Non-Pathogenic Mat-Forming Cyanobacteria, having been approved in respect to style and intellectual content, is referred to you for judgment.

We have read this thesis and recommend that it be approved.

Miroslav Gantar

Eric von Wettberg

Laurie L. Richardson, Major Professor

Date of Defense: March 24, 2014

The thesis of Abigael C. Brownell is approved.

$\begin{array}{r}\begin{array}{r}\text { Dean Kenneth G. Furton } \\ \text { College of Arts and Sciences }\end{array} \\ \hline \begin{array}{r}\text { Dean Lakshmi N. Reddi } \\ \text { University Graduate School }\end{array}\end{array}$

Florida International University, 2014 
(C) Copyright 2014 by Abigael C. Brownell

All rights reserved. 


\section{DEDICATION}

This thesis is dedicated to my parents, Katie and Dave. Without their love and support, this work would not have been possible. 


\section{ACKNOWLEDGMENTS}

This research was supposed by the National Science Foundation (Grant 1208784). 


\begin{abstract}
OF THE THESIS
THE ROLES OF MICROCYSTIN AND SULFIDE IN PHYSIOLOGY AND TACTIC RESPONSES OF PATHOGENIC AND NON-PATHOGENIC

MAT-FORMING CYANOBACTERIA
\end{abstract}

by

Abigael C. Brownell

Florida International University, 2014

Miami, Florida

Professor Laurie L. Richardson, Major Professor

Planktothricoides raciborskii and Roseofilum reptotaenium are physiologically

similar, yet ecologically distinct organisms found in a hot spring outflow and coral black band disease (BBD), respectively. The aim of this study was to elucidate the relationship between $R$. reptotaenium and sulfide in $\mathrm{BBD}$, to compare microcystin (MC) production in response to environmental factors, and to determine chemotactic responses to MC and sulfide by the two organisms. Results showed that the pathogenicity of $R$. reptotaenium in BBD is dependent on sulfate-reducing bacteria as secondary pathogens. Roseofilum reptotaenium produced significantly more $\mathrm{MC}$ than $P$. raciborskii, as measured using ELISA. Roseofilum reptotaenium was negatively chemotactic to sulfide, determined using horizontal and vertical gradients in agar, while $P$. raciborskii was not affected. Neither cyanobacterium was chemotactic to MC in the agar assays. The ecophysiology of $P$. raciborskii and $R$. reptotaenium in relation to $\mathrm{MC}$ production and response to sulfide reflected their pathogenic versus non-pathogenic status. 


\section{TABLE OF CONTENTS}

CHAPTER

PAGE

COMPARISON OF PLANKTOTHRICOIDES RACIBORSKII FROM HUNTER'S HOT SPRINGS, OREGON AND ROSEOFILUM REPTOTAENIUM FROM

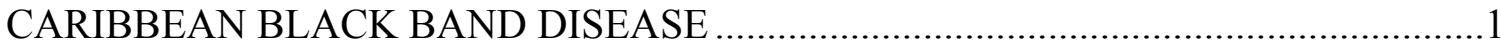

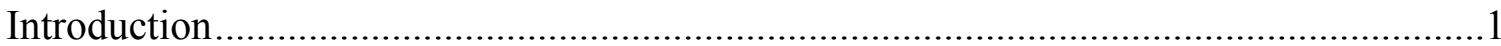

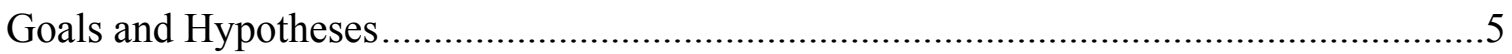

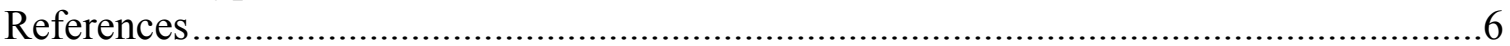

SULFATE REDUCING BACTERIA AS SECONDARY AND NECESSARY PATHOGENS IN BLACK BAND DISEASE OF CORAL ………….........................12

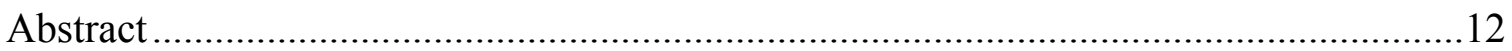

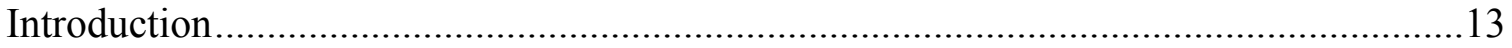

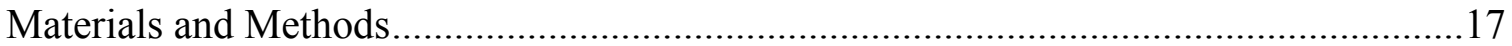

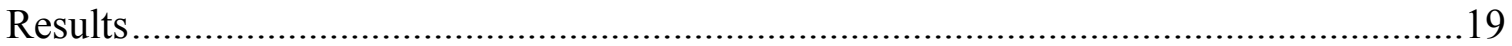

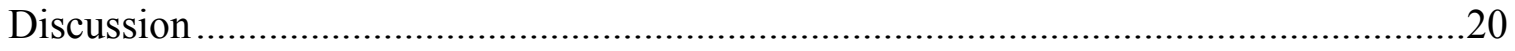

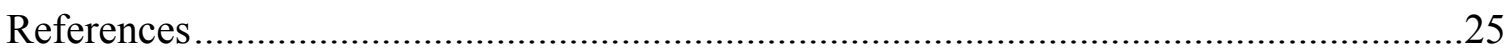

COMPARISON OF MICROCYSTIN PRODUCTION BY THE CYANOBACTERIA PLANKTOTHRICOIDES RACIBORSKII AND ROSEOFILUM REPTOTAENIUM IN RESPONSE TO ENVIRONMENTAL FACTORS .................................................

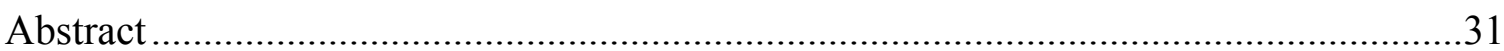

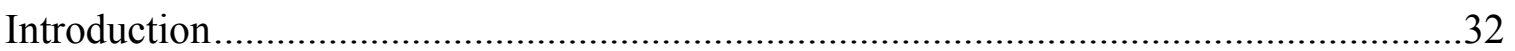

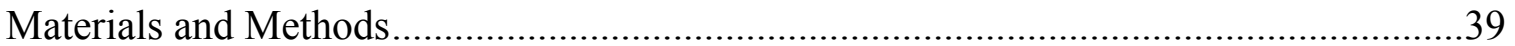

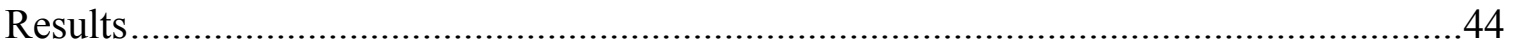

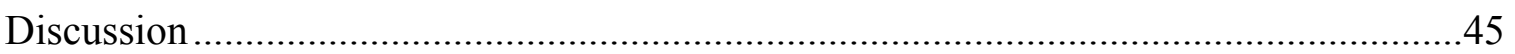

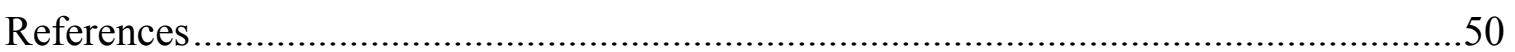

CHEMOTACTIC RESPONSE TO MICROCYSTIN AND SULFIDE BY PLANKTOTHRICOIDES RACIBORSKII AND ROSEOFILUM REPTOTAENIUM .......62

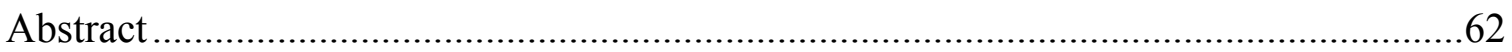

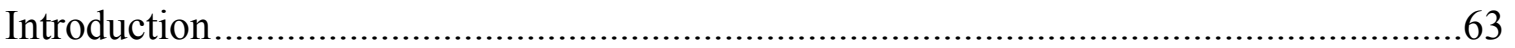

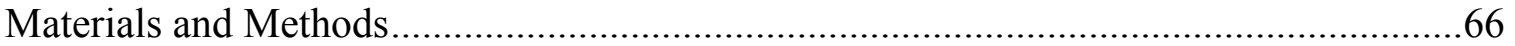

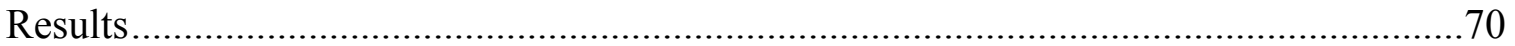

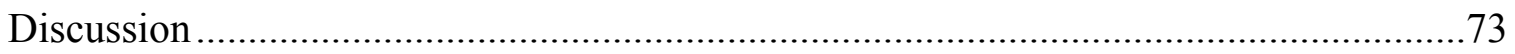

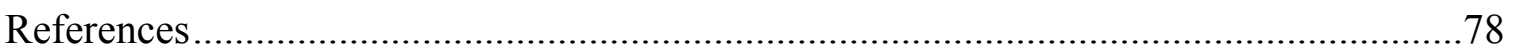

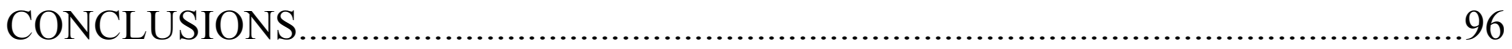

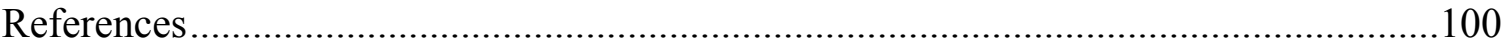




\section{LIST OF TABLES}

$\begin{array}{lll}\text { TABLE } & \text { PAGE }\end{array}$

\section{CHAPTER III}

Table 1. Microcystin production by Planktothricoides raciborskii as measured by ELISA assay

\section{CHAPTER IV}

Table 1. Chemotactic response of Roseofilum reptotaenium and Planktothricoides raciborskii to sulfide

Table 2. Chemotactic response of Roseofilum reptotaenium and Planktothricoides raciborskii to microcystin

Table 3. Chemotactic response of Roseofilum reptotaenium and Planktothricoides raciborskii to microcystin when incubated under a diffuse light source

Table 4. Chemotactic response of Roseofilum reptotaenium and Planktothricoides raciborskii to microcystin and sulfide in vertical gradients 


\section{LIST OF FIGURES}

FIGURE

PAGE

\section{CHAPTER I}

Figure 1. Comparison of black band disease mat and Hunter's Hot Springs mat displaying their physical similarities

Figure 2. Hunter's Hot Springs in Oregon .............................................................10

Figure 3. Black band disease infecting a scleractinian coral head in Curaçao .11

\section{CHAPTER II}

Figure 1. Photomicrograph of the laboratory culture of Roseofilum reptotaenium strain 101-1

Figure 2. Successful infection of a Montastraea cavernosa coral fragment after inoculation with Roseofilum reptotaenium in the control (artificial seawater only) tank

Figure 3. Unsuccessful infection of a Montastraea cavernosa coral fragment after inoculation with Roseofilum reptotaenium in the experimental aquarium containing artificial seawater and sodium molybdate

\section{CHAPTER III}

Figure 1. Structure of microcystin

Figure 2. The microcystin gene complex found in toxic cyanobacteria depicting the microcystin synthase gene clusters, mcyABC, mcyDE, mcyGF, and mcyHIJ ...58

Figure 3. Photomicrograph of Planktothricoides raciborskii, a hot spring cyanobacterium from Hunter's Hot Springs

Figure 4. Microcystin production by Planktothricoides raciborskii in response to environmental factors

Figure 5. Comparison of microcystin production by Roseofium reptotaenium and Planktothricoides raciborskii. 


\section{CHAPTER IV}

Figure 1. A depiction of the migration distance measurement in the horizontal chemotaxis experiment

Figure 2. Sample collection for the Pachmayr Assay to document the sulfide gradient in the horizontal sulfide chemotaxis experiments

Figure 3. Diffusion of a mixture of microcystin and safranin dye into agar ...................87

Figure 4. Depiction of the vertical chemotaxis experiment ........................................88

Figure 5. Comparison of Roseofilum reptotaenium and Planktothricoides raciborskii control plates in the sulfide and microcystin chemotaxis experiments.

Figure 6. Movement of Roseofilum reptotaenium filaments around the sulfide-ring .......90

Figure 7. Chemotaxis of Planktothricoides raciborskii filaments into the area of high sulfide concentration

Figure 8. Chemotactic response of Roseofilum reptotaenium to microcystin

Figure 9. Chemotactic response of Planktothricoides raciborskii to microcystin

Figure 10. Response of Roseofilum reptotaenium to artificial gradients of microcystin and sulfide in the vertical chemotaxis experiment

Figure 11. Response of Planktothricoides raciborskii to artificial gradients of microcystin and sulfide in a vertical chemotaxis trial 


\section{CHAPTER I}

\section{COMPARISON OF PLANKTOTHRICOIDES RACIBORSKII FROM HUNTER'S \\ HOT SPRINGS, OREGON AND ROSEOFILUM REPTOTAENIUM FROM \\ CARIBBEAN BLACK BAND DISEASE \\ Introduction}

\section{Overview of Research}

My study focused on two cyanobacterial mat systems, one present in a hot spring outflow (Hunter's Hot Springs, Lakeview, Oregon), and one in cyanobacterially dominated black band disease (BBD) of tropical and sub-tropical coral. Cyanobacteria present in both systems are microcystin (MC) producers, but the overall ecology of the two systems is extremely different (Figure 1). The hot spring system depends on photoautotrophic production. In contrast, BBD is heterotrophically-based and dependent on lysing coral tissue. Both mats contain filamentous, gliding, phycoerythrin-rich, nonheterocystous, mat forming cyanobacteria. In both systems a vertically migrating oxygensulfide interface occurs in the top 1-2 mm of mat, creating an anoxic-oxic interface (Richardson and Castenholz, 1987a; Carlton and Richardson, 1995). The upper layer is supersaturated with $\mathrm{O}_{2}$ during daylight (caused by cyanobacterial oxygenic photosynthesis), while the lower layer is anaerobic, reducing, and contains high concentrations of sulfide (Richardson and Castenholz, 1987a; Carlton and Richardson, 1995). Cyanobacteria in both systems are able to conduct sulfide-resistant, oxygenic photosynthesis (Richardson and Castenholz, 1987b; Richardson and Kuta, 2003; Myers and Richardson, 2008), which is an unusual trait among cyanobacteria in general. 


\section{Ecology of Hunter's Hot Springs Cyanobacterial Mats}

Hunter's Hot Springs is an alkaline, geothermal spring with high sulfur concentrations found in south-central Oregon (Figure 2) (Wickstrom and Castenholz, 1985). These unique conditions lead to the formation of stratified cyanobacterial mats where the dominating cyanobacterial population is dependent on a combination of temperature tolerance, light intensity, and predation. The temperature within the mat decreases as the water flows away from the source pool. Temperatures within the source pool have been recorded at $88^{\circ} \mathrm{C}$ in winter and $96^{\circ} \mathrm{C}$ in summer. Populations of the unicellular cyanobacterium Synechococcus lividus dominate the overmat below $74^{\circ} \mathrm{C}$ and above $54^{\circ} \mathrm{C}$ with an undermat consisting mainly of the green sulfur bacterium, Chloroflexus aurantiacus (Wickstrom and Castenholz, 1985). In temperatures lower than $54^{\circ} \mathrm{C}$ a filamentous cyanobacterium, originally described as Oscillatoria terebriformis but identified as Planktothricoides raciborskii on the basis of 16S rRNA gene sequencing (discussed in Chapter III), becomes dominant in the overmat (Wickstrom and Castenholz, 1985). While S. lividus, C. aurantiacus, and the filamentous cyanobacterium can grow at temperatures as low as $35^{\circ} \mathrm{C}$, predation by the thermophilic ostracod Potamocypris, whose upper temperature limit is $48{ }^{\circ} \mathrm{C}$, prevents the mat from moving into lower temperatures (Wickstrom and Castenholz, 1985). In the hot spring mat system, $P$. raciborskii exhibits a unique pattern of diel movements - it is found in the aerobic, overmat during the day but moves into the anaerobic undermat at night (Richardson and Castenholz, 1987a). 


\section{Ecology of Black Band Disease of Coral}

Black band disease affects both scleractinian and gorgonian corals on tropical and sub-tropical reefs around the world (Figure 3) (Edmunds, 1991). The disease manifests as a dark band that travels across the surface of coral, lysing coral tissue and leaving behind bare coral skeleton (Richardson, 1996). Different BBD-associated factors can cause tissue lysis, including anoxia, sulfide produced by BBD sulfate reducers, and microcystin (MC) produced by BBD cyanobacteria (Richardson, 1996; Richardson et al., 2009). Microcystin is damaging to coral tissue, symbiotic zooxanthellae, and the microbial community of the coral (Richardson et al., 2009). In addition to cyanobacteria, the BBD mat contains diverse heterotrophic bacteria including sulfate reducers and sulfide oxidizers (Richardson, 1996). Cyanobacteria in BBD are well adapted to the sulfide-rich environment and are able to perform sulfide-resistant, oxygenic photosynthesis (Myers et al., 2007). Myers et al. (2007) identified two cyanobacterial genera in BBD on reefs of the Florida Keys capable of this process, Geitlerinema and Leptolyngbya. Roseofilum reptotaenium is also able to conduct oxygenic photosynthesis in the presence of sulfide and is implicated as the primary pathogen in BBD of coral (Stanić, 2010; Casamatta et al., 2012). The BBD cyanobacterial microbial mat is unique because it is both pathogenic and motile.

\section{Hunter's Hot Springs and Black Band Disease Cyanobacterial Mats}

Microcystin production by cyanobacteria in BBD has been suggested to be a significant virulence factor for this coral disease (Richardson et al., 2009). Cyanobacteria isolated from BBD mat samples in Caribbean coral, identified as Geitlerinema sp., Leptolyngbya sp. and Roseofilum reptotaenium, all tested positive for MC production; the 
most common MC variant present was MC-LR (Stanić et al., 2011). Microcystin-LR is considered the most toxic variant of MC (Butler et al., 2009). Microcystin production in various hot spring mats around the world and its response to environmental factors is well documented (e.g., Krienitz et al., 2003; Kotut et al., 2006; Mohamed, 2008), but there have been no studies quantifying the production of MC in Hunter's Hot Springs. Environmental factors affect MC production by BBD cyanobacteria (Stanić et al., 2011), and environmental changes could affect MC production in Hunter's Hot Springs as well. However, these environmental factors can have different significance in each system because of their ecological dissimilarities. For example in the BBD system, increased nutrients (linked to eutrophication) amplified the pathogenicity of the disease (Voss and Richardson, 2006) but it is not known how such nutrient dynamics affect the physiology of the BBD mat. There are no reported studies on the effect of nutrient enrichment on MC production in Hunter's Hot Springs mats.

While the potential role of toxic cyanobacteria in BBD has been examined, few studies have focused on the role of sulfide and sulfate reducing bacteria in BBD pathogenesis. The presence of sulfate reducing bacteria (SRB) in the BBD mat has been suggested and/or characterized by many research groups (Carlton and Richardson, 1995; Cooney et al., 2002; Frias-Lopez et al., 2002, 2004; Viehman et al., 2006; Sekar et al., 2006, 2008; Barneah et al., 2007; Sato et al., 2010; Glas et al., 2012). Richardson et al. (2009) investigated the role of SRB in disease pathogenesis and found that sulfate reduction is important to BBD development. However, this research was conducted using a sample of naturally collected BBD, thus the complete disease consortium was present 
(Richardson et al., 2009). Currently, no studies can specify whether SRB are necessary for the initiation of BBD.

\section{Goals and Hypotheses}

The overall objective of my thesis is to elucidate the impact of microcystin and sulfide on potential pathogenicity of the cyanobacteria Planktothricoides raciborskii and Roseofilum reptotaenium. I will further investigate the role of sulfide in black band disease pathogenesis. I will examine and compare the effects of environmental factors on microcystin production by cyanobacteria in Hunter's Hot Springs and black band disease. I will determine the tactic response of these cyanobacteria to two toxic compounds, $\mathrm{MC}$ and sulfide.

Hypothesis \#1: I hypothesize that the presence of both Roseofilum reptotaenium and sulfate reducing bacteria will be required for black band disease pathogenesis.

Hypothesis \#2: Environmental factors (temperature, $\mathrm{pH}$, trace metals, and nutrients) influence microcystin production by the hot spring cyanobacterium Planktothricoides raciborskii and the black band disease cyanobacterium Roseofilum reptotaenium.

Hypothesis \#3: Environmental factors will affect microcystin production of mat-forming, hot spring cyanobacteria and black band disease cyanobacteria differently as a result of their dissimilar ecologies. Hypothesis \#4: Planktothricoides raciborskii and Roseofilum reptotaenium will both respond chemotactically to the environmental toxins microcystin and sulfide. 


\section{References}

Barneah, O, E Ben-Dov, E Kramarsky-Winter, and A Kushmaro. Characterization of black band disease in Red Sea stony corals. Environ microbiol (2007) 9: 1995-2006.

Butler, N, JC Carlisle, R Linville, and B Washburn. Microcystins: A brief overview of their toxicity and effects, with special reference to fish, wildlife, and livestock. California Environmental Protection Agency, Sacramento (2009) 5: 1-8.

Carlton, RD, and LL Richardson. Oxygen and sulfide dynamics in horizontally migrating cyanobacterial mat: black band disease of corals. FEMS Microbiol Ecol (1995) 18: 155162.

Casamatta, D, D Stanić, M. Gantar and L.L. Richardson. 2012. Characterization of Roseofilum reptotaenium (Oscillatoriales, Cyanobacteria) gen. et sp. nov. isolated from Caribbean black band disease. Phycologia 51: 489-499.

Cooney, R, O Pantos, M Le Tissier, M Barer, A O'Donnell, and J Bythell. Characterization of the bacterial consortium associated with black band disease in coral using molecular microbiological techniques. Environ Microbiol (2002) 4: 401-413.

Edmunds, PJ. Extent and effect of black band disease on a Caribbean Reef. Coral Reefs (1991) 10: 161-165.

Frias-Lopez, J, AL Zerkle, GT Bonheyo, and BW Fouke. Partitioning of bacterial communities between seawater and healthy, black band diseased, and dead coral surfaces. Appl Environ Microbiol (2002) 68: 2214-2228.

Frias-Lopez, J, JS Klaus, GT Bonheyo, and BW Fouke. Bacterial community associated with black band disease in corals. Appl Environ Microbiol (2004) 70: 5955-5962.

Glas, MS, Y Sato, KE Ulstrup, and DG Bourne. Biogeochemical conditions determine virulence of black band disease in corals. The ISME J (2012) 6: 1526-1534.

Kotut, K, A Ballot, and L Krienitz. Toxic cyanobacteria and their toxins in standing waters of Kenya: implication for water resource use. J Water Health (2006) 4: 233-245.

Krienitz, L, A Ballot, K Kotut, C Wiegand, S Putz, JS Metcalf, GA Codd, and S Pflugmacher. Contribution of hot spring cyanobacteria to the mysterious deaths of Lesser Flamingos at Lake Bogoria, Kenya. FEMS Microbiol Ecol (2003) 43: 141-148.

Mohamed, ZA. Toxic cyanobacteria and cyanotoxins in public hot springs in Saudi Arabia. Toxicon (2008) 51: 17-27. 
Myers, JL, and LL Richardson. Adaptation of cyanobacteria to the sulfide-rich microenvironment of black band disease of coral. Microb Ecol (2008) 67: 242-251.

Myers, JL, R Sekar, and LL Richardson. Molecular detection and ecological significance of the cyanobacteria Oscillatoria and Leptolyngbya in black band disease of corals. Appl Environ Microbiol (2007) 73: 5173-5182.

Richardson, LL. Horizontal and vertical migration patterns of Phormidium corallyticum and Beggiatoa spp. associated with black-band disease of coral. Microb Ecol (1996) 32: 323-335.

Richardson, LL, and RW Castenholz. Diel vertical movements of the cyanobacterium Oscillatoria terebriformis in a sulfide-rich hot spring microbial mat. Appl Environ Microbiol (1987a) 53: 2142-2150.

Richardson, LL, and RW Castenholz. Enhanced survival of Oscillatoria terebriformis in darkness under anaerobic conditions. Appl Environ Microbiol (1987b) 53: 2151-2158.

Richardson, LL, and KG Kuta. Ecological physiology of the black band disease cyanobacterium Phormidium corallyticum. FEMS Microb Ecol (2003) 43: 287-298.

Richardson, LL, AW Miller, E Broderick, L Kaczmarsky, M Gantar, D Stanić, and R Sekar. Sulfide, microcystin, and the etiology of black band disease. Dis Aquat Organ (2009) 87: 79-90.

Sato, Y, BL Willis, and DG Bourne. Successional changes in bacterial communities during the development of black band disease on the reef coral, Montipora hispida. The ISME J (2010) 4: 203-214.

Sekar, R, DK Mills, ER Remily, JD Voss, and LL Richardson. Microbial communities in the surface mucopolysaccharide layer and the black band microbial mat of black banddiseased Siderastrea siderea. Appl Environ Microbiol (2006) 72: 5963-5973.

Sekar, R, LT Kaczmarsky, and LL Richardson. Microbial community composition of black band disease on the coral host Siderastrea siderea from three regions of the wider Caribbean. Mar Ecol-Prog Ser (2008) 362: 85-98.

Stanić, D. Characterization of Oscillatoria spp. and their role in black band disease of coral. M. S. Thesis, Florida International University, Miami, Florida. (2010) 103 pp.

Stanić, D, S Oehrle, M Gantar, and LL Richardson. Microcystin production and ecological physiology of Caribbean black band disease cyanobacteria. Environ Microbiol (2011) 13: 900-910. 
Viehman, S, DK Mills, G Meichel, and LL Richardson. Culture and identification of Desulfovibrio spp. from corals infected by black band disease on Dominican and Florida Keys reefs. Dis Aquat Organ (2006) 69: 119-127.

Voss, JD, and LL Richardson. Nutrient enrichment enhances black band disease progression. Coral Reefs (2006) 25: 569-576.

Wickstrom, CE, and RW Castenholz. Dynamics of cyanobacterial and ostracod interactions in an Oregon hot spring. Ecology (1985) 66: 1024-1041. 


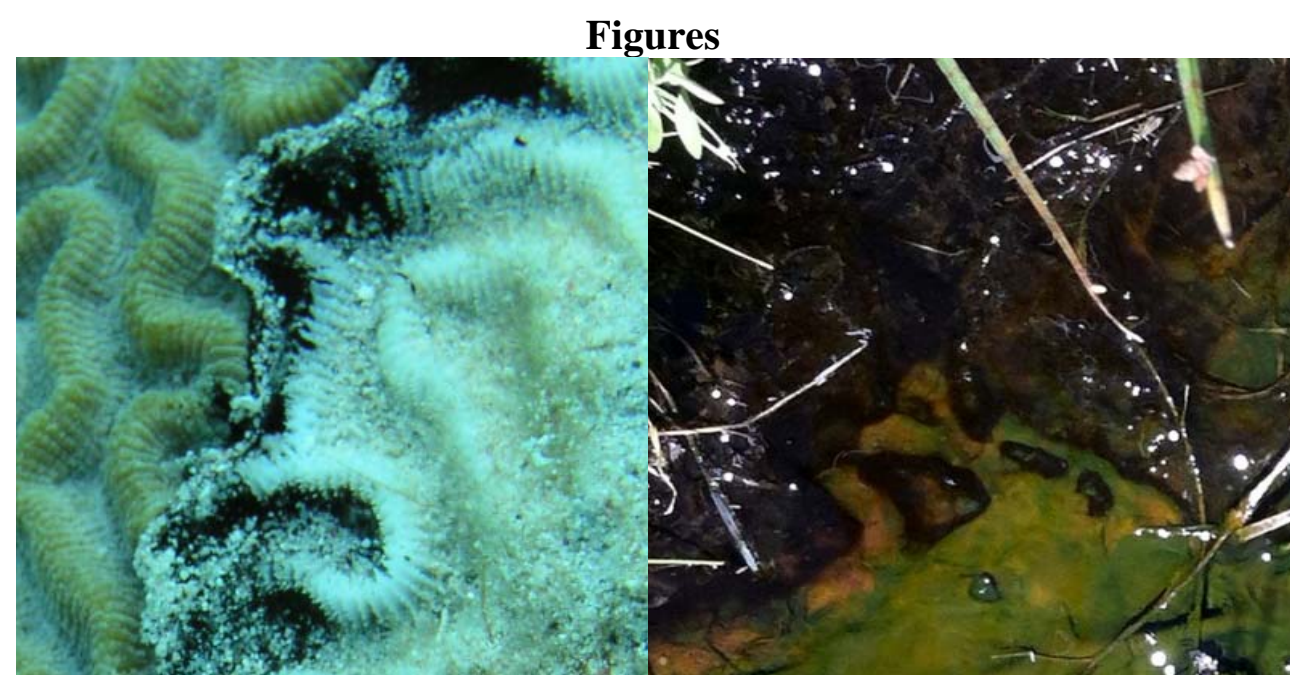

Figure 1. A comparison of black band disease mat and Hunter's Hot Springs mat displaying their physical similarities. The left photograph shows black band disease; the dark red and black coloring indicates the presence of phycoerythrin rich cyanobacteria. The right photograph is of the Hunter's Hot Springs benthic mat; the dark red coloring is also indicative of phycoerythrin rich cyanobacteria.

(Photographs by: AC Brownell and LL Richardson) 


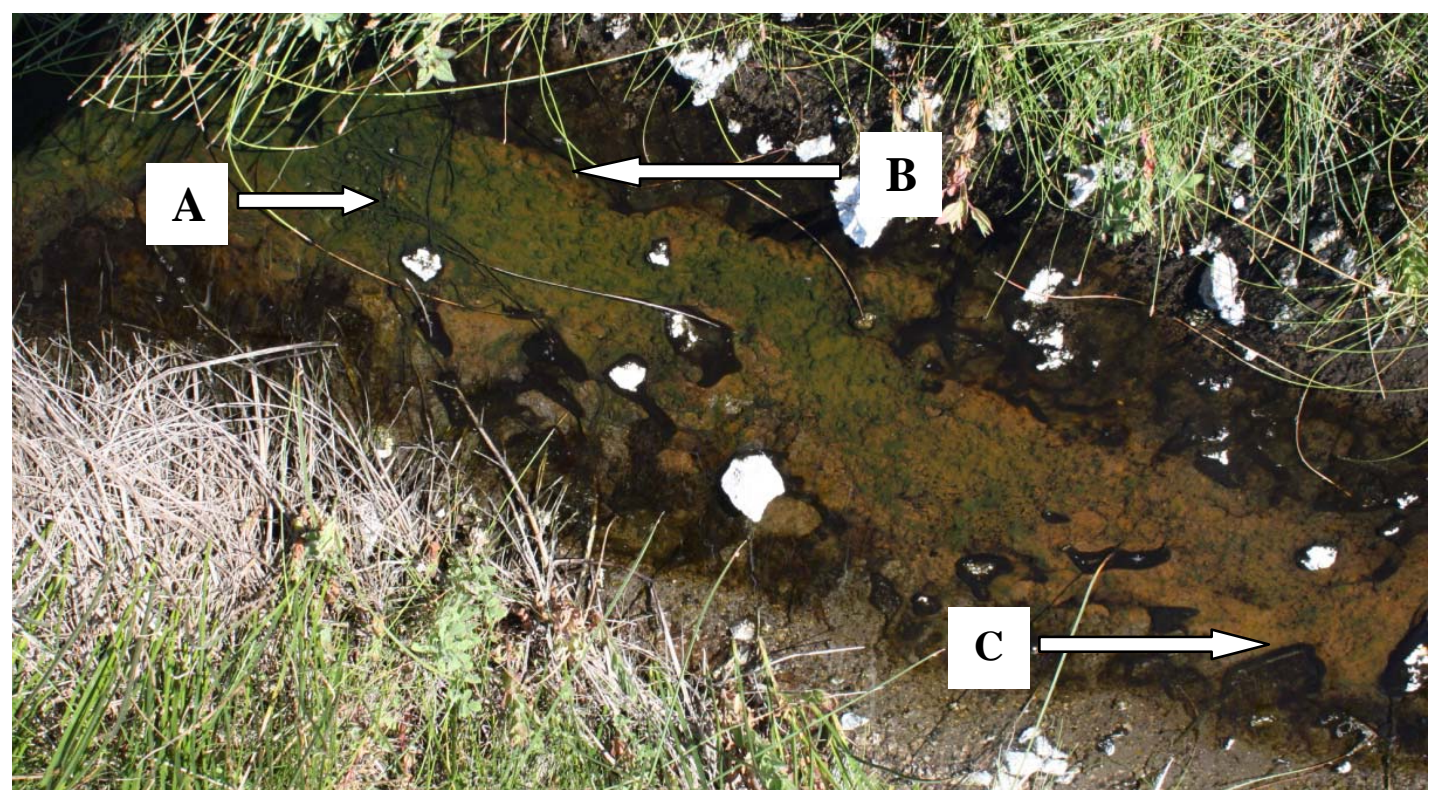

Figure 2. Hunter's Hot Springs in Oregon. The top of the picture shows the source pool; water flows in the direction of the black arrow. A) Synechococcus, temperature range 74 $54^{\circ} \mathrm{C}$, green (phycocyanin) areas within the spring; B) Chloroflexus, temperature range $68-54^{\circ} \mathrm{C}$, orange (carotenoids) areas within the spring; C) Planktothricoides, temperature range $54-47^{\circ} \mathrm{C}$, dark (phycoerythrin) areas within the spring. (Photograph by: LL Richardson) 


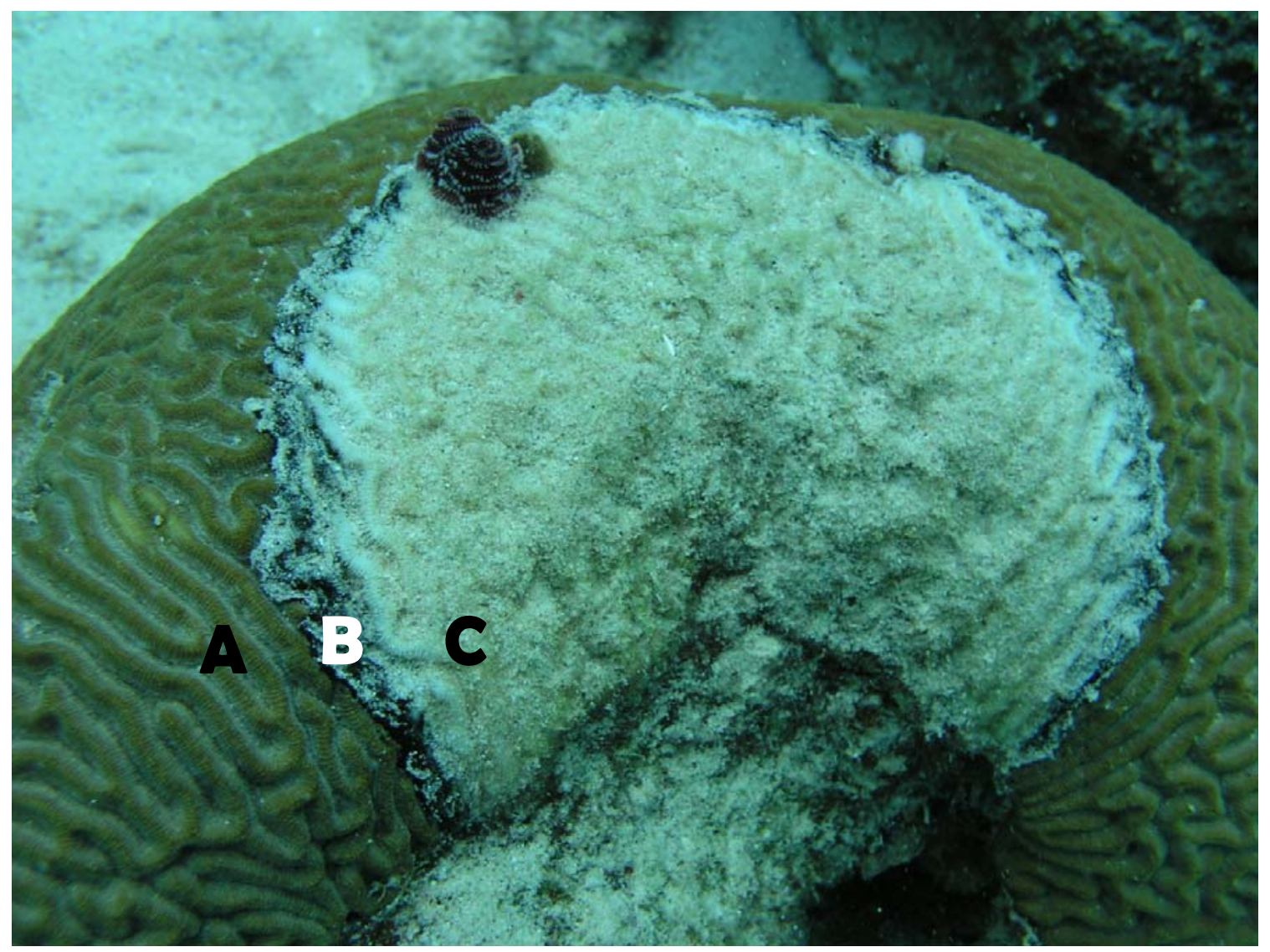

Figure 3. Black band disease infecting a scleractinian coral head in Curaçao. A) healthy coral tissue; B) black band disease; C) bare coral skeleton that has been colonized by microalgae. (Photograph by: AC Brownell) 


\title{
Chapter II
}

\section{SULFATE REDUCING BACTERIA AS SECONDARY AND NECESSARY PATHOGENS IN BLACK BAND DISEASE OF CORAL}

\begin{abstract}
Black band disease (BBD) is a complex, polymicrobial disease that consists of cyanobacteria, sulfide-oxidizing and sulfate-reducing bacteria (SRB), and heterotrophic bacteria. The cyanobacterium Roseofilum reptotaenium has been implicated as the primary pathogen of $\mathrm{BBD}$, but other consortium members may be secondary pathogens necessary for the development of the disease. Populations of the sulfate-reducing bacterium Desulfovibrio are present in BBD and they generate sulfide within the band as a byproduct of dissimilatory sulfate reduction. Exposure of healthy corals to sulfide leads to cell lysis and coral tissue death. When freshly collected BBD, which easily infects healthy corals, is exposed to sodium molybdate, a specific inhibitor of sulfate reduction, infection does not occur. In this study I examined the effect of sodium molybdate on infection of corals by a unialgal culture of $R$. reptotaenium. Coral fragments of Montastraea cavernosa and Siderastrea siderea were transferred into two experimental aquaria, one a control with only artificial seawater (ASW) and the second containing ASW and $2 \mathrm{mM}$ sodium molybdate. Small mats of cultured $R$. reptotaenium were inoculated onto the surface of experimental coral fragments. Both M. cavernosa $(\mathrm{n}=6)$ and S. siderea $(\mathrm{n}=4)$ became infected and developed BBD-like infections in the control tank. There were temporary attachments to, but no successful infection of M. cavernosa $(n=3)$ or $S$. siderea $(n=2)$ in the experimental tank containing sodium molybdate. The results of my study reveal that a secondary pathogen is essential to the infection process
\end{abstract}


and development of BBD in scleractinian corals. Specifically, SRB such as Desulfovibrio are required for the development of BBD on the coral host. This is the first step in understanding the roles of secondary pathogens in a complex, polymicrobial coral disease.

\section{Introduction}

Coral diseases were first observed in the 1970s on reefs of the Caribbean (Antonius, 1976; Garret and Ducklow, 1975; Dustan, 1977; Gladfelter et al., 1977). Since then, the number of documented coral diseases has increased significantly both in the Caribbean and on reefs worldwide. Coral diseases are correlated with many anthropogenic factors including elevated sea surface-temperature, sewage pollution, eutrophication, and sedimentation (Rogers, 1990; Harvell et al., 2002; Voss and Richardson, 2006). Such anthropogenic factors increase pathogen virulence and disease severity. For example, Voss and Richardson (2006) found that in situ nutrient dosing increased the migration rate of the band in black band disease (BBD) infected corals and accelerated coral tissue loss. Although several drivers of coral disease have been identified, the causative agents of most coral diseases are unknown. Of the 27 coral diseases documented worldwide, pathogens of only seven have been proposed, and Koch's postulates have only been fulfilled for five - white plague type II, aspergillosis, white pox, and two cases of bacterial bleaching (Harvell et al., 2002; Weil, 2004; Harvell et al., 2007).

A wide range of diseases afflict corals on reefs in the Caribbean (Weil, 2004). Of these, BBD is of particular interest because it kills large, reef-building coral. BBD is comprised of a polymicrobial consortium of cyanobacteria, sulfate-reducing and sulfide- 
oxidizing bacteria, and a diverse assemblage of heterotrophic bacteria that together form a dark, band-shaped microbial mat (Antonius, 1976; Garret and Ducklow, 1975; Ducklow and Mitchell, 1979; Cooney et al., 2002; Frias-Lopez et al., 2002, 2004; Sekar et al., 2006, 2008). The BBD mat migrates across the surface of infected scleractinian, as well as gorgonian coral hosts, lysing coral tissue and leaving behind bare coral skeleton (Antonius, 1981). At rates of up to $1 \mathrm{~cm}$ a day, BBD can denude an entire coral colony in one summer season (Richardson, 1996). The pathogenicity of BBD is caused by a combination of factors: anoxia at the BBD mat-coral interface, high levels of the toxin sulfide, the presence of the cyanotoxin microcystin, and a synergistic interaction between sulfide and microcystin (Richardson et al., 1997; Gantar et al., 2009; Glas et al., 2012; Miller and Richardson, 2012).

Black band disease infection can be easily modeled in a laboratory setting due to the highly infectious nature of the disease. In the model system, infection can be initiated when an inoculum of naturally-occurring BBD mat from an infected coral is placed onto a healthy coral fragment (Antonius, 1985). The inoculum can be observed to attach to the coral surface, penetrate and invade tissue, and develop into a BBD lesion that migrates across the coral surface, lysing coral tissue and eventually killing the coral, leaving a bare coral skeleton. In this model, the inoculum contained a fully developed BBD-consortium: cyanobacteria, sulfide-oxidizing and sulfate-reducing bacteria, as well as associated heterotrophic bacteria. While several different members of the consortium have been proposed to be the primary pathogen of BBD, Koch's postulates have yet to be fulfilled for any member. It may be that BBD requires the entire consortium to be pathogenic - in 
this case it would not be possible to identify a primary pathogen and fulfill Koch's postulates.

There is much interest in identifying a primary pathogen of BBD. The major target has been BBD cyanobacteria, since the biomass of the band is dominated by filamentous cyanobacteria (Antonius, 1976). The other members of the consortium include sulfate reducing bacteria (SRB), sulfide oxidizing bacteria (Duckwell and Mitchell, 1979), and heterotrophic bacteria (Cooney et al., 2002). However, to date investigations of potential BBD pathogens have mainly focused on BBD cyanobacteria.

A critical member of the BBD consortium is Roseofilum reptotaenium (Casamatta et al., 2012). Roseofilum reptotaenium is a gliding, filamentous, phycoerythrin-rich cyanobacterium detected in BBD mats of tropical and sub-tropical coral reefs around the world (Miller and Richardson, 2011). The cyanobacterium forms the matrix of the mat, and it is adapted to the harsh BBD conditions because of its ability to conduct sulfideinsensitive oxygenic photosynthesis (Myers et al., 2007). The ability to conduct photosynthesis in the presence of sulfide is a rare trait among cyanobacteria since sulfide poisons electron flow in Photosystem II (Cohen et al., 1986). However, this trait is found in all BBD cyanobacterial strains tested to date (Myers and Richardson, 2009).

Roseofilum reptotaenium can perform sulfide-insensitive oxygenic photosynthesis in the presence of 0.5 mM sulfide (Myers and Richardson, 2009), comparable to sulfide levels measured in intact Caribbean BBD (Carlton and Richardson, 1995).

In 2009, samples of BBD were collected from BBD-infected Diploria strigosa and Siderastrea siderea on reefs in St. Croix, U.S. Virgin Islands. Two strains of $R$. reptotaenium were isolated from the mat, designated as strain 101-1 (isolated from $D$. 
strigosa) and 100-1 (isolated from S. siderea). Stanić (2010) found that exposure of apparently healthy $D$. strigosa and S. siderea coral fragments to both strains led to BBDlike lesions that ultimately killed the fragments. The inoculum of each strain attached to scleractinian coral tissue, caused an infection, and eventually developed into a BBD-like lesion.

Additional work on BBD pathogenicity has targeted SRB associated with the disease. SRB are the source of toxic sulfide present in the band (Carlton and Richardson 1995; Glas et al., 2012). To investigate the role of SRB in BBD pathogenesis, Richardson et al. (2009) used the coral fragment model of BBD infection to assess the effect of sodium molybdate on infection. Sodium molybdate is a specific metabolic inhibitor of the energy yielding, anaerobic respiratory pathway of dissimilatory sulfate reduction, which produces sulfide as a byproduct of the reaction. Sodium molybdate effectively stops this physiological process at concentrations of $2 \mathrm{mM}$ (Richardson et al., 2009). In a series of experiments in flow through aquaria containing natural, sand-filtered sea-water, Richardson et al. (2009) inoculated fragments of Montastraea annularis and S. siderea with freshly collected BBD from infected colonies on the reef. The inoculum consisted of the fully developed consortium of BBD microbes. Coral fragments that were inoculated with $\mathrm{BBD}$ exposed to $2 \mathrm{mM}$ of sodium molybdate prior to inoculation did not develop BBD infections (Richardson et al., 2009). Conversely, coral fragments infected with inocula that were not exposed to sodium molybdate all developed actively migrating BBD lesions. In parallel experiments, infected fragments were exposed to $2 \mathrm{mM}$ sodium molybdate however there was no effect on disease progression. The results demonstrated that when the entire BBD community is present, SRB are required for infection but not 
continued disease activity. Thus, the overall implication is that SRB are directly involved in the first stages of BBD pathogenesis.

The specific role of SRB as potential primary and/or secondary pathogens of BBD infection and development remains unknown. Sulfate reducing bacteria may be acting together with other, as yet unidentified, BBD bacteria to initiate the disease. The goal of my study was to further assess the role of SRB in BBD infection using a laboratory culture of $R$. reptotaenium for the inoculum. I hypothesized that the biomass of $R$. reptotaenium creates an anaerobic environment on the coral surface, that this environment enriches for SRB, and that the development of an SRB population is required for $\mathrm{BBD}$ infection.

\section{Materials and Methods}

\section{Experimental organisms}

Fragments of two Caribbean scleractinian coral species, Montastraea cavernosa and S. siderea, were collected from the Florida Keys National Marine Sanctuary in Key West (Permit number FKMNS-2012-153). After collection, fragments were maintained at ambient (reef water) temperature during transport to Florida International University where they were placed in a 340 liter flow-through holding tank. Following acclimation in the large tank for eight weeks, fragments approximately four to seven $\mathrm{cm}$ in diameter were transferred to two 21 liter experimental aquaria for further acclimation (seven days) prior to beginning the experiment. One (control) aquarium contained only artificial seawater (ASW) at 34 ppt salinity while the second (experimental) aquarium contained ASW (34 ppt) as well as $2 \mathrm{mM}$ sodium molybdate. Aquaria temperatures were kept between 27.5 and $29^{\circ} \mathrm{C}$ on a $12 / 12$ light-dark cycle using cool-white fluorescent light and 
metal halide bulbs. Light intensity, measured using a Biospherical Instruments Quantum Scalar Irradiance meter (model QSL100), was $1 \times 10^{15}$ quanta $\cdot \mathrm{s}^{-1} \cdot \mathrm{cm}^{-2}$. Experimental inoculations of the control fragments (ASW) and experimental fragments (ASW and sodium molybdate) were run in parallel.

\section{Cyanobacterial cultures}

Two unialgal cultures of $R$. reptotaenium were used as inocula for the experiments. Strains were originally isolated using the gliding method (Castenholz, 1988) from BBD samples collected on a reef in Frederiksted, St. Croix, U.S. Virgin Islands (Stanić, 2010). The cultures were maintained in BG-11 and ASW at room temperature in filtered, natural light. Strains 101-1 and 100-1 were used to inoculate M. cavernosa and S. siderea respectively. While strain 101-1 was not isolated from BBD on M. cavernosa, preliminary results proved it was infectious for this Caribbean coral species.

\section{Inoculation of coral fragments}

To inoculate the experimental coral fragments, fragments were taken out of the water and a small amount of $R$. reptotaenium biomass was placed on the fragment surface between polyps. A sterile glass pipette held the biomass onto the coral surface. Coral fragments were then returned to the aquaria with the pipette in place. Once the biomass attached to the surface of the coral, 24 - 48 hours later, the pipette was removed. Following pipette removal, if the biomass was sloughed from the coral surface, a reinfection was attempted in the same area. Reinfections were attempted at least twice on coral fragments with failed inoculations. When infection occurred, progression of the lesion was documented by photographing the fragments a minimum of once a week. 


\section{Results}

\section{Infection}

A total of 21 experiments were conducted using 18 coral fragments. Six of eight M. cavernosa fragments and four of five S. siderea fragments from the control (ASW only) aquarium were successfully infected using $R$. reptotaenium strain 101-1 (Figure 1) and 100-1 respectively. In infected coral fragments, the inoculum of $R$. reptotaenium filaments was observed to attach to the surface of the coral tissue within seven days (Figure 2). The small amount of inoculum developed into a BBD-like lesion as the cyanobacterial biomass increased and began to spread (Figure 2C-F). Thin tendrils of groups of cyanobacterial filaments could be observed to migrate between and into the coral polyps ahead of the advancing microbial mat (Figure 2C). Over a period of several weeks, the infection grew into a BBD-like lesion that migrated across the coral surface (Figure 2G), lysing tissue (Figure 2H), and leaving a bare coral skeleton (Figure 2I). Similar to naturally occurring BBD, the mat did not tightly attach to the surface of the coral and could be easily disturbed or dislodged from the coral surface.

\section{Resistance to infection}

In contrast to the controls, none of the experimental (ASW plus sodium molybdate) fragments - three $M$. cavernosa fragments and two $S$. siderea fragments became infected (Figure 3). While the R. reptotaenium inoculum was observed to attach to the surface of the coral initially (Figure 3A), within 72 hours following attachment the filaments were sloughed off of the surface of the coral (Figure 3B). None of the five fragments exposed to $R$. reptotaenium in the presence of sodium molybdate exhibited permanent attachment to the coral tissue or infection of the fragments, and there was no 
development of BBD lesions. Reinfection of each of the five coral fragments in the experimental tank containing sodium molybdate was attempted at least twice, each time with parallel fragments in ASW (no sodium molybdate) inoculated as the controls. In the sodium molybdate tanks, fresh clumps of $R$. reptotaenium were placed in the same area on the fragments as previous attempted infections. There was no successful infection of the coral fragments in the experimental tank. However, infection of coral fragments within the control tank was successful.

\section{Discussion}

The results of this study revealed that blocking the growth of SRB using the metabolic inhibitor sodium molybdate prevented the development of BBD-like lesions when using unialgal cultures of the BBD cyanobacterium $R$. reptotaenium as the inoculum. Cultured $R$. reptotaenium can produce BBD in controlled laboratory settings and populations of sulfur-cycle bacteria develop in the resulting BBD mat (Stanić 2010). Richardson et al. (2009) demonstrated that use of sodium molybdate prevented BBD infection using freshly collected BBD from infected corals in situ. In those experiments the inoculum contained the intact polymicrobial BBD community which always includes active populations of SRB (Miller and Richardson, 2011, Glas et al., 2012).

The two strains of $R$. reptotaenium used in the experiments presented here are unialgal (each derived from a single cyanobacterial filament), however neither culture is axenic. In each case, heterotrophic bacteria are growing in close association with the mucilaginous, polysaccharide-rich, filament sheaths. Like other cyanobacterial cultures, R. reptotaenium does not remain viable in an axenic culture for an extended period of time. Stanić (2010) was able to isolate strain 101-1 into axenic culture using the gliding 
method (Castenholz, 1988), however the culture died within six months. It is generally thought that bacteria associated with the mucilaginous sheath of cyanobacteria are obtaining a necessary vitamin or co-factor for growth and survival. Whatever the underlying reason, the associated bacteria preclude fulfillment of Koch's postulates, which require infection using a pure (axenic) culture.

The bacterial contaminants in the $R$. reptotaenium cultures were isolated, their 16S rRNA genes sequenced, and no SRB were found (Stanić, 2010). Therefore, I can conclude that SRB must be recruited from the environment into the BBD consortium. In any oxygenated environment with the presence of organic carbon, the dominant microbial metabolic mode is aerobic respiration, since oxygen is the most preferred (highest energy yielding) electron acceptor. When environments become anaerobic, any bacterium that is capable of anaerobic energy-yielding metabolic pathways has a competitive advantage for growth. For metabolically flexible SRB, anoxia and the availability of sulfate in freshwater and marine mats and sediments provide an optimal microenvironment for anaerobic respiration using sulfate as the electron acceptor (Plugge et al., 2011). In marine environments, high concentrations $(28 \mathrm{mM})$ of sulfate are present in seawater, providing SRB with an immediate alternate electron acceptor (Stal, 2002). A transition to anaerobic conditions in the marine environment, in the presence of organic carbon released by photosynthetic cyanobacteria, always enriches for SRB (Frund and Cohen, 1992).

In my experiments, no SRB were added to the artificial sea water of the control and experimental aquaria. Two potential reservoirs for SRB, however, were the coral fragments and the live-rock used to establish the tank for two weeks prior to the 
experiment. I theorize that as the cyanobacterial biomass increased at the site of infection on the coral surface, it created an anaerobic environment at the mat-coral interface. The anaerobic environment then enriched for SRB from the reservoirs in the tank, allowing them to proliferate in the anaerobic environment by using sulfate as a terminal electron acceptor and releasing toxic sulfide as a byproduct. Because prevention of sulfate reduction effectively blocked $\mathrm{BBD}$ initiation in the aquarium with sodium molybdate, the presence of SRB - thus sulfide production - appears to be crucial for the development of the band.

The presence of high levels of sulfide in BBD has proven to be critical for the pathogenicity of the disease. Using microelectrodes, sulfide levels within BBD have been measured at $>800 \mu \mathrm{M}$ on the Caribbean reefs and $\sim 5 \mathrm{mM}$ on the Great Barrier Reef (Carlton and Richardson, 1995; Glas et al., 2012). Sulfide is highly toxic to eukaryotes and most photosynthetic cyanobacteria at levels lower than $0.5 \mathrm{mM}$ (Padan, 1979), making conditions within $\mathrm{BBD}$ harmful to coral tissue. According to a tissue degradation rating developed by Miller and Richardson (2012), coral fragments exposed to $0.5 \mathrm{mM}$ sulfide for 22 hours rated as 2.80 out of 5.0, a rating two-fold higher than the control. In the presence of sulfide the coral epidermis visibly thinned and zooxanthellae were only loosely held in the gastrodermis (Miller and Richardson, 2012), leading to disintegration of coral tissue integrity as the band traveled across the surface.

In a series of experiments aimed at studying BBD pathogenesis on the Great Barrier Reef, researchers documented an increase in populations of SRB during a transition of cyanobacterial patches, shown to be precursors of BBD, to fully developed BBD infections (Sato et al., 2010). In cyanobacterial patches, SRB accounted for less 
than $1 \%$ of the total population but that number increased beyond $7 \%$ in $\mathrm{BBD}$ lesions (Bourne et al., 2011). The changes in the microbial community, specifically increasing $\mathrm{SRB}$, lead to enhanced production of sulfide, and sulfide concentrations within the mat increased as the cyanobacterial patch developed into a BBD lesion (Bourne et al., 2011). Five-fold faster migration rates were observed with increased numbers of SRB in BBDmats as opposed to the cyanobacterial patches (Sato et al., 2010), likely due to greater sulfide production in BBD.

While different genera of SRB have been identified by sequencing the BBD microbial community, members of the genus Desulfovibrio have been most consistently documented in BBD samples worldwide (Frias-Lopez et al., 2002, 2004; Viehman et al., 2006; Sekar et al., 2006, 2008; Sato et al., 2010). Viehman et al. (2006) cultured and sequenced eight strains of Desulfovibrio from BBD collected from six coral colonies of four species in the Florida Keys. Desulfovibrio was also detected by Sato et al. (2010) as the $\mathrm{SRB}$ in $\mathrm{BBD}$ lesions rather than cyanobacterial patches. The presence of Desulfovibrio and other SRB in BBD on different species of coral worldwide strengthens the proposal that $\mathrm{SRB}$ are required for all $\mathrm{BBD}$ infections.

When comparing my laboratory results using $R$. reptotaenium as the BBD inoculum with the results of Richardson et al. (2009) using the fully developed BBD community, marked differences in infection rate between the cyanobacterial culture and the fully developed BBD inoculum are apparent. While infection of scleractinian coral using naturally occurring BBD occurred within two days, with formation of an actively migrating band within two to three additional days (Richardson et al., 2009), infection using $R$. reptotaenium took place over a period of weeks. The time lag may be due to the 
need to recruit SRB from the aquarium environment. My results are in agreement with the results of Sato et al. (2010), who determined that the transition from a cyanobacterial patch to a BBD lesion in situ on the Great Barrier Reef (GBR) occurred over a period of $62 \pm 5$ days. Their time period may similarly be determined by the need to recruit SRB from the environment. Alternatively, the much longer time required for BBD to fully develop from inoculation with $R$. reptotaenium in the aquarium experiments, or from cyanobacterial patches on the GBR, may be determined by the necessity to recruit additional BBD bacteria in addition to the BBD cyanobacterium and SRB.

My work presented here, together with the body of research to date on the pathogenesis of $\mathrm{BBD}$, strongly suggests that $\mathrm{BBD}$ is induced by a sequential community of pathogens, beginning with the cyanobacterium $R$. reptotaenium, followed by recruitment of SRB, and perhaps involving incorporation of additional BBD bacteria. Based on these findings I propose that SRB are secondary and necessary pathogens of black band disease. My study is the first step in understanding the role of a secondary pathogen in a complex, polymicrobial coral disease. 


\section{References}

Antonius, A. New observations on coral destruction in reefs. Tenth Meeting of the Association of Island Marine Laboratories of the Caribbean (1976) 10: 3.

Antonius, A. The 'band'diseases in coral reefs. Proc 4th Int Coral Reef Symp (1981) 2: 714.

Antonius, A. Black band disease infection experiments on hexacorals and octocorals. Proc 5th Int Coral Reef Symp (1985) 6: 155-160.

Bourne, DG, A Muirhead, and Y Sato. Changes in sulfate-reducing bacterial populations during the onset of black band disease. The ISME J (2011) 5: 559-564.

Carlton, R, and LL Richardson. Oxygen and sulfide dynamics in a horizontally migrating cyanobacterial mat - black band disease of corals. FEMS Microbiol Ecol (1995) 18: 155162.

Casamatta, D, D Stanić, M Gantar, and LL Richardson. Characterization of Roseofilum reptotaenium (Oscillatoriales, Cyanobacteria) gen. et sp. nov. isolated from Caribbean black band disease. Phycologia (2012) 51: 489-499.

Castenholz, R. Culturing methods for cyanobacteria. Method Enzymol (1988) 167: 68-93.

Cohen, Y, B Jorgensen, N Revsbech and R Poplawski. Adaptation to hydrogen-sulfide of oxygenic and anoxygenic photosynthesis among cyanobacteria. Appl Environ Microbiol (1986) 51: 398-407.

Cooney, R, O Pantos, M Le Tissier, M Barer, A O'Donnell, and J Bythell. Characterization of the bacterial consortium associated with black band disease in coral using molecular microbiological techniques. Environ Microbiol (2002) 4: 401-413.

Ducklow, H, and R Mitchell. Observations on naturally and artificially diseased tropical corals - scanning electron-microscope study. Microbial Ecol (1979) 5: 215-223.

Dustan, P. Vitality of reef coral populations off Key Largo, Florida - recruitment and mortality. Environ Geol (1977) 2: 51-58.

Frias-Lopez, J, AL Zerkle, GT Bonheyo, and BW Fouke. Partitioning of bacterial communities between seawater and healthy, black band diseased, and dead coral surfaces. Appl Environ Microbiol (2002) 68: 2214-2228.

Frias-Lopez, J, JS Klaus, GT Bonheyo, and BW Fouke. Bacterial community associated with black band disease in corals. Appl Environ Microbiol (2004) 70: 5955-5962. 
Frund, C, and Y Cohen. Diurnal cycles of sulfate reduction under oxic conditions in cyanobacterial mats. Appl Environ Microbiol (1992) 58: 70-77.

Gantar, M, R. Sekar, and LL Richardson. Cyanotoxins from black band disease of corals and from other coral reef environments. Microbial Ecol (2009) 58: 856-864.

Garrett, P, and H Ducklow. Coral diseases in Bermuda. Nature (1975) 253: 349-350.

Gladfelter, W, E Gladfelter, R Monahan, J Ogden, and R Dill. Environmental studies of Buck Island Reef National Monument, St. Croix, U.S.V.I. National Park Service Rept. (1977)

Glas, MS, Y Sato, KE Ulstrup, and DG Bourne. Biogeochemical conditions determine virulence of black band disease in corals. The ISME J (2012) 6: 1526-1534.

Harvell, C, C Mitchell, J Ward, S Altizer, A Dobson, R Ostfeld, and M Samuel. Ecology - climate warming and disease risks for terrestrial and marine biota. Science (2002) 296: 2158-2162.

Harvell, D, E Jordan-Dahlgren, S Merkel, E Rosenberg, L Raymundo, and G Smith. Coral disease, environmental drivers, and the balance between coral and microbial associates. Oceanography (2007) 20: 172-195.

Miller, AW, and LL Richardson. A meta-analysis of 16S rRNA gene clone libraries from the polymicrobial black band disease of corals. FEMS Microbiol Ecol (2011) 75: 231241.

Miller, AW, and LL Richardson. Fine structure analysis of black band disease (BBD) infected coral and coral exposed to the BBD toxins microcystin and sulfide. $J$ Invertebr Pathol (2012) 109: 27-33.

Myers, J L, R Sekar, and LL Richardson. Molecular detection and ecological significance of the cyanobacterial genera Geitlerinema and Leptolyngbya in black band disease of corals. Appl Environ Microbiol (2007) 73: 5173-5182.

Myers, J L, and LL Richardson. Adaptation of cyanobacteria to the sulfide-rich microenvironment of black band disease of coral. FEMS Microbiol Ecol (2009) 67: 242251.

Padan, E. Facultative anoxygenic photosynthesis in cyanobacteria. Annu Rev Plant Phys (1979) 30: 27-40.

Plugge, CM, W Zhang, JCM Scholten, and AJM Stams. Metabolic flexibility of sulfatereducing bacteria. Front Microbiol (2011) 2:1. 
Richardson, LL. Horizontal and vertical migration patterns of Phormidium corallyticum and Beggiatoa spp. associated with black-band disease of corals. Microb Ecol (1996) 32: 323-335.

Richardson, LL, K Kuta, S Schnell, and R. Carlton. Ecology of the black band disease microbial consortium. Proc 8th Int Coral Reef Symp (1997) 1: 597-600.

Richardson, L L, AW Miller, E Broderick, L Kaczmarsky, M Gantar, D Stanić, and R Sekar. Sulfide, microcystin, and the etiology of black band disease. Dis Aquat Organ (2009) 87: 79-90.

Rogers, C. Responses of coral reefs and reef organisms to sedimentation. Mar Ecol-Prog Ser (1990) 62: 185-202.

Sato, Y, BL Willis, and DG Bourne. Successional changes in bacterial communities during the development of black band disease on the reef coral, Montipora hispida. The ISME J (2010) 4: 203-214.

Sekar, R, DK Mills, ER Remily, JD Voss, and LL Richardson. Microbial communities in the surface mucopolysaccharide layer and the black band microbial mat of black banddiseased Siderastrea siderea. Appl Environ Microbiol (2006) 72: 5963-5973.

Sekar, R, LT Kaczmarsky, and LL Richardson. Microbial community composition of black band disease on the coral host Siderastrea siderea from three regions of the wider Caribbean. Mar Ecol-Prog Ser (2008) 362: 85-98.

Stal, LJ. Cyanobacterial mats and stomatolites, pp. 62-111. In Whitton, BA, and M Potts (eds.), The Ecology of Cyanobacteria: Their Diversity in Time and Space. Kluwer Academic Publishers, New York (2002).

Stanić, D. Characterization of Oscillatoria spp. and their role in black band disease of coral. M. S. Thesis, Florida International University, Miami, Florida. (2010) 103 pp.

Viehman, S, DK Mills, G Meichel, and LL Richardson. Culture and identification of Desulfovibrio spp. from corals infected by black band disease on Dominican and Florida Keys reefs. Dis Aquat Organ (2006) 69: 119-127.

Voss, JD, and LL. Richardson. Nutrient enrichment enhances black band disease progression in corals. Coral Reefs (2006) 25: 569-576.

Weil, E. Coral reef disease in the wider Caribbean, pp. 35-68. In Loya, L, and E Rosenburg (eds.), Coral Health and Disease. Springer-Verlag, Berlin (2004). 


\section{Figures}

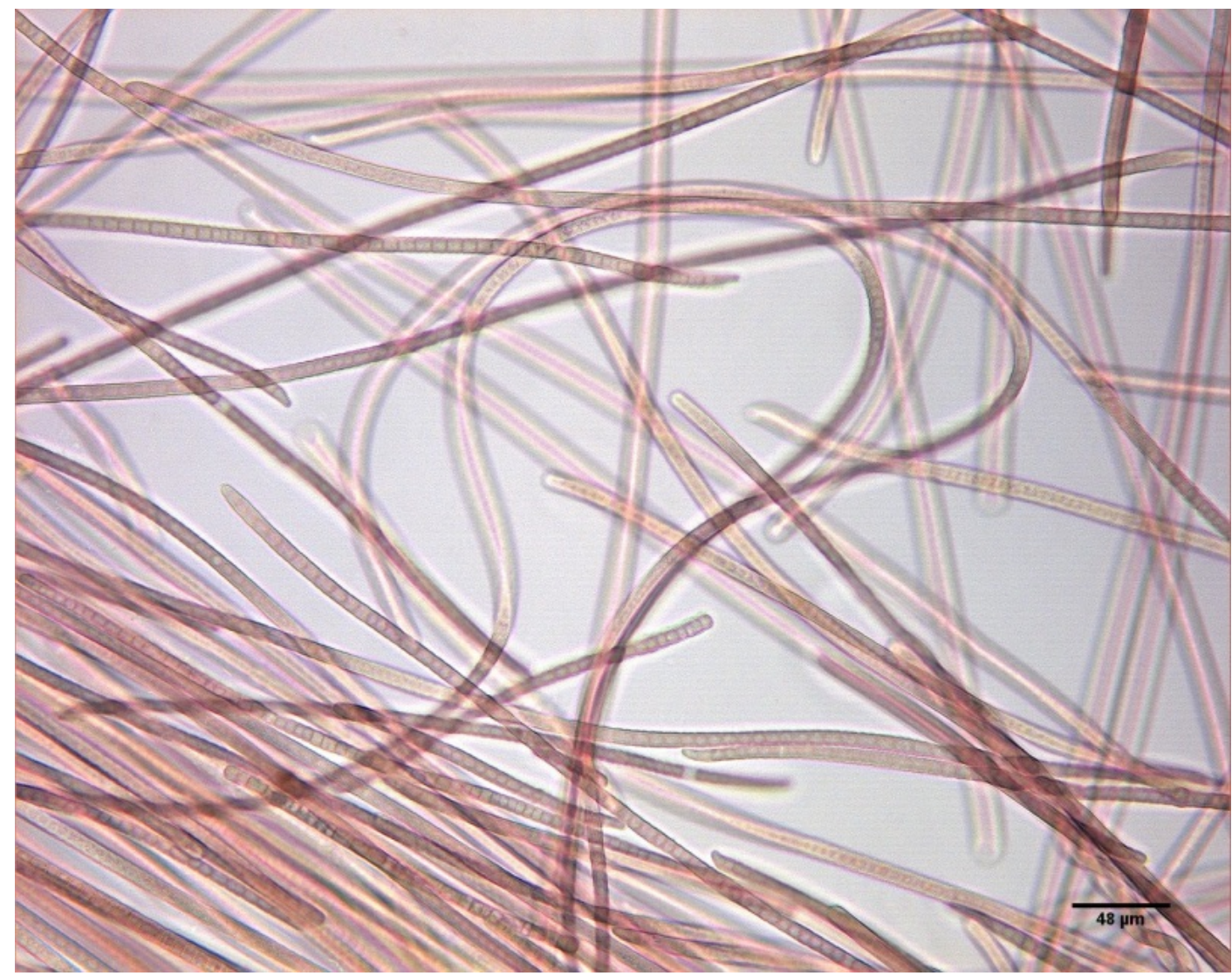

Figure 1. Photomicrograph of the laboratory culture of Roseofilum reptotaenium strain 101-1. The presence of phycoerythrin light-harvesting proteins gives the cyanobacterium a red hue. (Photograph by: AC Brownell) 

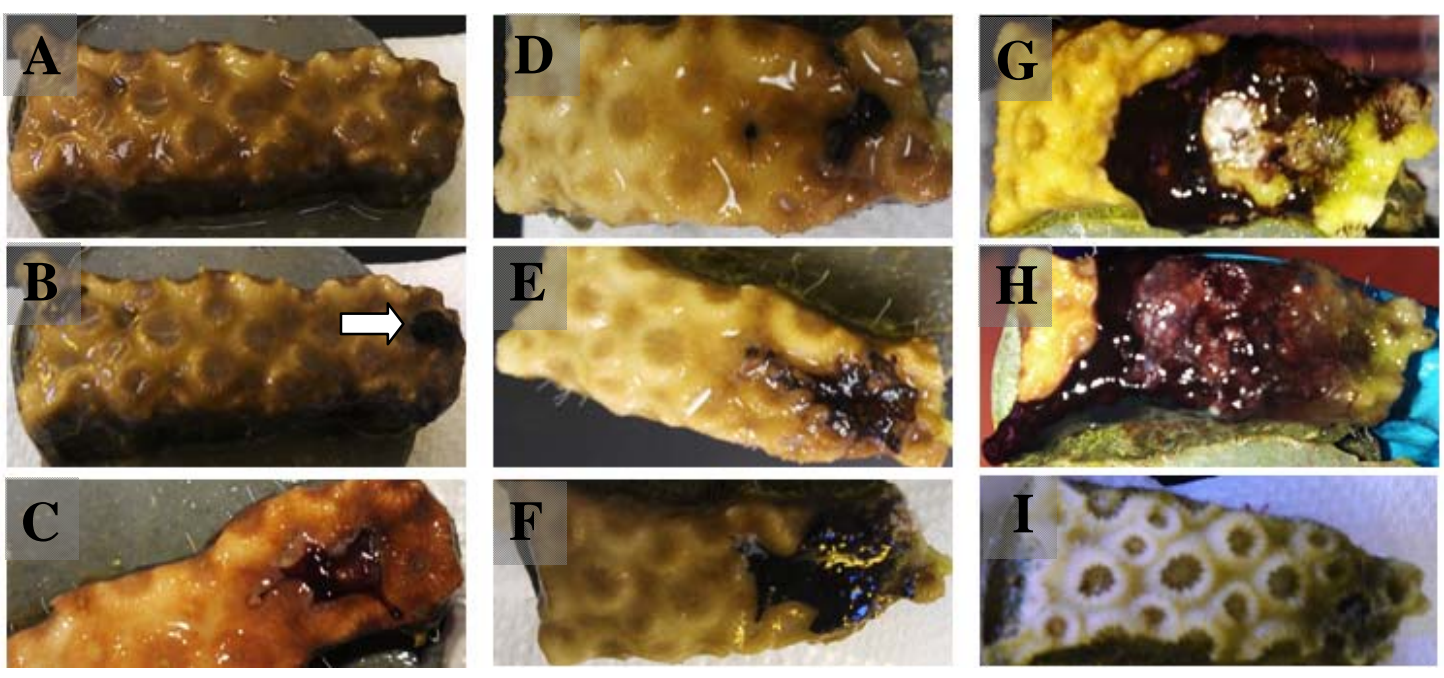

Figure 2. Successful infection of a Montastraea cavernosa coral fragment after inoculation with Roseofilum reptotaenium in the control (artificial seawater only) tank.

A) fragment before infection; B) $t=0$, the day of inoculation; C) $t=31$ days, filaments of R. reptotaenium are visible as they travel across the coral surface $\mathrm{D}) \mathrm{t}=53$ days; $\mathrm{E}) \mathrm{t}=$ 60 days; $F) t=66$ days; $G) t=73$ days, formation of a BBD-like band is apparent; $H) t=$ 83 days, the BBD-like band appeared to migrate across the entire coral surface; I) $t=115$ days, all that remains of the coral fragment is bare coral skeleton due to complete tissue lysis by the BBD-like mat. The arrow in frame B indicates the area containing cyanobacterial inoculum. (Photographs by AC Brownell) 

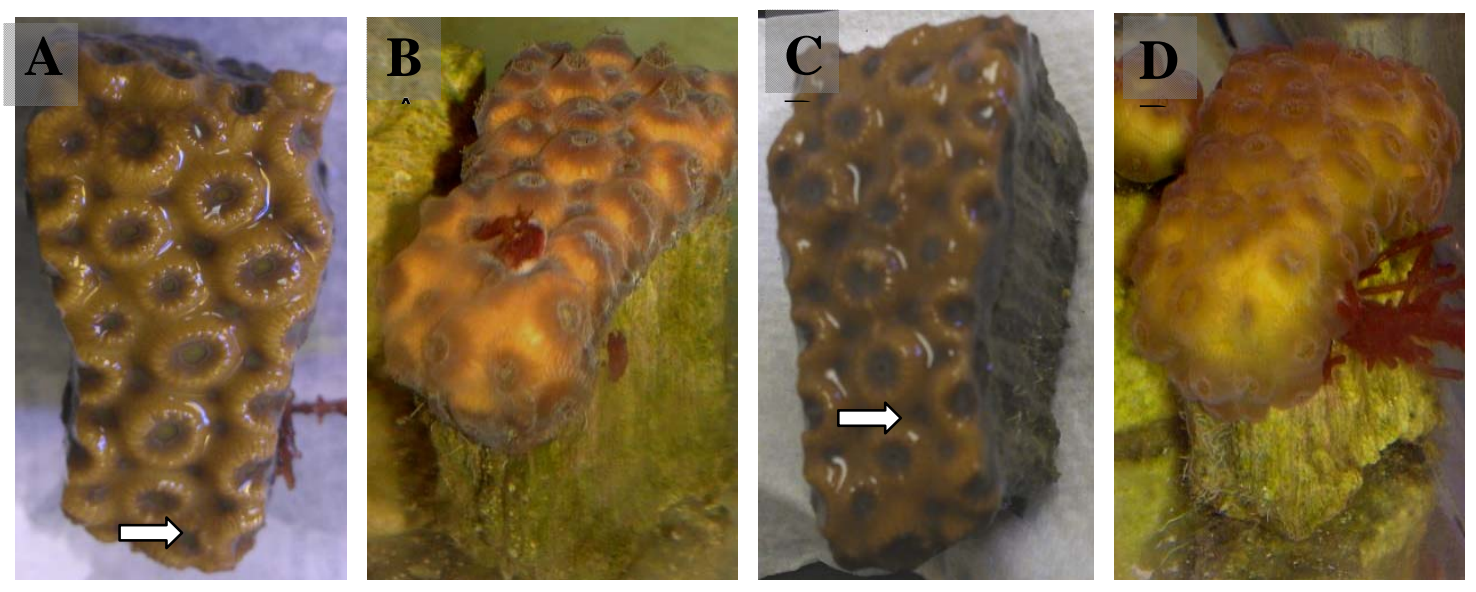

Figure 3. Unsuccessful infection of a Montastraea cavernosa coral fragment after inoculation with Roseofilum reptotaenium in the experimental aquarium containing artificial seawater and sodium molybdate. A) $t=0$, fragment before inoculation; $B$ ) $t=3$ days, attachment of inoculum which was subsequently sloughed off; $C) t=31$ days, prior to reinoculation; D) $t=115$ days, healthy coral fragment after three unsuccessful attempts at infection. Arrows in frame $\mathrm{A}$ and $\mathrm{C}$ indicate areas of inoculation and reinoculation. (Photographs by AC Brownell) 


\title{
CHAPTER III
}

COMPARISON OF MICROCYSTIN PRODUCTION BY THE

CYANOBACTERIA PLANKTOTHRICOIDES RACIBORSKII AND ROSEOFILUM REPTOTAENIUM IN RESPONSE TO ENVIRONMENTAL FACTORS

\begin{abstract}
Microcystin (MC), a potent cyanotoxin, is produced by both Planktothricoides raciborskii and Roseofilum reptotaenium. While MC has many proposed functions in cyanobacteria including protection from grazers, increasing environmental fitness, and serving as signaling molecules, many of these functions have not been confirmed. It is believed that environmental conditions may have the greatest impact on MC production, supporting the theory that MC aids in environmental fitness. Previous studies have shown that $R$. reptotaenium responds to changing environmental conditions ( $\mathrm{pH}$, temperature, and organic carbon) by increasing or decreasing $\mathrm{MC}$ production. To test the effects of environmental changes on MC production, $R$. reptotaenium was exposed to iron chloride $(\mathrm{FeCl})$ while $P$. raciborskii was exposed to $\mathrm{FeCl}$, nitrate, a range of $\mathrm{pH}$ values, and a range of temperatures. Following a one week incubation period, samples were analyzed for MC content using an ELISA. Results showed that $R$. reptotaenium is more toxic than P. raciborskii. By determining the toxicity of these two cyanobacteria, we gain a better understanding of cyanobacterial functional ecophysiology in both hot springs and black band disease. Toxin production by $R$. reptotaenium has been shown to degrade coral tissue, thus MC plays a role in the pathogenesis of the disease. Microcystin production by $P$. raciborskii does not seem to have detrimental effects on other organisms in its surrounding environment.
\end{abstract}




\section{Introduction}

Microcystin (MC) is a cyanobacterial toxin (cyanotoxin) found in cyanobacterial genera that include Microcystis, Anabaena, Planktothrix, Pseudanabaena, Synechocystis, Oscillatoria and Synechococcus (Glowacka et al., 2011; Pearson et al., 2010). Toxic strains produce $\mathrm{MC}$ in response to various changes in environmental conditions (e.g. $\mathrm{pH}$, temperature, trace metals, nutrients, and carbon sources), releasing the toxin into the environment when stress causes the cell to lyse (Zilliges et al., 2011). Microcystin is a cyclic heptapeptide with four variable amino acids at positions $\mathrm{R}^{1}, \mathrm{R}^{2}, \mathrm{X}$, and $\mathrm{Z}$ (Figure 1) resulting in more than eighty different structures, or variants (Tillett et al., 2000; Campos and Vasconcelos, 2010). The most common variants, MC-LA, MC-YR, MC-RR, and MC-LR (the most toxic MC variant), differ at the $\mathrm{X}$ - and Z- amino acid sites (Butler et al., 2009). A constant within the MC structure is the Adda region. Adda, (2S,3S,8S,9S)-3-amino-9-methoxy-2,6,8-trimethyl-10-phenyldeca-4,6-dienoic acid, is a unique amino acid found only in MCs and in a group of structurally related toxins, the nodularins (Campos and Vasconcelos, 2010).

There is currently a debate as to whether the original function of MC was to act as a true toxin, preventing predation and inhibiting other cyanobacteria from competing for limited resources, or alternatively to act as a form of physiological defense against environmental stressors. DeMott and Moxter (1991) believed their research supported the argument that MC evolved as a defense against copepod grazing. However, Rantala et al., (2004) determined MC genes to be of ancient origin — predating the rise of metazoan grazers. More recently a study showed MC is released by lysed cells as a form of infochemical to surrounding cells to indicate stressful environmental conditions (Schatz et 
al., 2007). In these experiments, when MC-producing cyanobacteria were placed in spent media containing MC, nearly $75 \%$ of the cells lysed, releasing MC; consequently, the remaining cells increased their $m с y B$ gene expression leading to increased MC production (Schatz et al., 2007). The mcyB gene is one in a MC gene (mcy) complex (Figure 2) (Kaebernick et al., 2000). The product, McyB, catalyzes peptide chain elongation necessary for synthesis of all MC variants (Dittman et al., 1997). Also in these experiments, when cells were mechanically broken and their MC-containing cell extracts were put into healthy MC-producing cyanobacterial cultures, there was an increase in MC production and release levels (Shatz et al., 2007).

Transcription of mcy genes is up-regulated under high stress conditions, including nutrient limitation and high light (Zilliges et al., 2011). Zilliges et al. (2011) suggest that MC is involved in cyanobacterial cell functions that include redox-dependent processes, the Calvin Cycle, amino acid biosynthesis, photosynthesis, and metabolism. This implies that the primary roles of MC are as a defense against oxidative stress and as a protein-modulating metabolite (Zilliges et al., 2011). MC is taxing for the cell to produce, due to the energy cost required to synthesize the toxin. However, it may help toxic strains outcompete non-toxin strains during nutrient-limited conditions (Zilliges et al., 2011). Molecular phylogenetic studies show a common MC-producing ancestor to most cyanobacterial species, but many no longer produce the toxin (Rantala et al., 2004). Researchers suggest that the many non-toxic cyanobacterial species have found a less taxing form of protection against oxidative stress and have lost the ability to produce MC (Zilliges et al., 2011). 
Microcystin is proving to be a troublesome toxin not only to environmental health due to its structural stability but to the health of organisms (Sivonen and Jones, 1999). These toxins remain in the environment for extended periods of time, only breaking down at high temperatures or extreme $\mathrm{pH}$ levels, either very acidic or very basic (Butler et al., 2009). When consumed by organisms, MC accumulates in the liver immediately damaging hepatocytes. Liver damage and apoptosis of hepatocytes was found to occur within 20 minutes of lethal injection in laboratory mice while complete liver damage and death occurred within an hour (Butler et al., 2009). At high concentrations, MC can cause disruption in hepatocyte cytoskeletons, blood accumulation in the liver, and death by hemorrhagic shock (Briand et al., 2003). At lower concentrations, MC slowly degrades hepatocytes, causes chronic inflammation, and eventually leads to death (Briand et al., 2003). Microcystin also inhibits protein synthesis as well as protein and nuclear protein phosphatases such as protein phosphatase 1 and 2A (Tillett et al., 2000; Briand et al., 2003; Codd et al., 2005). Without protein phosphatases 1 and 2A, a build-up of phosphorylated proteins leads to apoptosis of hepatocytes and other exposed cells (Butler et al., 2009). Microcystin can disrupt membrane integrity and conductivity resulting in cell apoptosis (Codd et al., 2005). Microcystin may also act as a tumor promoter by stimulating cancer cell growth but further studies are needed on this topic (Briand et al., 2003; Butler et al., 2009).

Because drinking and recreational water sources are intensively studied, $\mathrm{MC}$ toxicity in freshwaters is well-documented. Microcystin concentrations of $200 \mathrm{ng} / \mathrm{g}$ can cause lethal toxicity (Carmichael and $\mathrm{Li}, 2006$ ). Symptoms and signs of MC toxicity include diarrhea, vomiting, piloerection, cold extremities, liver destruction, weakness, 
and pallor (Briand et al., 2003; Codd, 2000; El-Ayouty and Abd-El-Rahman, 1996).

Death by MC toxicity in healthy humans has not been documented; however there was a MC water contamination event in a Brazilian dialysis center that killed 52 patients (Carmichael and Li, 2006; Butler et al., 2009). Many cases of deadly MC toxicity in animals have been well documented (Konst et al., 1965; Fawell et al., 1999). Environmental MC toxicity has also been observed in salmon, bass, shrimp, catfish, trout, carp, flamingos and Blue Heron indicating the vulnerability to MC toxicity of aquatic species (Carmichael and Li, 2006). Lethal toxicity of lower aquatic organisms may be of importance due to bioaccumulation causing highly toxic effects in apex predators, including humans (Martins et al., 2007).

Microcystin can also detrimentally affect invertebrate species such as coral. Richardson et al. (2009) found that exposing coral fragments to increasing concentrations of purified MC-LR led to thinning and/or loss of the coral gastrodermis and epidermis, and extrusion and/or clustering of symbiotic zooxanthellae. Microcystin is also essential to the pathogenicity of the polymicrobial coral disease, black band disease (BBD). The BBD mat is composed of cyanobacteria, sulfide-oxidizing and sulfate-reducing bacteria, and heterotrophic bacteria. Cyanobacteria associated with BBD, specifically Roseofilum reptotaenium, are necessary for the pathogenesis of $\mathrm{BBD}$ which may be due to toxin production. While $\mathrm{MC}$ production between $\mathrm{BBD}$ and non-BBD tropical marine cyanobacteria was found to be relatively equivalent (Gantar et al., 2009), it is likely that $\mathrm{MC}$ is retained and accumulates within the mat fabric. Microcystin within the matrix of the mat does not diffuse into the environment, thereby damaging the coral tissue below the mat. Microcystin may not only contribute to the pathogenicity of BBD by lysing coral 
tissue cells but also by influencing shifts, through stimulation or inhibition of bacterial species, in the structure of the bacterial disease community (Richardson et al., 2009). Microcystin alone is toxic to coral but its toxicity is increased when coral are coexposed to both MC and sulfide, also found in BBD. Miller and Richardson (2012) demonstrated that coral fragments exposed to $100 \mu \mathrm{g} / \mathrm{L} \mathrm{MC}$-LR and $0.5 \mathrm{mM}$ sulfide in experimental flasks displayed the same loss of structural integrity in the tissue layers as did samples taken from corals naturally infected with BBD. Both resulted in the removal and thinning of coral tissue, tissue lysis, and loss of zooxanthellae (Miller and Richardson, 2012).

\section{Environmental factors that affect MC production}

All blooms and mats of toxin producing cyanobacteria are not necessarily toxic. Toxicity levels within a bloom can change throughout a growing season - non-toxic at the beginning of the season followed by high-toxicity with increased biomass near the end of the season (Utkilen and Gjølme, 1992). Microcystin production within cyanobacterial cells has been shown to vary due to environmental factors. Orr and Jones (1998) proposed that altering levels of MC production is an indirect result of the environmental effects on growth conditions and rates. However, the consequences of changes in light intensity, temperature, $\mathrm{pH}$, organic carbon content, nutrient concentrations, and trace metals should be explored.

Multiple researchers have found that increased toxicity, or MC production, in many cyanobacterial species is correlated with increased light intensity (Utkilen and Gjølme, 1992; Tonk et al., 2005; Zilliges et al., 2011). In a study of Microcystis aeruginosa, a MC producing cyanobacterium, researchers found a two and a half fold 
increase in the toxin-to-biomass ratio when the light intensity was increased (Utkilen and Gjølme, 1992). However there was a sharp decline in toxin production when light intensity hit a certain threshold (van der Westhuizen and Eloff, 1985). Simultaneously, the ratio of toxin to protein production increased with light intensity, but was not affected by the same threshold (Kaerbernick et al., 2000). Similar results were observed in Planktothrix agardhii; MC production rate increased with increasing light intensity but decreased at light levels higher than $100 \mu \mathrm{mol} / \mathrm{m} / \mathrm{s}$ (Tonk et al., 2005). These results suggest that MC production continues to rise with increasing light intensity but cyanobacteria have a threshold at which toxin production ceases due to overwhelming cellular stress. Interestingly, MC production by Oscillatoria agardhii was lower at high light intensities, however, leakage of toxin from the cell was higher than at low light (Sivonen, 1990). These contrasting results indicate that generalizations for cyanobacterial toxin production may not be accurate. Toxin production dependent on varying light intensities is likely related to the amount of light harvesting photosynthetic pigments contained within the cell, and by variations in natural light source.

Seasonal temperature fluctuations can also have an effect on MC production. Temperatures at the high end of the tolerable range for cyanobacteria can hinder MC production. Temperatures between $18-25^{\circ} \mathrm{C}$ caused increases in toxin production while higher temperatures, above the optimal temperature of $32.5^{\circ} \mathrm{C}$, tended to hinder toxin production in M. aeruginosa (Wicks and Thiel, 1990; van der Westhuizen and Eloff, 1985). The optimal temperature range for toxin production varies per strain of cyanobacterium. Optimal growth temperature differs by cyanobacterial strain, causing variations in the level of toxin production dependent on environmental temperature 
(Sivonen, 1990). One study found that toxin production in one strain of O. agardhii was highest at $25^{\circ} \mathrm{C}$ and decreased when temperatures reached $30^{\circ} \mathrm{C}$, while another strain showed an equal production of toxin throughout a wide range of temperatures (Wicks and Thiel, 1990).

Wicks and Thiel (1990) found that $\mathrm{pH}$ values at the high and low ends of the range of $\mathrm{pH}$ tolerance caused an increase in toxin production in M. aeruginosa. Minimal toxin production occurred at $\mathrm{pH} 8.0$, which is the preferred $\mathrm{pH}$ of this cyanobacterium in terms of sustaining growth (Wicks and Thiel, 1990). Comparable results were found for Microcystis viridis whose optimal $\mathrm{pH}$ is 8.6 ; at $\mathrm{pH}$ values of 7.0 and 9.2 toxin production increased three-fold and two-fold respectively (Song et al., 1998).

Nutrient flux can also influence microcystin production in cyanobacteria. Oscillatoria agardhii toxin production increased with higher nitrogen concentrations in growth medium (Sivonen, 1990). Microcystin production in M. aeruginosa decreased with nitrogen-limitation (Orr and Jones, 1998). Nitrogen-limitation decreased cell division rates (Orr and Jones, 1998), and cell lysis caused increased toxin release from the cell. Phosphorous concentrations in the range of 0.4 to $5.5 \mathrm{mg} / \mathrm{liter}$ did not seem to affect toxin production; concentrations as low as $0.1 \mathrm{mg} /$ liter were unable to support growth and high toxin production in O. agardhii (Sivonen, 1990). Concentrations of orthophosphate were negatively correlated with toxin concentration in M. aeruginosa blooms found in an African reservoir (Wicks and Thiel, 1998). Conversely, M. viridis toxin production was unaffected by phosphorous limiting conditions (Song et al., 1998). Results from these studies show the variability between species of cyanobacteria in terms of toxin synthesis in response to environmental factors. 
Microcystin production is also affected by trace metal concentrations. Decreased iron in growth medium leads to increased toxin production in M. aeruginosa in a light dependent manner (Utkilen and Gjølme, 1995; Fujii et al., 2010). Utkilen and Gjølme (1995) also found that MC producing strains of M. aeruginosa were more efficient at iron uptake than a non-toxic strain. They suggest $\mathrm{MC}$ acts as an iron chelator that binds $\mathrm{Fe}^{2+}$ to keep intracellular levels of free iron low (Utkilen and Gjølme, 1995). Lyck et al., (1996) found that MC producing M. aeruginosa strains were also able to recover from iron starvation faster than non-microcystin producers. Again, $\mathrm{MC}$ production increased with iron starvation (Lyck et al., 1996). Not only does iron starvation lead to increased MC production but it triggers synthesis of the most toxic variant, MC-LR (Sevilla et al., 2008).

The goal of my study was to compare the toxin production of $R$. reptotaenium and P. raciborskii cultures in response to different environmental factors. I hypothesized that R. reptotaenium would produce more MC than P. raciborskii, that exposure to high temperatures and excess iron would decrease toxin production, and that sub-optimal $\mathrm{pH}$ and excess nitrate would cause increased toxin production.

\section{Materials and Methods}

\section{Growth and Identification of Experimental Cyanobacteria}

Planktothricoides raciborskii was collected from Hunter's Hot Springs on June 18, 2012. Mat samples were collected in cryovials and kept at room temperature until returned to Florida International University. A unialgal culture of P. raciborskii was isolated using the gliding method (Castenholz, 1988) on D-medium agar plates (Figure 3). Cultures were transferred to Erlenmeyer flasks of D-medium, an algal mineral 
medium. Subcultures of $P$. raciborskii (strain $\mathrm{OH}-12-\mathrm{Pr}$ ) were grown in multiple flasks of BG-11 and D-media to obtain enough biomass for ELISA assays. After growing the cultures at a range of temperatures, $32^{\circ} \mathrm{C}$ was found to be the optimal temperature to support growth. Cultures were kept at $32^{\circ} \mathrm{C}$ and hand-swirled daily to ensure even distribution of nutrients. Cultures were grown in diel cycles of filtered, natural light.

Upon collection at Hunter's Hot Springs in June 2012, the cyanobacterial sample was morphologically identified as Geitlerinema terebriformis (formerly Oscillatoria terebriformis but currently phylogenetically identified as Planktothricoides raciborskii in my thesis). Once isolated into pure culture, a DNA extraction from the hot spring cyanobacterium was performed using a FastDNA Spin Kit for Soil (Qbiogene, Vista, CA, USA). DNA was PCR-amplified using the hypervariable V1 and V9 domains of the 16S rRNA gene with a 27F primer 5'-AGA GTT TGA TCM TGG CTC AG-3' and 1492R primer (5'-TAC GGY TAC CTT GTT ACG ACT T-3') (Integrated DNA technologies, Coralville, IA, USA). Gel electrophoresis was used to verify PCR products. Products were cleaned using ExoSAP-IT. The clean DNA was used for cycle sequencing using BigDye Terminator v3.1 Cycle Sequencing kits for both forward and reverse sequences. Final products were given to the Florida International University DNA core for sequencing. Sequences were trimmed using DNA Baser and analyzed using BLAST. Results containing matches of $97 \%$ or higher were accepted. Also, a culture of Geitlerinema terebriformis from Hunter's Hot spring was obtained from the Culture Collection of Microorganisms from Extreme Environments, Oregon. This culture was grown in BG-11 liquid medium at $45^{\circ} \mathrm{C}$. This cyanobacterium has been referred to as $G$. terebriformis in previous research based upon morphological identification; however, 
DNA sequencing performed as described above to determine its identity revealed that the highest sequence homology (98\%) was to $P$. raciborskii.

Roseofilum reptotaenium was originally isolated using the gliding method from BBD samples collected on a reef in Frederiksted, St. Croix, U.S. Virgin Island (Stanić, 2010). Cultures of R. reptotaenium have been maintained within Dr. Richardson's laboratory. Cultures are grown in BG-11+ASW medium in filtered, natural light at room temperature.

\section{Light Microscopy}

The laboratory culture of $R$. reptotaenium strain 101-1 was photographed using a Leica Application Suite (version 2.8.1) imaging system with a Leica/Leitz DMRB light microscope. The image was analyzed using ImageJ processing (Rasband, 1997-2012).

\section{Effects of Environmental Factors on Microcystin Production (Laboratory Cultures)}

Laboratory cultures of $P$. raciborskii were exposed to different environmental conditions to determine changes in MC concentrations. Cultures were first grown in four liter flasks for four weeks at $32^{\circ} \mathrm{C}, \mathrm{pH} 8.2$, in $\mathrm{BG}-11$. The biomass was harvested and transferred to fresh BG-11, homogenized to resuspend the filaments, and $5 \mathrm{~mL}$ was used to inoculate triplicate $125 \mathrm{~mL}$ culture flasks. Cultures were kept under cool fluorescent

light on a $12 / 12$ hour cycle at $6 \times 10^{14}$ quanta $\cdot \mathrm{s}^{-1} \cdot \mathrm{cm}^{-2}$. Light intensity was measured using a Biospherical Instruments Quantum Scalar Irradiance meter QSL100.

To test for the effects of temperature on MC production, triplicate flasks were inoculated and incubated at $32^{\circ} \mathrm{C}$ (control), $35^{\circ} \mathrm{C}$, and $40^{\circ} \mathrm{C}$ in water baths. After one week, flask contents were filtered through $0.45 \mu \mathrm{m}$ pore size GF/B Whatman filters following the methods of Gantar et al. (2009) and frozen at $-80^{\circ}$. To test the effects of $\mathrm{pH}$ 
on the cultures, the $\mathrm{pH}$ of flasks containing fresh culture medium was adjusted to 7.0 and 9.0 units using $1 \% \mathrm{HCl}$ and $1 \mathrm{M} \mathrm{NaOH}$ respectively before inoculating triplicate $125 \mathrm{~mL}$ Erlenmeyer flasks with $P$. raciborskii. Samples were filtered after one week at each $\mathrm{pH}$ and frozen at $-80^{\circ}$. To test the effects of nutrients and trace metals on MC production, 10 $\mu \mathrm{M}$ nitrate (using sodium nitrate, $\mathrm{NaNO}_{3}$ ) and $10 \mu \mathrm{M}$ iron (using ferric chloride) were added to triplicate $125 \mathrm{~mL}$ Erlenmeyer flasks of $P$. raciborskii. After one week, cultures of $P$. raciborskii were filtered and frozen at $-80^{\circ} \mathrm{C}$. Controls were kept at $32^{\circ} \mathrm{C}, \mathrm{pH} 8.2$, in BG-11 for the length of each trial then filtered, collected and frozen.

Laboratory cultures of $R$. reptotaenium were exposed to different environmental conditions to determine changes in $\mathrm{MC}$ concentrations. Cultures were first grown in four liter flasks for four weeks at $27^{\circ} \mathrm{C}, \mathrm{pH} 8.2$, in $\mathrm{BG}-11+\mathrm{ASW}$. The biomass was harvested and transferred to fresh BG-11, homogenized to resuspend filaments, and $5 \mathrm{~mL}$ was used to inoculate triplicate $125 \mathrm{~mL}$ culture flasks. Cultures were kept under cool fluorescent light on a $12 / 12$ hour cycle at $6 \times 10^{14}$ quanta $\cdot \mathrm{s}^{-1} \cdot \mathrm{cm}^{-2}$.

To test the effects of trace metals on MC production, $10 \mu \mathrm{M}$ iron (ferric chloride) was added to triplicate $125 \mathrm{~mL}$ Erlenmeyer flasks of $R$. reptotaenium. After one week, cultures of $R$. reptotaenium were filtered and frozen at $-80^{\circ} \mathrm{C}$. Controls were kept at $27^{\circ} \mathrm{C}$, $\mathrm{pH} 8.2$, in BG-11+ASW for the length of each trial then filtered, collected and frozen.

For comparison analysis, results from Stanić (2010) were used in addition to the results obtained in this experiment. Stanić (2010) challenged $R$. reptotaenium with a $3^{\circ} \mathrm{C}$ temperature increase $\left(30^{\circ} \mathrm{C}\right)$, a wide $\mathrm{pH}$ range $(5.5,7.0$, and $9.0 \mathrm{pH})$, and an influx of glucose or fructose (not included in comparison). 


\section{Enzyme-Linked Immunosorbent Assay (ELISA)}

ELISA assays were utilized to determine the amount of MC produced by experimental cyanobacteria (Carmichael and An, 1999). The Abraxis Microcystins-DM ELISA kits (Product No. 520011) are used to detect both microcystins and nodularins using Adda specific antibodies. A modified extraction was used to process laboratory experimental samples. Cell extracts were prepared by adding $10 \mathrm{~mL}$ of $70 \%$ methanol per $100 \mathrm{mg}$ of freeze-dried biomass to falcon tubes containing the filtered biomass of each sample. Samples were extracted for 48 hours at $4^{\circ} \mathrm{C}$ with intermittent hand shaking. Samples were then centrifuged to remove the biomass and the supernatant was transferred to culture tubes and dried using a Savant speed vacuum (SPD111V). To perform the assay, $200 \mu \mathrm{L}$ of $\mathrm{diH}_{2} \mathrm{O}$ was added to each culture tube.

ELISA assays were performed according to the manual provided with the ABRAXIS test kit. Samples were run in duplicate (controls) or triplicate (experimental) wells. Six standards $(0,0.15,0.40,1.0,2.0$, and $5.0 \mathrm{ppb} \mathrm{MC})$ along with a positive control $(0.75 \pm 0.185 \mathrm{ppb} \mathrm{MC})$ were used to construct a standard curve. The absorbance of each sample was then compared along the fitted-line and $\mathrm{MC}$ concentration was deduced.

\section{Statistical Analysis}

Statistical analysis was performed using Minitab software. Absorbance values $\left(\mathrm{B} \% / \mathrm{B}_{0}\right)$ from the ELISA were used for the statistical analysis. Significance between pooled MC production of $P$. raciborskii and $R$. reptotaenium was determined using a one way ANOVA. Significance between MC production in response to environmental factors by $P$. raciborskii was determined using a one-way ANOVA. P-values less than 0.05 were 
considered statistically significant. A Fisher's LSD post-hoc test was conducted to determine which environmental factors caused significantly different concentrations of MC production by $P$. raciborskii.

\section{Results}

\section{DNA Sequencing}

Results of DNA sequencing conclusively prove that the cyanobacterium used in this study is Planktothricoides raciborskii. Overlapping the sequences from both primers produced a 1333 base pair sequence that was a $98 \%$ match to $P$. raciborskii (accession number: NR040858). These results are congruent with a metagenomic data set performed on the Hunter's Hot Springs mat collected by Laurie Richardson in 2012. Analysis of metagenomic data was performed by Dr. Pat Gillevet at George Mason University. The sample of G. terebriformis (OH-80-Ot) obtained from Culture Collection of Microorganisms from Extreme Environments, Oregon, was also determined to be $P$. raciborskii based on a 1319 base pair sequence that was a $98 \%$ match to $P$. raciborskii (accession number: AB045960). Sequences are identical according to the NCBI database “comments" section.

\section{Effects of Environmental Factors on Microcystin Production}

Planktothricoides raciborskii produced $\mathrm{MC}$ when cultured in the laboratory (Figure 4). A $3^{\circ} \mathrm{C}$ rise $\left(35^{\circ} \mathrm{C}\right)$ in incubation temperature did not affect $\mathrm{MC}$ production but an $8^{\circ} \mathrm{C}\left(40^{\circ} \mathrm{C}\right)$ increase caused $\mathrm{MC}$ to drop. Toxin production decreased in response to 7.0 and $9.0 \mathrm{pH}$ as compared to the control kept at $8.2 \mathrm{pH}$. The concentration of $\mathrm{MC}$ at $7.0 \mathrm{pH}$ was equal to the concentration at $9.0 \mathrm{pH}$. Incubation in $10 \mu \mathrm{M}$ iron reduced $\mathrm{MC}$ 
production by $P$. raciborskii. A significant decrease $(\mathrm{P}<0.05)$ in toxin production occurred when incubated in $10 \mu \mathrm{M}$ nitrate.

Incubation in $10 \mu \mathrm{M}$ iron enriched-medium caused a decrease in $\mathrm{MC}$ production by $R$. reptotaenium. Altering the $\mathrm{pH}$ of the medium to 7.0 and 9.0 units did not affect MC production (Stanić, 2010). A $3^{\circ} \mathrm{C}$ increase $\left(30^{\circ} \mathrm{C}\right)$ in incubation temperature caused a decrease in MC production (Stanić, 2010).

\section{Comparison of Microcystin Production}

Overall, Roseofilum reptotaenium produced significantly more $(\mathrm{P}<0.05) \mathrm{MC}$ than $P$. raciborskii when all samples were pooled (Figure 5). In the control cultures, $R$. reptotaenium produced nearly fivefold more MC than P. raciborskii. A one unit change in $\mathrm{pH}$, towards both more acidic and more basic $\mathrm{pH}$, did not affect MC production by $R$. reptotaenium. In contrast, $P$. raciborskii exhibited decreased MC production. Ironenriched medium led to decreased MC production by both cultures. While $R$ reptotaenium still produced more toxin than $P$. raciborskii in response to excess iron, the drop in $\mathrm{MC}$ production was substantial. A $3^{\circ} \mathrm{C}$ rise in incubation temperature did not affect $P$. raciborskii, but it caused diminished MC production in $R$. reptotaenium.

\section{Discussion}

Previous work on P. raciborskii and $R$. reptotaenium described physiological aspects, motility, and metabolic functions of the cyanobacteria (Richardson and Castenholz, 1987a, 1987b, 1989; Stanić 2010, Miller and Richardson, 2012). In this chapter, I exposed cultures of $P$. raciborskii to different environmental factors (increased temperature, $\mathrm{pH}$, and excess nitrate and iron) then determined the change in $\mathrm{MC}$ production by the cyanobacterium utilizing an ELISA assay. I also built upon work by 
Stanić (2010) by determining the effects of excess iron on cultures of the BBD cyanobacterium, $R$. reptotaenium. By comparing the response of these cyanobacteria to various environmental factors, it is possible to draw conclusions about the pathogenic versus non-pathogenic role of the organisms within their systems.

The two cultures investigated in this study did not always respond in the same way to environmental factors. The response of the cyanobacteria to increased temperature coincides with previous research that found decreased toxicity with increased temperature (Wicks and Thiel, 1990; van der Westhuizen and Eloff, 1985; Gantar et al., 2009).While exposure to a $3^{\circ} \mathrm{C}$ spike in temperature did not affect MC production by $P$. raciborskii, it decreased MC production in R. reptotaenium (Stanić, 2010). An $8^{\circ} \mathrm{C}$ rise was required for P. raciborskii to reduce toxin production, likely due to the high thermal tolerance of the cyanobacterium within the hot spring.

The response to $\mathrm{pH}$ values outside of the optimal $(8.2 \mathrm{pH})$ by both cyanobacteria was unexpected. In previous research, exposing cyanobacterium to non-optimal $\mathrm{pH}$ values caused increased toxin production (Wicks and Thiel, 1990; Song et al., 1998). Stanić (2010) showed that $R$. reptotaenium did not alter MC production in response to the change in $\mathrm{pH}$. In this study, $P$. raciborskii decreased toxin production in both 7.0 and 9.0 $\mathrm{pH}$. The lack of response by R. reptotaenium may be due to the cyanobacterium's adaptation to fluctuating $\mathrm{pH}$ conditions within the $\mathrm{BBD}$ mat, $7.4-8.6 \mathrm{pH}$ (Glas et al., 2012). Planktothricoides raciborskii also experiences $\mathrm{pH}$ fluctuation within the Hot Springs mat, $6.3-8.8 \mathrm{pH}$ on a diel cycle (Richardson and Castenholz, 1987a). However, since these cultures are both exposed to $\mathrm{pH}$ fluctuations, I would have expected the cyanobacteria to respond similarly. 
Supplementing culture media with $10 \mu \mathrm{M}$ iron resulted in decreased MC production in both cyanobacteria. A similar response by both cyanobacteria is interesting because Hunter's Hot Springs has a low iron content while within BBD large amounts of iron are available due to the destruction of coral tissue and zooxanthellae (Pierson and Parenteau, 2000; Frias-Lopez et al., 2004). I would have expected the cyanobacteria to have opposing reactions to the trace metal. An overall decrease in MC production by both cyanobacteria in response to excess iron seems to support the theory that $\mathrm{MC}$ acts as an iron chelator (Utkilen and Gjølme, 1995). When exposed to low iron conditions, cyanobacteria usually respond by increasing MC production (Utkilen and Gjølme, 1995; Lyck et al., 1996). It is possible that when growing in excess iron, the cyanobacteria do not require $\mathrm{MC}$ to function as an iron chelator and therefore can decrease production of the toxin.

Finally, exposure to $10 \mu \mathrm{M}$ nitrate significantly decreased $(\mathrm{P}<0.05)$ toxin production in $P$. raciborskii. Nitrogen containing compounds have been showed to have mixed effects on toxicity and the response is often species dependent (Sivonen, 1990; Orr and James, 1998). In this study, P. raciborskii excess nitrogen caused the cyanobacterium to decrease MC and therefore lessened its toxicity. A future study investigating the effects of excess nitrate on $R$. reptotaenium's toxin production would be warranted; Voss and Richardson (2006) showed that BBD progression was enhanced when exposed to nitrate.

While both organisms in this study produce MC, it is apparent that $R$. reptotaenium is significantly more toxic than $P$. raciborskii. This difference in pathogenicity is obvious when taken in context of BBD versus the hot spring system. 
Roseofilum reptotaenium has been implicated as the primary pathogen of $\mathrm{BBD}$, necessary to infection of coral tissue, and dominates the pathogenic cyanobacterial mat (Cooney et al., 2002; Sekar et al., 2006, 2008; Myers et al., 2007; Gantar et al., 2009; Sato et al., 2010; Stanić, 2010; Miller and Richardson, 2011; Casamatta et al., 2012; KramarskyWinter et al., 2013). Microcystin production by $R$. reptotaenium has proven to have toxic effects on coral hosts, causing tissue degradation (Miller and Richardson, 2012). However there are no reports of P. raciborskii playing a toxic role within Hunter's Hot Springs. Further studies are necessary to determine whether the cyanobacterium's MC production is detrimental to the other organisms within the system.

The response of the cyanobacterium $R$. reptotaenium to increased incubation temperatures has interesting implications. As global temperatures continue to rise, the occurrence of cyanobacterial blooms will become more common (Wagner and Adrian, 2009). Warm water temperatures coupled with eutrophication of water sources create optimal conditions for cyanobacterial growth (Paerl and Huisman, 2008; Paul, 2008). Cyanobacterial blooms are harmful to aquatic ecosystems because they cause water turbidity which suppressed photosynthetic functions in aquatic plants, they can deplete oxygen availability due to massive die-offs, they elevate the $\mathrm{pH}$ of the system, and toxic blooms can kill aquatic organisms (Havens, 2008; Paerl and Huisman, 2008). However when taking into consideration the results of my thesis and previous work, it appears that global temperature increase may decrease the toxicity of cyanobacterial blooms by inhibiting production of microcystin (Wicks and Thiel, 1990; van der Westhuizen and Eloff, 1985). If we consider that MC production is inhibited by increased temperatures, the incidences of $\mathrm{BBD}$ on coral reefs would be expected become less common. However, 
this is not what is seen in the field. Coral diseases, like BBD, have shown increased disease prevalence and mat progression in summer months when the water temperature is warm (Kuta and Richardson, 2002; Boyett et al., 2007; Bruno et al., 2007). If warm water temperatures cause decreased toxicity, then the driving force behind BBD pathogenicity may not be dependent on MC production. It is possible that sulfide, not $\mathrm{MC}$, is the more important toxin in disease pathogenesis of $\mathrm{BBD}$ and thus causes the increased pathogenicity in summer months.

In conclusion, results from my study showed that $P$. raciborskii produces the cyanotoxin MC, and that the two species of cyanobacteria used in my study respond differently to most environmental factors. The difference in toxin production between the two cyanobacteria is in agreement with their toxic versus non-toxic roles in their respective habitats. Roseofilum reptotaenium is an integral part of BBD pathogenesis because of its ability to produce MC (Richardson et al., 2009; Miller and Richardson, 2012). Toxin production by $R$. reptotaenium has been shown to degrade coral tissue and stimulate the growth of BBD-associated bacteria (Richardson et al., 2009).

Planktothricoides raciborskii may be a toxic cyanobacterium but due to the relatively low concentrations of MC that is produces, it appears to be non-toxic to other organisms in its environment. Any toxic role of P. raciborskii in Hunter's Hot Springs would be limited to inter-prokaryotic competition interactions since the system is dominated by prokaryotes competing for light and nutrient availability. 


\section{References}

Boyett, HW, DG Bourne, and BL Willis. Elevated temperature and light enhance progression and spread of black band disease on staghorn corals on the Great Barrier Reef. Mar Biol (2007) 151: 1711-1720.

Briand, JF, S Jacquet, C Bernard, and JF Humbert. Health hazards for terrestrial vertebrates from toxic cyanobacteria in surface water ecosystems. Vet Res (2003) 34: 361-377.

Butler, N, JC Carlisle, R Linville, and B Washburn. Microcystins: A brief overview of their toxicity and effects, with special reference to fish, wildlife, and livestock. OEHHA Ecotoxicology (2009) 5: 1-8.

Bruno, JF, ER Selig, KS Casey, CA Page, BL Willis, CD Harvell, H Sweatman, and AM Melendy. Thermal stress and coral cover as drivers of coral disease outbreaks. PLoS Biol (2007) 5: e124.

Campos, A, and V Vasconcelos. Molecular mechanisms of microcystin toxicity in animal cells. Int J Mol Sci (2010) 11: 268-287.

Carmichael, WW, and J An. Using an enzyme immunosorbent assay( ELISA) and a protein phosphate inhibition assay (PP1A) for the detection of microcystins and nodularins. Nat Toxins (1999) 7: 377-385.

Carmichael, WW, and R Li. Cyanobacteria toxins in the Salton Sea. Saline Systems (2006) 2: 5-17.

Casamatta, D, D Stanić, M. Gantar and L.L. Richardson. 2012. Characterization of Roseofilum reptotaenium (Oscillatoriales, Cyanobacteria) gen. et sp. nov. isolated from Caribbean black band disease. Phycologia 51: 489-499.

Castenholz, RW. Culturing methods for cyanobacteria. Methods Enzymol (1988) 167: 6893.

Cooney, R, O Pantos, M Le Tissier, M Barer, A O'Donnell, and J Bythell. Characterization of the bacterial consortium associated with black band disease in coral using molecular microbiological techniques. Environ Microbiol (2002) 4: 401-413.

Codd, GA. Cyanobacterial toxins, the perception of water quality, and the prioritization of eutrophication control. Ecol Eng (2000) 16: 51-60.

Codd, GA, LF Morrison and JS Metcalf. Cyanobacterial toxins: risk management for health protection. Tox Appl Pharm (2005) 203: 264-272. 
DeMott, WR, and F Moxter. Foraging cyanobacteria by copepods: responses to chemical defense and resource abundance. Ecology (1991) 72: 1820-1834.

Dittman, E, BA Neilan, M Erhard, H von Döhren, and T Börner. Insertional mutagenesis of a peptide synthetase gene that is responsible for hepatotoxin production in the cyanobacterium Microcystis aeruginosa PCC 7806. Mol Microbiol (1997) 26: 779-787.

El-Ayouty, YM, and S Abd-El-Rahman. Structural variations in peptide toxins of Microcystis aeruginosa grown on different carbon sources. J Nat Tox (1996) 5: 39-47.

Fawell, JK, RE Mitchell, DJ Everett, and RE Hill. The toxicity of cyanobacterial toxins in the mouse: I Microcystin-LR. Hum Exp Toxicol (1999) 18: 162-167.

Frias-Lopez, J, GT Bonheyo, and BW Fouke. Identification of differential gene expression in bacteria associated with coral black band disease by using RNA-arbitrarily primed PCR. Appl Environ Microbiol (2004) 70: 3687-3694.

Fujii, M, AL Rose, T Omura, and TD Waite. Effects of Fe(II) and Fe(III) transformation kinetics on iron acquisition by a toxic strain of Microcystis aeruginosa. Environ Sci Technol (2010) 44: 1980-1986.

Gantar, M, R Sekar, and LL Richardson. Cyanotoxins from black band disease of corals and from other coral reef environments. Microb Ecol (2009) 58: 856-864.

Githeko, AK, SW Lindsay, UE Confalonieri, and JA Patz. Climate change and vectorborne diseases: a regional analysis. Bull World Health Organ (2000) 78: 1136-1147.

Glowacka, J, M Szefel-Markowska, M Waleron, E Lojkowska, and K Waleron. Detection and identification of potentially toxic cyanobacteria in Polish water bodies. ACTABP (2011) 58: 1-13.

Havens, KE. Cyanobacterial blooms: effects on aquatic ecosystems. Adv Exp Med Biol (2008) 619: 733-747.

Kaebernick, M, BA Neilan, T Börner, and E Dittmann. Light and the transcriptional response of the microcystin biosynthesis gene cluster. Appl Environ Microbiol (2000) 66: 3387- 3392.

Konst, H, PD McKercher, PR Gorham, A Robertson, and J Howell. Symptoms and pathology produced by toxic Microcystis aeruginosa NRC-1 in laboratory and domestic animals. Con J Comp Med Vet Sci (1965) 29: 221-228.

Kramarsky-Winter, E, L Arotsker, D Rasoulouniriana, N Siboni, Y Loya, and E Kushmaro. The possible role of cyanobacterial filaments in coral black band disease pathology. Microb Ecol (2013) 1-9. 
Kuta, K, and LL Richardson. Ecological aspects of black band disease of corals: relationships between disease incidence and environmental factors. Coral Reefs (2002) 21: 393-398.

Lyck, S, N Gjølme, and H Utkilen. Iron starvation increases toxicity of Microcystis aeruginosa CYA 228/1 (Chroococcales, Cyanophyceae). Phycologia (1996) 35: 120124.

Martins, R, N Fernandez, R Beiras, and V Vasconcelos. Toxicity assessment of crude and partially purified extracts of marine Synechocystis and Synechococcus cyanobacterial strains in marine invertebrates. Toxicon (2007) 50: 791-799.

Miller, AW, P Blackwelder, H Al-Sayegh, and LL Richardson. Fine-structural analysis of black band disease-infected coral reveals boring cyanobacteria and novel bacteria. Dis Aquat Org (2011) 93: 179-190.

Miller, AW, and LL Richardson. Fine structure analysis of black band disease (BBD) infected coral and coral exposed to BBD toxins microcystin and sulfide. $J$ Invertebr Pathol (2012) 109: 27-33.

Myers, JL, and LL Richardson. Adaptation of cyanobacteria to the sulfide-rich microenvironment of black band disease of coral. Microb Ecol (2008) 67: 242-251.

Orr, PT, and GJ Jones. Relationship between microcystin production and cell division rates in nitrogen-limited Microcystis aeruginosa cultures. Limnol Oceanogr (1998) 43: $1604-1614$.

Paerl, HW, and J Huisman. Climate — blooms like it hot. Science (2008) 320: 57-58.

Paul, VJ. Global warming and cyanobacterial harmful algal blooms, pp. 239-247. In Kudnell, KH (ed.), Cyanobacterial Harmful Algal Blooms: State of the Science Research Needs Series: Advances in Experimental Medicine and Biology. Springer, New York (2008).

Pearson, L, T Mihali, M Moffitt, R Kellmann, and B Neilan. On the chemistry, toxicology, and genetics of the cyanobacterial toxins, microcystin, nodularins, saxitoxin and cylindrospermopsin. Mar Drugs (2010) 8: 1650-1680.

Pierson, BK, and MN Parenteau. Phototrophs in high iron microbial mats: microstructure of mats in iron-depositing hot springs. FEMS Microbiol Ecol (2000) 32: 181-196.

Rantala, A, DP Fewer, M Hisbergues, L Rouhiainen, J Vaitomaa, T Börner, and K Sivonen. Phylogenetic evidence for the early evolution of microcystin synthesis. PNAS (2004) 101: 568-573. 
Rasband, WS. ImageJ. U. S. National Institutes of Health, Bethesda, Maryland, USA. http://imagej.nih.gov/ij/, 1997-2012.

Richardson, LL, and RW Castenholz. Diel vertical movements of the cyanobacterium Oscillatoria terebriformis in a sulfide-rich hot spring microbial mat. Appl Environ Microbiol (1987a) 53: 2142-2150.

Richardson, LL, and RW Castenholz. Enhanced survival of the cyanobacterium Oscillatoria terebriformis in darkness under anaerobic conditions. Appl Environ Microbiol (1987b) 53: 2151-2158.

Richardson, LL, and RW Castenholz. Chemokinetic motility responses of the cyanobacterium Oscillatoria terebriformis. Appl Environ Microbiol (1989) 55: 261-263.

Richardson, LL, AW Miller, E Broderick, L Kaczmarsky, M Gantar, D Stanić, and R Sekar. Sulfide, microcystin, and the etiology of black band disease. Dis Aquat Organ (2009) 87: 79-90.

Sato, Y, BL Willis, and DG Bourne. Successional changes in bacterial communities during the development of black band disease on the reef coral, Montipora hispida. The ISME J (2010) 4: 203-214.

Schatz, D, Y Keren, A Vardl, A Sukenlk, S Carmell, T Börner, E Dittmann, and A Kaplan. Towards clarification of the biological role of microcystins, a family of cyanobacterial toxins. Env Microb (2007) 9: 965-970.

Sekar, R, DK Mills, ER Remily, JD Voss, and LL Richardson. Microbial communities in the surface mucopolysaccharide layer and the black band microbial mat of black banddiseased Siderastrea siderea. Appl Environ Microbiol (2006) 72: 5963-5973.

Sekar, R, LT Kaczmarsky, and LL Richardson. Microbial community composition of black band disease on the coral host Siderastrea siderea from three regions of the wider Caribbean. Mar Ecol-Prog Ser (2008) 362: 85-98.

Sevilla, E, B Martin-Luna, L Vela, MT Bes, MF Fillat, and ML Peleato. Iron availability affects mcyD expression and microcystin-LR synthesis in Microcystis aeruginosa PCC7806. Environ Microbiol (2008) 10: 2476-2483.

Sivonen, K. Effects of light, temperature, nitrate, orthophosphate, and bacteria on growth of and hepatotoxin production by Oscillatoria agardhii strains. Appl Environ Microbiol (1990) 56: 2658-2666.

Sivonen, K, and G Jones. Cyanobacterial toxins, pp. 41-112. In Chorus, I, and J Bartman (eds.), Toxic Cyanobacteria in Water: A Guide to their Public Health Consequences, Monitoring, and Management. St Edmundsbury Press, Great Brittain (1999). 
Song L, T Sano, R Li, MW Watanabe, Y Liu, and K Kaya. Microcystin production of Microcystis viridis (cyanobacteria) under different culture conditions. Phycolo Res (1998) 46: $19-23$

Stanić, D. Characterization of Oscillatoria spp. and their role in black band disease of coral. M. S. Thesis, Florida International University, Miami, Florida. (2010) 103 pp.

Sutherst, RW. Global change and human vulnerability to vector-borne diseases. Clin Microbiol Rev (2004) 17: 136-173.

Tanabe, Y, T Sano, F Kasai, and MW Wanatabe. Recombination, cryptic clades and neutral molecular divergence of the microcystin synthetase ( cyanobacterium Microcystis aeruginosa. BMC Evol Biol (2009) 9: 115-129.

Tillett, D, E Dittmann, M Erhand, H von Döhren, T Börner, and BA Neilan. Structural organization of microcystin biosynthesis in Microcystis aeruginosa PCC7806: an integrated peptide-polyketide synthetase system. Chem \& Biol (2000) 7: 753-764.

Tonk, L, PM Visser, G Christiansen, E Dittmann, EOFM Snelder, C Wiedner, LR Mur, and J Huisman. The microcystin composition of the cyanobacterium Planktothrix agardhii changes toward a more Toxic variant with increasing light intensity. Appl Environ Microbiol (2005) 71: 5177-5181.

Utkilen, $\mathrm{H}$, and $\mathrm{N}$ Gjølme. Toxin production by Microcystis aeruginosa as a function of light in continuous cultures and its ecological significance. Appl Environ Microbiol (1992) 58: 1321-1325.

Utkilen, $\mathrm{H}$ and N Gjølme. Iron-stimulated toxin production in Microcystis aeruginosa. Appl Environ Microbiol (1995) 61: 797-800.

Van der Westhuizen, AJ, and JN Eloff. Effect of temperature and light on the toxicity and growth of the blue-green alga Microcystis aeruginosa (UV-006). Planta (1985) 163: 5559.

Voss, JD, and LL Richardson. Nutrient enrichment enhances black band disease progression. Coral Reefs (2006) 25: 569-576.

Wagner, C, and R Adrian. Cyanobacteria dominance: quantifying the effects of climate change. Limnol Oceanogr (2009) 54: 2460-2468.

Wicks, RJ, and PG Thiel. Environmental factors affecting the production of peptide toxins in floating scums of the cyanobacterium Microcytis aeruginosa in a hypertrophic African reservoir. Environ Sci Technol (1990) 24: 1413-1418. 
Zilliges, Y, JC Kehr, S Meissner, K Ishida, S Mikkat, M Hagemann, A Kaplan, T Börner, and E Dittman. The cyanobacterial hepatotoxin microcystin binds to proteins and increases the fitness of Microcystis under oxidative stress conditions. PLoS ONE (2011) 6: e17615. 


\section{Tables}

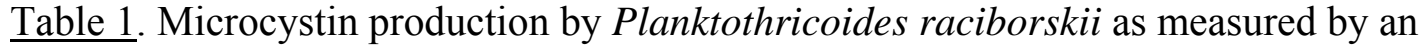
ELISA assay. A standard concentration curve was constructed using the absorbance $\left(\% \mathrm{~B} / \mathrm{B}_{0}\right)$ from standards provided with the ELISA kit. Microcystin concentration within each sample was deduced using the average absorbance of duplicate trials containing triplicate flasks per environmental factor.

\begin{tabular}{ccc}
\hline Environmental Factor & Average Absorbance \pm SE & MC Concentration [ug/g] \\
\hline Control & $0.40 \pm 0.035$ & 0.0079 \\
$35^{\circ} \mathrm{C}$ & $0.39 \pm 0.042$ & 0.0078 \\
$40^{\circ} \mathrm{C}$ & $0.44 \pm 0.029$ & 0.0048 \\
$7.0 \mathrm{pH}$ & $0.48 \pm 0.033$ & 0.0032 \\
$9.0 \mathrm{pH}$ & $0.49 \pm 0.031$ & 0.0031 \\
$\mathrm{FeCl}$ & $0.51 \pm 0.038$ & 0.0025 \\
$\mathrm{NaNO}_{3}$ & $0.56 \pm 0.026$ & 0.0017 \\
\hline
\end{tabular}




\section{Figures}

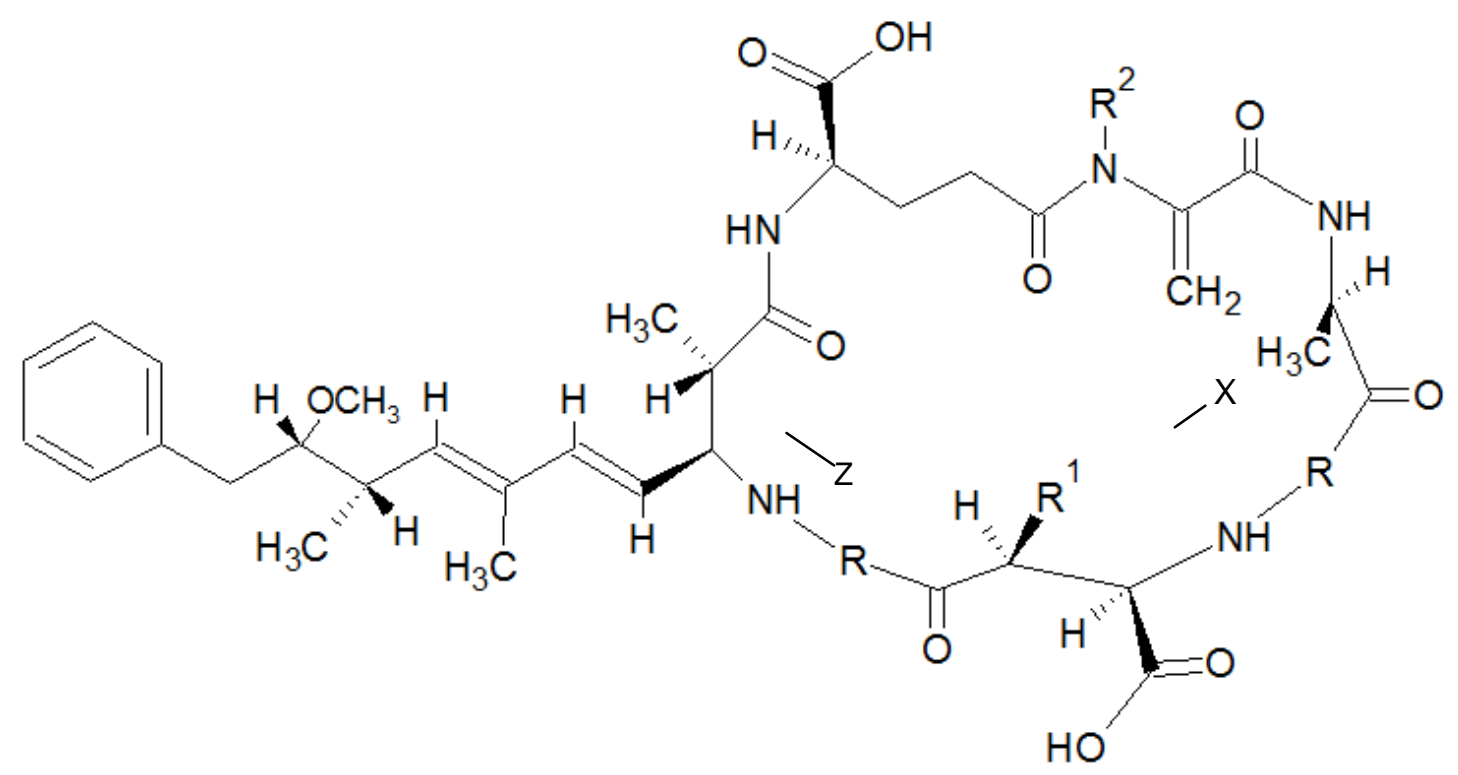

Figure 1. Structure of microcystin. The general structure of microcystin is cyclo - (DAlanine - X - Methylaspartic Acid - Z — Adda - D-Glutamic Acid Methyldehydroalanine). Variable amino acid at positions 2 and 4 are represented by X and $\mathrm{Z}$ respectively. $\mathrm{R}^{1}$ and $\mathrm{R}^{2}$ are variable methyl groups. The Adda amino acid is the region of microcystin identified by Adda-specific antibodies within ELISA wells (Redrawn from Sivonen and Jones, 1999) 


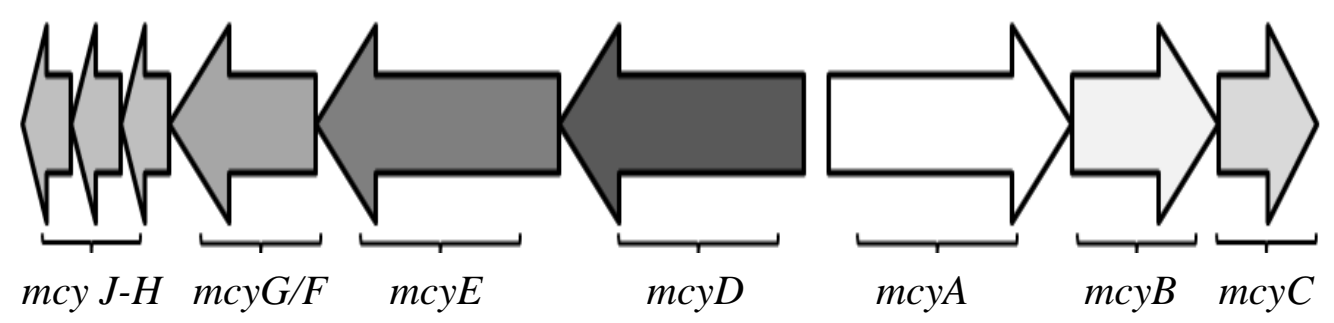

Figure 2. The microcystin gene complex found in toxic cyanobacteria depicting the microcystin synthase gene clusters, mcyABC, mcyDE, mcyGF, and mcyHIJ. The product of the $m с y B$ gene, McyB, is required to synthesize all variants of microcystin. (Redrawn from Tanabe et al., 2009) 


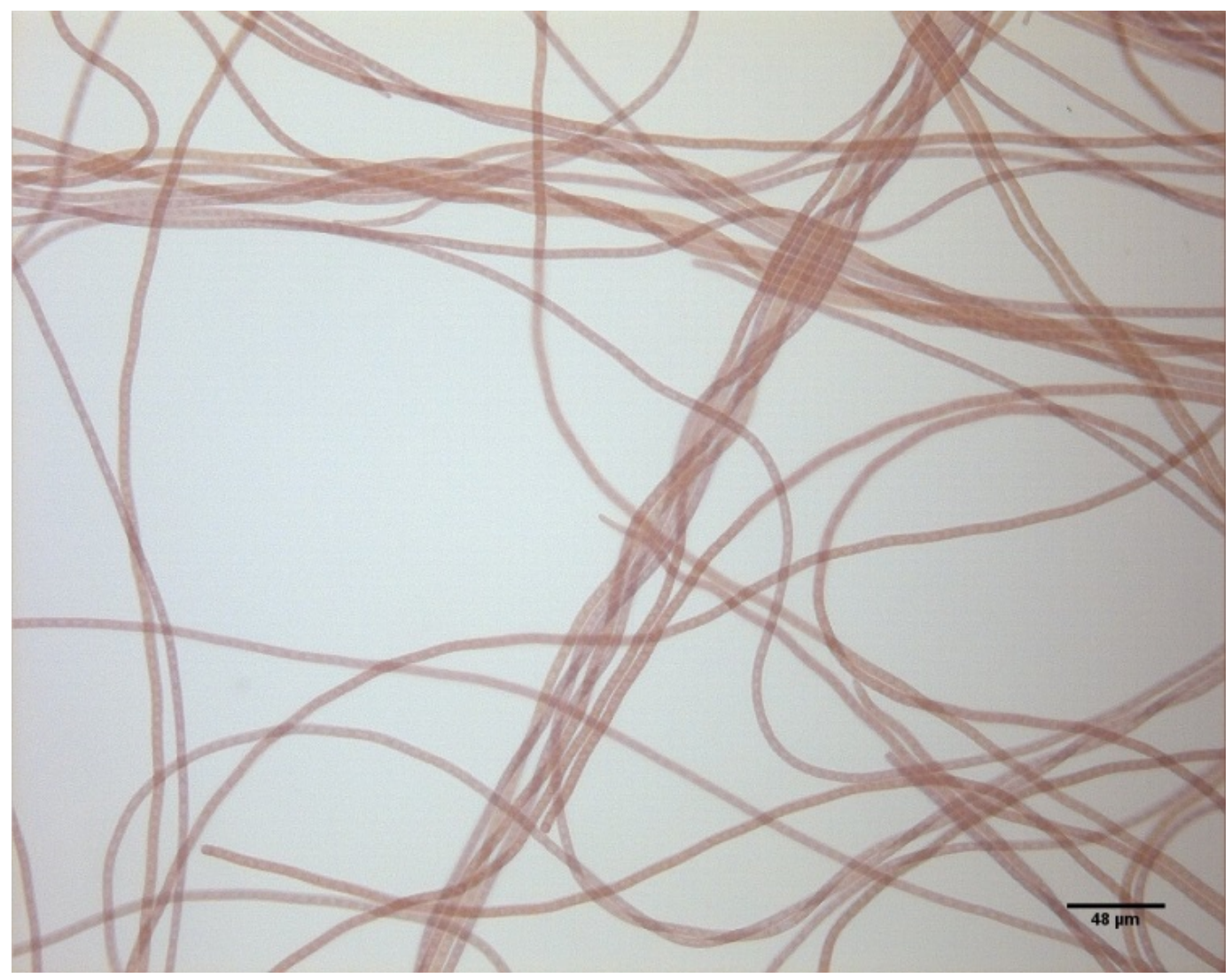

Figure 3. Photomicrograph of Planktothricoides raciborskii, a hot spring cyanobacterium from Hunter's Hot Springs. The presence of phycoerythrin light-harvesting proteins gives the cyanobacterium a red hue. (Photograph by: AC Brownell) 


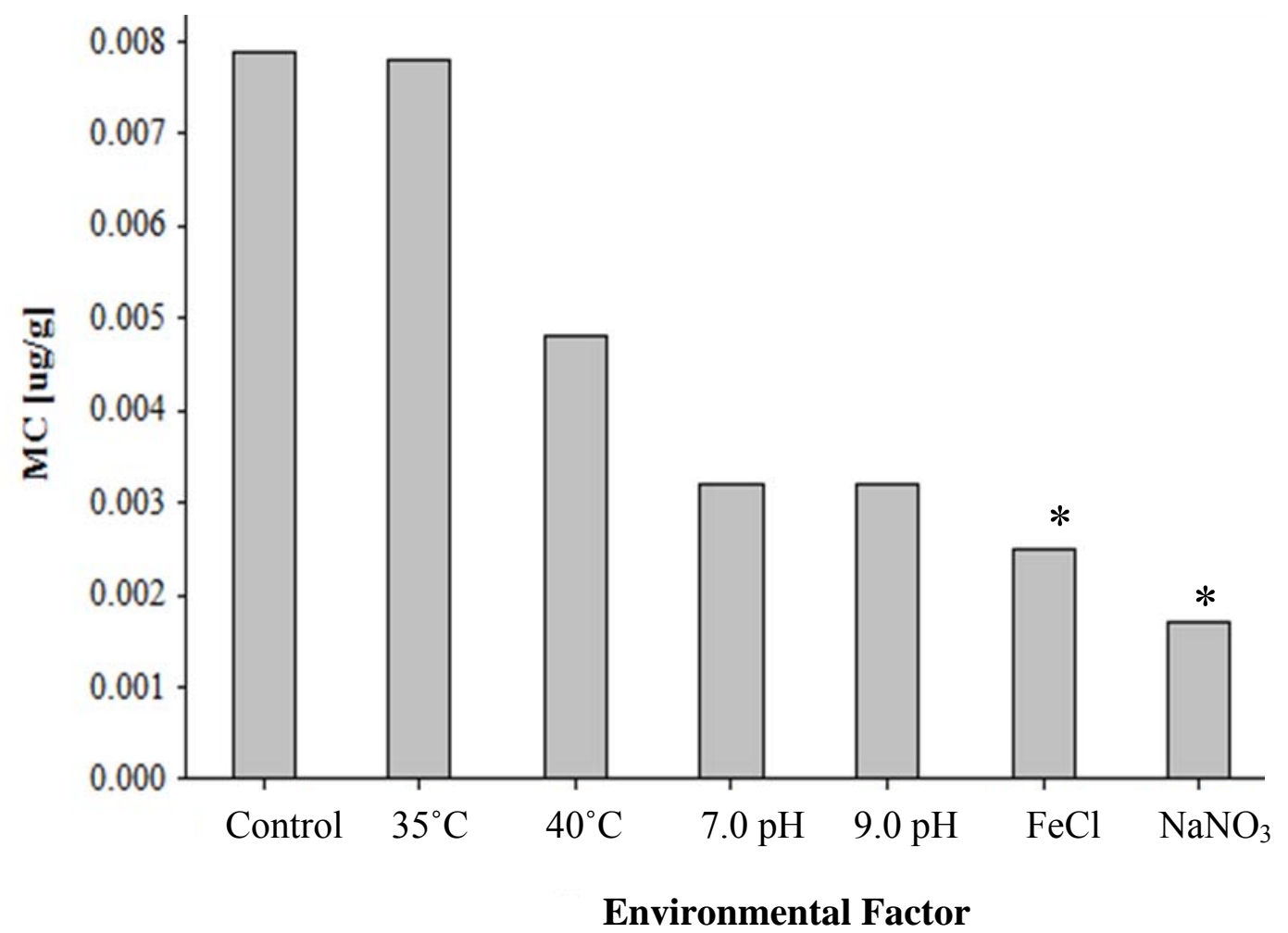

Figure 4. Microcystin production by Planktothricoides raciborskii in response to environmental factors. There was a significant difference $(\mathrm{F}(6,35)=3.240, \mathrm{P}<0.05)$ in microcystin production between environmental challenges. A Fisher's LSD post-hoc test was used to determine significance between each environmental challenge and the control; significant difference is indicated by *. 


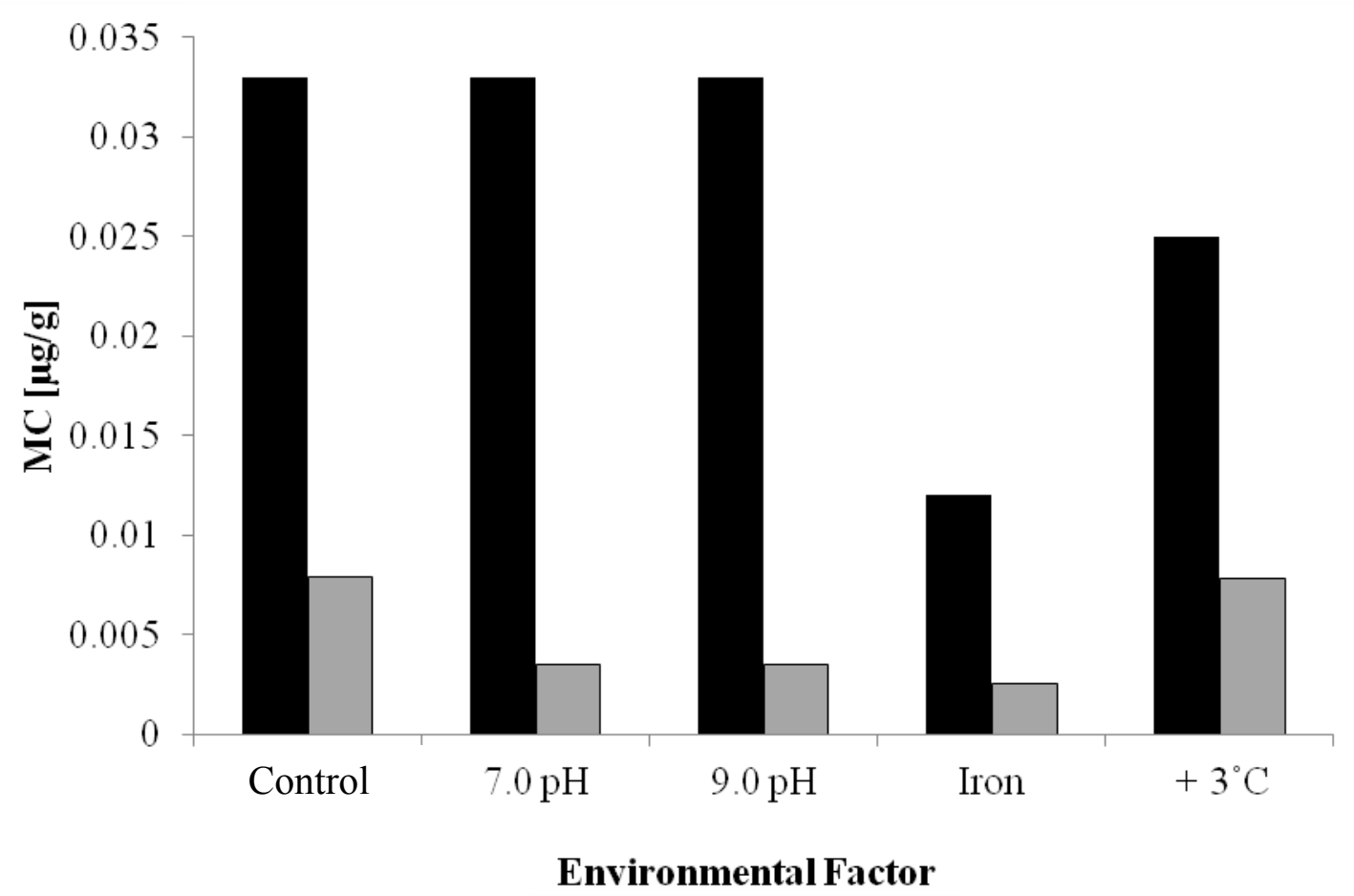

Figure 5. Comparison of microcystin production by Roseofilum reptotaenium and Planktothricoides raciborskii. Roseofilum reptotaenium (black) produced significantly more $(\mathrm{F}(1,8)=27.62, \mathrm{P}<0.001)$ microcystin than Planktothricoides raciborskii (gray) when microcystin concentration values were pooled. 


\title{
CHAPTER IV \\ CHEMOTACTIC RESPONSES TO MICROCYSTIN AND SULFIDE BY \\ PLANKTOTHRICOIDES RACIBORSKII AND ROSEOFILUM REPTOTAENIUM
}

\begin{abstract}
Roseofilum reptotaenium and Planktothricoides raciborskii are both toxin

producing, mat-forming, filamentous cyanobacteria that exhibit gliding motility. The two species are found in very different environments, the first in association with a pathogenic coral disease, black band disease (BBD), and the second in a hot spring outflow. Isolation and comparative study of cultures of these two physiologically similar cyanobacteria provides an interesting opportunity for testing chemotactic responses to toxins in the context of environment for each system. Both black band disease and Hunter's Hot Springs contain high levels of sulfide and microcystin (MC) in the cyanobacterial mats. Experiments were designed to test the chemotactic response of $R$. reptotaenium and $P$. raciborskii to $\mathrm{MC}$ and sulfide in both horizontal and vertical artificial gradients. Test cultures were exposed to either MC $(1 \mu \mathrm{g} / \mathrm{L}, 50 \mu \mathrm{g} / \mathrm{L}$, or 100 $\mu \mathrm{g} / \mathrm{L})$ or sulfide $(1 \mu \mathrm{M}, 100 \mu \mathrm{M}$, or $1 \mathrm{mM})$. In chemotaxis experiments (horizontal and vertical gradients) $R$. reptotaenium was negatively chemotactic to sulfide, which thus acts as a repellant. Conversely, $P$. raciborskii was neither repelled nor attracted to sulfide. Roseofilum reptotaenium and P. raciborskii displayed variable responses to MC. Overall, both appear unaffected by MC. Results of this work further substantiate the role of $R$. reptotaenium as a necessary component of $\mathrm{BBD}$ pathogenesis by implicating a role of sulfide in the band as an environmental driver of mat migration across the coral host. The lack of chemotactic response to MC by both test organisms indicates that this
\end{abstract}


substance is not important in controlling the motility patterns of these two cyanobacteria in the two distinct systems.

\section{Introduction}

\section{Sulfide and Microcystin Production in Cyanobacterial Mats in Black Band Disease of Corals and Hunter's Hot Springs}

Roseofilum reptotaenium is a filamentous, gliding cyanobacterium that migrates as a distinct band (or microbial mat) horizontally across host corals as well as vertically within the band itself. The vertical migration during the day is in accordance with light conditions (phototaxis), with $R$. reptotaenium migrating under populations of Beggiatoa, a sulfide oxidizing bacterium, during high light intensity (Richardson, 1996). Sulfide is always present at depth in the BBD mat (Carlton and Richardson, 1995). While this cyanobacterium may tolerate sulfide, its chemotactic response to sulfide may help explain the role of $R$. reptotaenium in the pathogenesis of BBD. The horizontal movement of BBD across the coral surface has been proposed to be based on escape from the high levels of sulfide that build within the mat (negative chemotaxis), termed the "escaped convict hypothesis" (Dr. DeEtta Mills). The specific chemotactic response of $R$. reptotaenium to sulfide is unknown.

Planktothricoides raciborskii, also a filamentous, gliding cyanobacterium, has been shown to exhibit both chemotactic and phototactic responses (Castenholz 1968; Richardson and Castenholz, 1987, 1989). Studies on P. raciborskii (formerly Oscillatoria terebriformis) show that filaments migrate down into the hot spring mat, also under populations of Beggiatoa, at night or during periods of extremely high light intensity (Richardson and Castenholz, 1987). Similar to BBD, below the mat surface, $P$. 
raciborskii is exposed to a microenvironment that is anaerobic, reducing, and high in sulfide (Richardson and Castenholz, 1987). The overall diel migration of $P$. raciborskii is similar to $R$. reptotaenium's vertical migration in BBD but in this system the downward migration was shown to be based on a negative chemokinetic response to sulfide. As filaments move into the mat and encounter high concentrations of sulfide, they stop moving and become trapped (Richardson and Castenholz, 1987). This response is alleviated in light conditions as oxygenic photosynthesis oxidizes (and removes) the sulfide (Richardson and Castenholz, 1987). Also, upon sunrise the phototactic cyanobacterium then migrates out of the high sulfide concentrations and back to the surface of the mat (Richardson and Castenholz, 1987)

Levels of sulfide as low as $0.1 \mathrm{mM}$ are toxic to most oxygenic, photosynthetic organisms by inhibiting Photosystem II of photosynthetic electron transport (Cohen et al., 1986; Miller and Bebout, 2004). However, R. reptotaenium and P. raciborskii, which both conduct sulfide-resistant oxygenic photosynthesis, can survive in their respective sulfidic environments (Castenholz, 1977; Myers et al., 2008). Sulfide concentrations within the hot spring mat can be as high as $0.8 \mathrm{mM}$ during the night while concentrations within the water column are consistently $\sim 2.6 \mathrm{mM}$ (Richardson and Castenholz, 1987). Thus, Hunter's Hot Springs cyanobacteria are adapted to sulfidic environments and can tolerate toxic-levels of sulfide for extended periods of time. The concentration of sulfide in BBD ranges depending on location; in the Caribbean where R. reptotaenium was collected, levels exceed 0.8 mM within the mat (Carlton and Richardson, 1995). While both species of cyanobacteria tolerate sulfide in their respective systems it is unknown whether filaments will actively avoid low or high concentrations of this toxic substance. 
Microcystin is a potent cyanotoxin produced by both $R$. reptotaenium and $P$. raciborskii. As stated in Chapter III, MC has many functions within cyanobacterial cells but the debate over the evolutionary purpose of the toxin continues (DeMott and Moxter, 1991; Rantala et al., 2004; Schatz et al., 2007; Zilliges et al., 2011). One widely supported notion is that MC is relatively most important to cellular physiology and maintenance of proper cell function (Holland and Kinnear, 2013). Proteins associated with photosynthesis, energy metabolism, protein biosynthesis, and many others have been shown to up- or down-regulated as a consequence of toxin production capabilities (Zilliges et al., 2011). Microcystin has been shown to bind to and protect such proteins, especially in times of high light or oxidative stress (Zilliges et al., 2011).

Microcystin also plays a role in defense against grazers (DeMott et al., 1991). In addition to this role and cell physiology, $\mathrm{MC}$ has been shown to act as a signal molecule to other toxic cyanobacteria. When MC from lysed cells is released into the environment, surrounding cells have shown an exponential increase in MC production (Schatz et al., 2007), leading these researchers to suggest that MC is a warning signal to the surrounding cells of possible danger, either abiotic (e.g. high light) or biotic (e.g. grazers or competition). In addition to $\mathrm{MC}$ acting as a physiological signal molecule, it is possible that cyanobacterial filaments respond to the presence of this toxin in a chemotactic manner.

\section{The Potential Role of Chemotaxis in BBD and Hunter's Hot Springs Mats}

Chemotaxis is the directional movements of motile organisms towards or away from chemical substances (Dunn, 1990). Both R. reptotaenium and P. raciborskii are capable of gliding motility (Richardson and Castenholz, 1987; Rütlzer and Santavy, 
1983), which allows trichomes of these cyanobacteria to alter their position within the BBD or hot spring mat in response to environmental cues. Reponses to attractants or repellants can also include chemokinesis, which is the ability to alter migration rate in response to chemical gradients (Dunn, 1990; Jang et al., 2003). A positive chemokinetic response causes increased motility rates while a negative chemokinetic response leads to decreased motility rates. The goal of the work presented here was to determine whether the toxins MC and sulfide act as chemoattractants or chemorepellants to $R$. reptotaenium and $P$. raciborskii and to assess the ecological relevance of any response to these compounds. I hypothesized that both cultures would be positively chemotactic to MC but negatively chemotactic to sulfide.

\section{Materials and Methods}

\section{Chemotactic and Phototactic Responses against Horizontal Gradients}

Biomass (clumps of filaments approximately $5 \times 5 \mathrm{~mm}$ ) from cultures of $R$. reptotaenium and $P$. raciborskii was plated onto ASN-III and BG-11 agar, respectively, using sterile forceps. ASN-III medium is used to culture marine cyanobacteria while BG11 is used to culture freshwater cyanobacteria. To test the chemotactic and phototactic responses to sulfide, crystals of sodium sulfide nonahydrate $\left(\mathrm{Na}_{2} \mathrm{~S} \cdot 9 \mathrm{H}_{2} \mathrm{O}\right)$ weighing 25 mg were plated approximately $4 \mathrm{~cm}$ from the cyanobacterial sample. To prevent contamination of plates, biomass used for inoculation was not weighed. Plates were incubated, in a 12/12 hour cycle of cool light at $3.4 \times 10^{14}$ quanta $\cdot \mathrm{s}^{-1} \cdot \mathrm{cm}^{-2}$ and darkness, in a $28^{\circ} \mathrm{C}$ incubator. Light intensity was measured using a Biospherical Instruments Quantum Scalar Irradiance meter QSL100. Plates were oriented so that the side of the plate containing sulfide was closest to the light source, forcing the phototactic 
cyanobacterium to travel towards the sulfide crystals. Two control plates were used per trial, with each control plate containing only cyanobacterial filaments. Tactic responses of filaments were observed using a dissecting microscope two days after plating $(\mathrm{t}=1)$ and four days after plating $(\mathrm{t}=2)$. Migration of the filaments was marked, measured with a metric ruler, and photographed. Total migration was reported as the distance between the point where the sulfide crystals were plated and the closest cyanobacterial filament (see green line in Figure 1).

The change in sulfide concentration within the sulfide-ring at the different time points as well as the change in sulfide concentration within the gradient over time was documented. Four time points were used for the documentation: $t=0$ (before plating sulfide), $\mathrm{t}=1$ ( 1 hour after plating), $\mathrm{t}=2$ (12 hours after plating), $\mathrm{t}=3$ (24 hours after plating), and $t=4$ (96 hours after plating). Agar plates were first marked at the point where the $25 \mathrm{mg}$ of sulfide crystals was plated. At the designated time points, samples for sulfide analysis were collected using the open end of a sterile $200 \mu \mathrm{L}$ pipette tip, producing agar disks approximately $6 \mathrm{~mm}$ wide $\times 3 \mathrm{~mm}$ deep. Four agar disk samples were collected per plate, moving from the center of each sulfide-diffusion ring towards the outer edge of the ring (Figure 2) and analyzed using the Pachmayr assay (Brock et al., 1971). Upon collection, samples were added to $5 \mathrm{~mL}$ of sterile $\mathrm{diH}_{2} \mathrm{O}$ in $20 \mathrm{~mL}$ scintillation vials. Immediately $1 \mathrm{~mL}$ of phenylenediamine reagent and $0.1 \mathrm{~mL}$ ferric reagent were added to the samples. The phenylenediamine reagent was prepared by dissolving $0.2 \mathrm{~g}$ of $N$, $N$-dimethyl-p-phenylenediamine sulfate in $20 \mathrm{~mL}$ of $\mathrm{H}_{2} \mathrm{O}$ then adding $20 \mathrm{~mL}$ of concentrated $\mathrm{H}_{2} \mathrm{SO}_{4}$, after cooling the solution the total volume was brought to $100 \mathrm{~mL}$ with $\mathrm{H}_{2} \mathrm{O}$. The ferric reagent was prepared by dissolving $10 \mathrm{~g}$ ferric 
ammonium sulfate $\bullet 12 \mathrm{H}_{2} \mathrm{O}$ in $2 \mathrm{~mL}$ concentrated $\mathrm{H}_{2} \mathrm{SO}_{4}$ and the volume was brought to $100 \mathrm{~mL}$ with $\mathrm{H}_{2} \mathrm{O}$. After addition of the reagents, an additional $3.5 \mathrm{~mL}$ of $\mathrm{diH}_{2} \mathrm{O}$ was added to each sample 20 minutes before spectrophotometric analysis. Optical density (OD) was determined at $668 \mathrm{~nm}$ using a Genesys 10S UV-Vis Spectrophotometer. Standards $\left(0 \mu \mathrm{M}, 50 \mu \mathrm{M}, 100 \mu \mathrm{M}\right.$, and $\left.1 \mathrm{mM} \mathrm{Na}_{2} \mathrm{~S} \cdot 9 \mathrm{H}_{2} \mathrm{O}\right)$ were used to construct a calibration curve. Utilizing the standard calibration, the OD of each sample was used to determine the sulfide concentration within each disk.

The Pachmayr assay revealed that the sodium-sulfide crystals absorbed and diffused into the agar within one hour of plating. After 12 hours, the concentration of sulfide within the center of the sulfide-ring was as high as $12 \mathrm{mM}$, decreasing around the edge of the sulfide-ring. After 24 hours the outer edge of the sulfide-ring, contained between 0.15 and $0.1 \mathrm{mM}$ sulfide. After 96 hours sample 4 did not contain sulfide but sample 3 contained between 1.2 and $1.5 \mathrm{mM}$ sulfide.

To test the chemotactic response to $\mathrm{MC}$, holes were punched into the agar (using the open end of a sterile culture tube) $4 \mathrm{~cm}$ from the cyanobacterial biomass. Challenge wells were filled with $50 \mu \mathrm{L}$ of $1 \mu \mathrm{g} / \mathrm{L}, 50 \mu \mathrm{g} / \mathrm{L}$, or $100 \mu \mathrm{g} / \mathrm{L}$ MC. Stock solutions of MC used in BG-11 (freshwater) plates were made with $\mathrm{diH}_{2} \mathrm{O}$ while stock solutions of $\mathrm{MC}$ for ASN-III plates were made with artificial seawater (ASW). Microcystin is colorless, making visualization of MC diffusion impossible. To assess diffusion, $25 \mu \mathrm{L}$ of safranin dye was mixed with $25 \mu \mathrm{L}$ of $100 \mu \mathrm{g} / \mathrm{L}$ MC stock solution and pipetted into a challenge well. The mixture diffused in to the agar and formed a MC-ring approximately $4 \mathrm{~cm}$ in diameter (Figure 3). As in the sulfide chemotaxis assays two control plates were used per trial with control plates containing only cyanobacterial filaments. Challenge wells were 
created but not filled. For the assays plates were incubated in a 12/12 hour cycle of cool light at $3.4 \times 10^{14}$ quanta $\cdot \mathrm{s}^{-1} \cdot \mathrm{cm}^{-2}$ and darkness, in a $28^{\circ} \mathrm{C}$ incubator. Plates were oriented so that the challenge well was closest to the light source. Tactic responses of filaments were observed using a dissecting microscope two days after plating $(t=1)$ and four days after plating $(\mathrm{t}=2)$. Migration of the filaments was marked, measured with a metric ruler, and photographed and recorded as the distance from the challenge well containing $\mathrm{MC}$ to the closest cyanobacterial filament (Figure 1).

To ensure responses to $\mathrm{MC}$ were not solely due to a positive phototactic response, trials were conducted utilizing a diffuse overhead light source. After inoculation the plates were incubated on a bench top within the laboratory at room temperature. The light intensity from the fluorescent lights $\left(3.9 \times 10^{14}\right.$ quanta $\left.\cdot \mathrm{s}^{-1} \cdot \mathrm{cm}^{-2}\right)$ was comparable to the incubator light intensity. Due to the positioning of the light, the filament migration direction would not be biased by positive phototaxis. Tactic responses to $\mathrm{MC}$ were again observed and recorded.

\section{Chemotactic Responses in Vertical Gradients}

Vertical gradients were created in vials containing BG-11 or ASN-III soft (70\%) agar. Different concentrations of MC $(1 \mu \mathrm{g} / \mathrm{L}, 50 \mu \mathrm{g} / \mathrm{L}$, or $100 \mu \mathrm{g} / \mathrm{L})$ or sulfide $(1 \mu \mathrm{M}$, $100 \mu \mathrm{M}$, or $1 \mathrm{mM}$ ) were first added to $8 \mathrm{~mL}$ of molten agar (cooled to $45^{\circ} \mathrm{C}$ ) and poured into $20 \mathrm{~mL}$ vials. When the agar solidified in the bottom of the vial it formed a "test plug”. Control vials did not contain test substances. Additional $45^{\circ} \mathrm{C}$ agar was used for the cyanobacterial inoculum. A $10 \mathrm{~mL}$ sterile syringe was used to evenly disperse the cyanobacterial filaments within the molten agar. Immediately following dispersal, $8 \mathrm{~mL}$

of agar containing cyanobacterial filaments was added on top of the test plug and allowed 
to solidify. All vials were incubated in natural, filtered light in a south-facing windowsill. Vials containing filaments of $R$. reptotaenium were incubated at room temperature while vials containing filaments of $P$. raciborskii were incubated at $32^{\circ} \mathrm{C}$ in a heated glass aquarium placed on the window sill. Movement of filaments was recorded, marked, and photographed. To describe chemotactic movement into the test plug, the depth to which the filaments traveled was measured at $1 / 4,1 / 2,3 / 4$, or to the bottom of the vial, representing distances of $0.63,1.25,1.88$ and $2.5 \mathrm{~cm}$ (Figure 4).

\section{Statistical Analysis}

Statistical analysis of migration rates was performed using Minitab software. Significance between migration rates of filaments on experimental plates and control plates was determined using a one-way ANOVA. P-values less than 0.05 were considered statistically significant.

\section{Results}

\section{Chemotactic Responses to Horizontal Gradients of Sulfide}

Within hours following inoculation of $R$. reptotaenium onto test plates of ASN-III agar, the sodium sulfide crystals had melted and diffused into the agar, forming a ring of sulfide - henceforth referred to as the "sulfide ring" (see Figure 1). The orientation of the plates forced the positively phototactic cyanobacterium towards the sulfide ring. In all trials, $R$. reptotaenium trichomes moved around the sulfide ring as they moved to the light source. Upon reaching the outer edge of the sulfide ring, the filaments either became immobile or moved around the outer perimeter of the ring (Figure 5). The few filaments that entered the edge of the ring appeared to be dead. This assessment was based on their green color which occurs when cyanobacterial cells lyse, the water soluble red pigment 
phycoerythrin is released, leaving behind membrane bound chlorophyll a (Cohen-Bazire and Bryant, 1982). Since chlorophyll $a$ is not water-soluble it remains within the cyanobacterial cell, causing the previously red-colored cyanobacteria to appear green. There were no trials in which filaments entered and moved through the sulfide ring (Table 1). Statistical analysis of the migration measurement indicated that filaments on control plates travelled significantly closer $(\mathrm{P}<0.05)$ to the sulfide-containing side of the plate as compared to filaments on the experimental plates.

Planktothricoides raciborskii was tested using 100\% BG-11 (freshwater) agar plates. Unlike the marine plates made with ASN-III, as the sulfide crystals diffused into the agar, a distinct sulfide ring was not visualized. For these experiments the edge of the sulfide ring was identified based on the results of the Pachmayr assays. In these experiments it was determined that $P$. raciborskii was less phototactic than $R$. reptotaenium. Planktothricoides raciborskii filaments travelled throughout the plate but not always towards the light source. Filaments moved around the plate with no apparent preferred direction as opposed to the well-defined movement towards the light source exhibited by $R$. reptotaenium (Figure 6). Although there were multiple trials in which filaments of $P$. raciborskii entered the area of high sulfide concentrations (Figure 7). These filaments did not appear to have a chemotactic response to sulfide. The overall motility was random in terms of both light source and sulfide concentration (Table 1). Statistical analysis indicated that there was not a significant difference $(\mathrm{P}=0.56)$ in filament migration between control and experimental plates. Additionally, some filaments were observed to travel into the area where the sodium sulfide crystals were 
originally plated. These results indicates that the filaments were unaffected by the highest levels of sulfide $(1 \mathrm{mM})$ present on the plate.

\section{Chemotactic Responses to Horizontal Gradients of Microcystin}

Movement of filaments of Roseofilum reptotaenium plated onto 100\% ASN-III agar was consistent with previous results. The filaments were positively phototactic and travelled towards the light source (control plates). Filaments of $R$. reptotaenium were not negatively affected by the presence of $\mathrm{MC}$ and seemed to be positively phototactic to the toxin (Table 2). In some trials, filaments of $R$. reptotaenium travelled directly to the challenge well edge (Figure 8). To assess if this response was movement up the MC gradient or to the light source plates were incubated under an overhead light source. Results showed that filaments did not travel in any specific direction - likely due to the lack of a directional light source (Table 3). There was no statistical difference $(\mathrm{P}=0.75)$ in distance travelled by filaments on control and experimental plates.

Planktothricoides raciborskii did not exhibit a chemotactic response to $\mathrm{MC}$ (Table 2). Filaments travelled in all directions throughout the plate. In some trials $P$. raciborskii filaments moved directly towards the areas of high MC concentration (Figure 9). When incubated under a diffuse light source, filaments of $P$. raciborskii were not chemotactic to MC (Table 3). The distance travelled by filaments on control plates and experimental plates was not statistically different $(\mathrm{P}=0.30)$.

\section{Chemotactic Responses to Vertical Gradients of Sulfide and Microcystin}

Filaments of $R$. reptotaenium migrated to the bottom of the test plug containing 1 $\mu \mathrm{M}$ sulfide but at higher concentrations, migration of filaments was hindered (Table 4). At $100 \mu \mathrm{M}$ filaments only travelled $3 / 4$ towards the bottom. At $1 \mathrm{mM}$, migration occurred 
through $1 / 2$ of the test plug. Filaments within control vials travelled through the entire test plug, to the bottom. When exposed to $1 \mu \mathrm{g} / \mathrm{L} \mathrm{MC}$, filaments of $R$. reptotaenium traveled $3 / 4$ of the way in to the test plug. At higher concentrations of MC (50 and $100 \mu \mathrm{g} / \mathrm{L})$ the filaments only traveled $1 / 4$ of the way in to the test plug. Filaments in the control vial were evenly distributed (Figure 10).

Migration of $P$. raciborskii filaments was not affected by MC concentrations (Table 4). Filaments traveled $3 / 4$ through the test plug in the vial containing $1 \mu \mathrm{g} / \mathrm{L} \mathrm{MC}$ but traveled to the bottom at the highest concentrations of $\mathrm{MC}$ (50 and $100 \mu \mathrm{g} / \mathrm{L})$. The migration of $P$. raciborskii filaments when exposed to sulfide was variable. At $1 \mu \mathrm{M}$ sulfide concentrations, filaments migrated to the bottom of the test plug. Filaments exposed to $50 \mu \mathrm{M}$ sulfide only travelled through $1 / 2$ of the test plug but at $100 \mu \mathrm{M}$ the filaments travelled $3 / 4$ through the test plug. Filaments within control vials travelled throughout the vial and did not accumulate (Figure 11).

\section{Discussion}

The results of the sulfide chemotaxis experiments indicated an ecological relevance of sulfide taxis for both cyanobacterial species. Based on the Pachmayr assay, the sulfide concentrations measured at the edges of the sulfide rings were comparable to those found in BBD and in the HHS mat. The experiments showed that $R$. reptotaenium will actively avoid sulfide concentrations equivalent to, or lower than, the levels measured in BBD. In contrast, $P$. raciborskii filaments travelled into the ring, revealing that they are not affected by extremely high levels of sulfide.

Roseofilum reptotaenium is negatively chemotactic to the sulfide. The outcome of the horizontal chemotaxis experiment revealed that $R$. reptotaenium actively avoids 
concentrations of sulfide equivalent to those found in BBD (Carlton and Richardson, 1995). In response to vertical gradients of sulfide, filaments migrated further into the test plug at the lower concentrations than at the highest. Roseofilum reptotaenium is tolerant to concentrations of sulfide lower than those found in $\mathrm{BBD}$, but sulfide at concentrations found in BBD, or higher, elicited a negative response. This response supports the "escaped convict hypothesis" proposed by Dr. DeEtta Mills, which states that the cyanobacterial population of BBD is likely trying to escape from the high sulfide concentrations caused by the presence of large populations of sulfate-reducing bacteria within the $\mathrm{BBD}$ mat. It is well documented that $\mathrm{BBD}$ sulfate-reducing bacteria proliferate and generate sulfide within the cyanobacterial matrix that constitutes BBD (Frias-Lopez et al., 2004; Viehman et al., 2006; Sekar et al., 2006, 2008; Sato et al., 2010). In an attempt to avoid the building sulfide concentrations, the cyanobacteria move away by migrating through the coral skeleton and coral tissue (Miller et al., 2011). A recent publication highlighted the importance of chemotaxis and chemokinesis in coral disease. The coral pathogen Vibrio coralliilyticus responds to dimethylsulfoniopropionate (DMSP), a chemical released by stressed corals, in both a chemotactic and chemokinetic manner (Garren et al., 2013). Results from Garren et al., (2013) exhibit the importance of chemical cues, like sulfur compounds, and pathogen motility to coral disease occurrence. In my results, I demonstrate a motility-based pathogenic role that $R$. reptotaenium plays in $\mathrm{BBD}$, specifically a mechanism by which the $\mathrm{BBD}$ mat moves across the host coral tissue. The chemotactic response exhibited by $R$. reptotaenium in response to chemical cues from sulfide is central to the pathogenicity of BBD. 
In contrast to $R$. reptotaenium, movement of $P$. raciborskii filaments was unaffected by high concentrations of sulfide. For this species, filaments were positively phototactic causing them to move across the plate and into the sulfide ring. Upon reaching areas of high sulfide content in both the horizontal and vertical gradient chemotactic experiments, $P$. raciborskii migration was not inhibited. The lack of chemotactic response may be explained by the cyanobacterium's exposure to sulfide within the hot spring. Hunter's Hot Springs is a sulfidic spring with concentrations recorded consistently at $2.6 \mathrm{mM}$ in the source water (Ward and Castenholz, 2000). Within the hot spring mat, sulfide concentrations can reach $0.8 \mathrm{mM}$ at night (Richardson and Castenholz, 1987). Constant exposure to these highly sulfidic conditions has likely forced the cyanobacterium to adapt to the toxin, negating a chemotactic response.

Roseofilum reptotaenium's chemotactic response to $\mathrm{MC}$ was not as clear cut as the response to sulfide. It seemed that filaments of $R$. reptotaenium were hindered by the higher concentrations ( 50 and $100 \mu \mathrm{g} / \mathrm{L}$ ) of $\mathrm{MC}$ in the test plug due to the lack of downwards migration. Yet within the horizontal migration experiments, filaments were unaffected by MC concentrations. The response to the directional light source caused filaments to travel through the areas of high MC concentration. The cause of discrepancy in response is likely due to the phototactic response to a directional light source. I concluded that MC is neither an attractant or repellant to $R$. reptotaenium.

Exposure to MC did not elicit a chemotactic reaction from P. raciborskii filaments. Although filaments of P. raciborskii travelled into areas of high MC concentrations in the horizontal experiment with the directional light source, results of the experiment with the non-directional (overhead) light-source demonstrated that MC 
was not acting as a chemoattractant. Therefore the positive reaction observed in the first experiment was likely a strong phototactic response.

While both test organisms used in this culture produce MC (Chapter III), neither was chemotactic to the toxin. Various researchers have shown that many of MC's proposed functions pertain to cyanobacterial cell metabolism and general cell functions (Zilliges et al., 2011), and the majority of studies have focused on MC production response based on environmental challenges (Holland and Kinnear, 2013; Neilan et al., 2013). It has been suggested that MC is a cell signaling molecule in that its presence will affect the synthesis of more microcystin (Schatz et al., 2007). My experiments conducted here assessed yet another potential signaling role of $\mathrm{MC}$, that of a signal in chemotaxis. However, there was no evidence to support this role.

In conclusion sulfide, as an elicitor of a chemotactic response, was shown to be different between two (pathogenic versus non-pathogenic) species of sulfide-tolerant cyanobacteria. The role of $R$. reptotaenium as a pathogenic cyanobacterium within BBD appears to be linked to its chemotactic response to sulfide in that the horizontal movement of the cyanobacterium away from the band may be controlled by a negative response to sulfide that is generated within the band. Thus the mechanism of horizontal movement of the entire pathogenic community may be based on the movement of the cyanobacteria that form the physical matrix of the band. The lack of response to sulfide by $P$. raciborskii suggests that this cyanobacterium is well adapted to the environmental conditions within Hunter's Hot Springs. Unlike the BBD environment, in which it is known that as the band develops there is a transition from oxygenated to sulfide-rich conditions (Carlton and Richardson, 1995; Glas et al., 2012), hot spring outflows such as 
Hunters Hot Springs exhibit the continual presence of sulfide. The different responses may therefore be related to the evolution of these cyanobacterial species in each system. The absence of a tactic response to a second toxin, microcystin, by either cyanobacterial species may similarly be based on the fact that the cyanobacteria themselves are the source of this compound. These results agree with the findings of others who have shown that the primary roles of microcystins are as toxins to other organisms and as secondary metabolites that regulate cyanobacterial physiology. 


\section{References}

Brock, TD, ML Brock, TL Bott, and MR Edwards. Microbial life at $90^{\circ} \mathrm{C}$ : the sulfur bacteria of Boulder Spring. J Bacteriol (1971) 107: 303-314.

Carlton, RD, and LL Richardson. Oxygen and sulfide dynamics in horizontally migrating cyanobacterial mat: black band disease of corals. FEMS Microbiol Ecol (1995) 18:155162.

Cohen-Bazire, G, and DA Bryant. Phycobilisomes: Composition and structure, pp. 143190. In Carr, NG, and BA Whitton (eds.), The Biology of Cyanobacteria. University of California Press, USA (1982).

Castenholz, RW. The behavior of Oscillatoria terebriformis in Hot Springs. J Phycol (1968) 4: 132-139.

Castenholz, RW. The effect of sulfide on the blue-green algae of hot springs. II. Yellowstone National Park. Microb Ecol (1977) 3: 79-105

Cohen, Y, B Jorgensen, N Revsbech, and R Poplawski. Adaptation to hydrogen-sulfide of oxygenic and anoxygenic photosynthesis among cyanobacteria. Appl Environ Microbiol (1986) 51: 398-407.

DeMott, WR and F Moxter. Foraging cyanobacteria by copepods: responses to chemical defense and resource abundance. Ecology (1991) 72: 1820-1834.

DeMott, WR, QX Zhang, and WW Carmichael. Effects of toxic cyanobacteria and purified toxins on the survival and feeding of a copepod and three species of Daphnia. Limnol Oceanogr (1991) 36: 1346-1357.

Dunn, GA. Conceptual problems with kinesis and taxis, pp. 1-43. In Armitage, JP and JM Lackie (eds.), Biology of the Chemotactic Response. Cambridge UP, UK. (1990).

Frias-Lopez, J, JS Klaus, GT Bonheyo, and BW Fouke. Bacterial community associated with black band disease in corals. Appl Environ Microbiol (2004) 70: 5955-5962.

Garren, M, K Son, JB Raina, R Rusconi, F Menolascina, OH Shapiro, J Tout, DG Bourne, JR Seymour, and R Stocker. A bacterial pathogen uses

dimethylsulfoniopropionate as a cue to target heat-stressed corals. The ISME J (2013) 19.

Glas, MS, Y Sato, KE Ulstrup, and DG Bourne. Biogeochemical conditions determine virulence of black band disease in corals. ISME J (2012) 6: 1526-1534. 
Holland, A, and S Kinnear. Interpreting the possible ecological role(s) of cyanotoxins: Compounds for competitive advantage and/or physiological aide? Mar Drugs (2013) 11: 2239-2258.

Jang, MH, K Ha, GJ Joo, and N Takamura. Toxin production of cyanobacteria is increased by exposure to zooplankton. Freshwater Biol (2003) 48: 1540-1550.

Miller, SR, and BM Bebout. Variation in sulfide tolerance of photosystem II in phylogenetically diverse cyanobacteria from sulfidic habitats. Appl Environ Microbiol (2004) 70: 736-744.

Miller, AW, P Blackwelder, H Al-Sayegh, and LL Richardson. Fine-structural analysis of black band disease-infected coral reveals boring cyanobacteria and novel bacteria. Dis Aquat Org (2011) 93: 179-190.

Mills, DK. Forensic DNA Profiling Laboratory. Florida International University. Personal communication.

Myers, JL, and LL Richardson. Adaptation of cyanobacteria to the sulfide-rich microenvironment of black band disease of coral. Microb Ecol (2008) 67: 242-251.

Neilan, BA, LA Pearson, J Muenchhoff, MC Moffitt, and E Dittman. Environmental conditions that influence toxin biosynthesis in cyanobacteria. Environ Microbiol (2013) 15: $1239-1253$.

Rantala, A, DP Fewer, M Hisbergues, L Rouhiainen, J Vaitomaa, T Börner and K Sivonen. Phylogenetic evidence for the early evolution of microcystin synthesis. PNAS (2004) 101: 568-573.

Richardson, LL. Horizontal and vertical migration patterns of Phormidium corallyticum and Beggiatoa spp. associated with black-band disease of coral. Microb Ecol (1996) 32: 323-335.

Richardson, LL, and RW Castenholz. Diel vertical movements of the cyanobacterium Oscillatoria terebriformis in a sulfide-rich hot spring microbial mat. Appl Environ Microbiol (1987) 53: 2142-2150.

Richardson, LL, and RW Castenholz. Chemokinetic motility responses of the cyanobacterium Oscillatoria terebriformis. Appl Environ Microbiol (1989) 55: 261-263.

Rützler, K, and DL Santavy. The black band disease of Atlantic reef corals: I. Description of the cyanophyte pathogen. Mar Ecol (1983) 4: 301-319. 
Sato, Y, BL Willis, and DG Bourne. Successional changes in bacterial communities during the development of black band disease on the reef coral, Montipora hispida. The ISME J (2010) 4: 203-214.

Sekar, R, DK Mills, ER Remily, JD Voss, and LL Richardson. Microbial communities in the surface mucopolysaccharide layer and the black band microbial mat of black banddiseased Siderastrea siderea. Appl Environ Microbiol (2006) 72: 5963-5973.

Sekar, R, LT Kaczmarsky, and LL Richardson. Microbial community composition of black band disease on the coral host Siderastrea siderea from three regions of the wider Caribbean. Mar Ecol-Prog Ser (2008) 362: 85-98.

Schatz, D, Y Keren, A Vardl, A Sukenlk, S Carmell, T Börner, E Dittmann, and A Kaplan. Towards clarification of the biological role of microcystins, a family of cyanobacterial toxins. Env Microb (2007) 9: 965-970.

Viehman, S, DK Mills, GW Meichel, and LL Richardson. Culture and identification of Desulfovibrio spp. from corals infected by black band disease on Dominican and Florida Keys reefs. Dis Aquat Org (2006) 69: 119-127.

Ward, DM, and RW Castenholz. "Cyanobacteria in geothermal habitats." The Ecology of Cyanobacteria. Springer, Netherlands (2000) 37-59.

Zilliges, Y, JC Kehr, S Meissner, K Ishida, S Mikkat, M Hagemann, A Kaplan, T Börner, and E Dittman. The cyanobacterial hepatotoxin microcystin binds to proteins and increases the fitness of Microcystis under oxidative stress conditions. PLoS ONE (2011) 6: e17615. 


\section{Tables}

Table 1. Chemotactic response of Roseofilum reptotaenium and Planktothricoides raciborskii to sulfide. The average distance ( \pm range) of the filaments from the sulfide ring on triplicate plates per trial is reported in centimeters. Filaments of $R$. reptotaenium in control plates travelled significantly further $(\mathrm{F}(1,11)=5.551, \mathrm{P}<0.05)$ than filaments on experimental plates towards the side of the plate closest to the light source. There was no a significant difference $(\mathrm{F}(1,10)=0.353, \mathrm{P}=0.5)$ between distance travelled on experimental and control plates of $P$. raciborskii. Triplicate plates were used per trial.

\begin{tabular}{ccc}
\hline Trial & \multicolumn{2}{c}{ Distance from Sulfide $(\mathrm{cm})$} \\
\hline & R. reptotaenium & P. raciborskii \\
1 & $3.1 \pm 0.8$ & $0.7 \pm 1.6$ \\
2 & $3.1 \pm 1.0$ & $0.4 \pm 1.1$ \\
3 & $3.0 \pm 1.7$ & $0.8 \pm 0.8$ \\
\hline Control & $1.8 \pm 3.1$ & $0.9 \pm 0.8$ \\
\hline
\end{tabular}


Table 2. Chemotactic response of Roseofilum reptotaenium and Planktothricoides raciborskii to microcystin. The average distance ( \pm range) of the filaments from the challenge well on triplicate plates per trial is reported in centimeters. Statistical analysis indicated that there was not a significant difference $(\mathrm{F}(3,32)=0.031, \mathrm{P}=0.99)$ in distance travelled between experimental and control plates of $R$. reptotaenium. Statistical analysis indicated there was not a significant difference $(\mathrm{F}(3,32)=0.337, \mathrm{P}=0.79)$ in migration distance of P. raciborskii filaments between control and experimental plates. Triplicates plates containing each concentration of microcystin were used per trial.

\begin{tabular}{cccc}
\hline$[\mathrm{MC}]$ & Trial & \multicolumn{2}{c}{ Distance from challenge well $(\mathrm{cm})$} \\
\hline & & R. reptotaenium & P. raciborskii \\
$1 \mu \mathrm{g} / \mathrm{L}[\mathrm{MC}]$ & 1 & $0.8 \pm 0.5$ & $0.7 \pm 0.7$ \\
& 2 & $1.5 \pm 0.3$ & $1.6 \pm 0.8$ \\
& 3 & $1.2 \pm 1.1$ & $0.5 \pm 1.4$ \\
Control & & $1.4 \pm 0.8$ & $0.4 \pm 1.6$ \\
\hline $50 \mu \mathrm{g} / \mathrm{L}[\mathrm{MC}]$ & 1 & $1.2 \pm 1.1$ & $1.2 \pm 1.1$ \\
& 2 & $1.2 \pm 0.8$ & $0.3 \pm 1.0$ \\
& 3 & $0.9 \pm 1.9$ & $0.4 \pm 0.5$ \\
Control & & $1.5 \pm 0.5$ & $1.3 \pm 0.8$ \\
\hline $100 \mu \mathrm{g} / \mathrm{L}[\mathrm{MC}]$ & 1 & $1.1 \pm 1.7$ & $0.9 \pm 1.2$ \\
& 2 & $1.5 \pm 1.6$ & $1.3 \pm 0.8$ \\
& 3 & $1.1 \pm 0.9$ & $0.9 \pm 2.4$ \\
\hline Control & & $1.0 \pm 1.3$ & $0.6 \pm 1.3$ \\
\hline
\end{tabular}


Table 3. Chemotactic response of Roseofilum reptotaenium and Planktothricoides raciborskii to microcystin when incubated under a diffuse light source. The average distance ( \pm range) of the filaments from the challenge well on triplicate plates per trial is reported in centimeters. There was not a significant difference $(\mathrm{F}(3,32)=0.395, \mathrm{P}=$ 0.75 ) in the distance travelled by filaments on experimental versus control plates of $R$. reptotaenium. Statistical analysis showed that there is not a significant difference (F (3, $32)=1.260, \mathrm{P}=0.30)$ in migration distances of experimental and control plates of $P$. raciborskii.

\begin{tabular}{cccc}
\hline$[\mathrm{MC}]$ & Trial & \multicolumn{2}{c}{ Distance from challenge well $(\mathrm{cm})$} \\
\hline & & R. reptotaenium & P. raciborskii \\
$1 \mu \mathrm{g} / \mathrm{L}[\mathrm{MC}]$ & 1 & $3.4 \pm 1.0$ & $3.6 \pm 0.7$ \\
& 2 & $3.6 \pm 0.4$ & $3.7 \pm 0.4$ \\
& 3 & $3.6 \pm 0.1$ & $3.1 \pm 0.6$ \\
Control & & $3.5 \pm 0.4$ & $3.7 \pm 0.4$ \\
\hline $50 \mu \mathrm{g} / \mathrm{L}[\mathrm{MC}]$ & 1 & $3.4 \pm 0.4$ & $3.7 \pm 0.4$ \\
& 2 & $3.7 \pm 0.4$ & $3.6 \pm 0.8$ \\
Control & 3 & $3.4 \pm 0.5$ & $3.5 \pm 0.5$ \\
\hline $100 \mu \mathrm{g} / \mathrm{L}[\mathrm{MC}]$ & 1 & $3.5 \pm 0.5$ & $3.6 \pm 0.1$ \\
& 2 & $3.8 \pm 0.2$ & $3.6 \pm 0.2$ \\
& 3 & $3.5 \pm 0.3$ & $3.6 \pm 0.1$ \\
\hline Control & & $3.6 \pm 0.2$ & $3.8 \pm 0.2$ \\
\hline
\end{tabular}


Table 4.Chemotactic response of Roseofilum reptotaenium and Planktothricoides raciborskii to microcystin and sulfide in vertical gradients. The average distance $( \pm$ range) of filaments travelled into the agar plug is reported in centimeters. Triplicate experiments were combined to represent measurement data.

\begin{tabular}{ccc}
\hline Toxin Concentration & \multicolumn{2}{c}{ Downward Migration [cm] } \\
\hline & R. reptotaenium & P. raciborskii \\
$1 \mu \mathrm{g} / \mathrm{L}[\mathrm{MC}]$ & $2.29 \pm 0.63$ & $1.25 \pm 0.63$ \\
$50 \mu \mathrm{g} / \mathrm{L}[\mathrm{MC}]$ & $1.25 \pm 0$ & $2.08 \pm 1.25$ \\
$100 \mu \mathrm{g} / \mathrm{L}[\mathrm{MC}]$ & $2.08 \pm 1.25$ & $2.5 \pm 0$ \\
\hline $1 \mu \mathrm{M}$ Sulfide & $2.5 \pm 0$ & $2.08 \pm 1.25$ \\
$100 \mu \mathrm{M}$ Sulfide & $1.49 \pm 0.63$ & $1.67 \pm 1.25$ \\
$1 \mu \mathrm{M}$ Sulfide & $1.67 \pm 0.63$ & $2.08 \pm 0.625$ \\
\hline Control & $2.5 \pm 0$ & $2.08 \pm 1.25$ \\
\hline
\end{tabular}




\section{Figures}

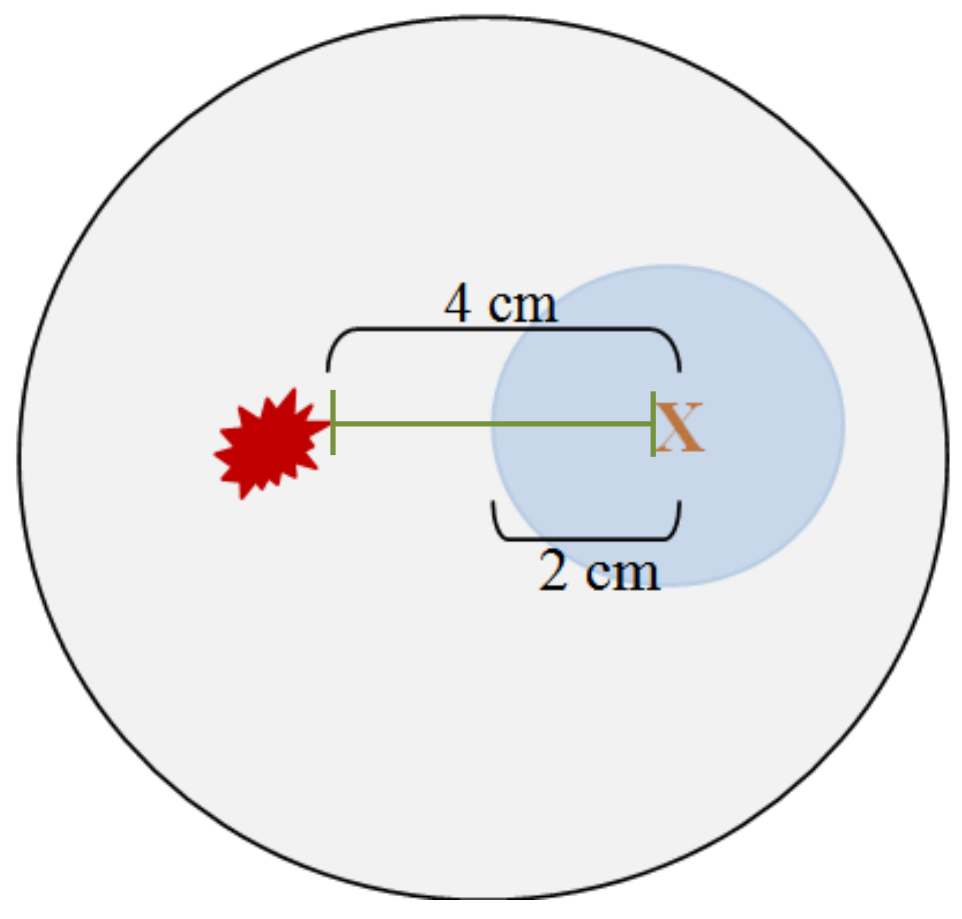

Figure 1. A depiction of the migration distance measurement in the horizontal chemotaxis experiment. The green line indicates the distance measured from the closest cyanobacterial filament $\left(\frac{3}{m}\right)$ to the area where either microcystin or sulfide was plated (X). The blue circle denotes the diffusion ring of sulfide and microcystin the sulfide-ring. Note: The sulfide ring is not visible on BG-11 agar plates. The microcystin ring was not visible on either type of agar plate. 


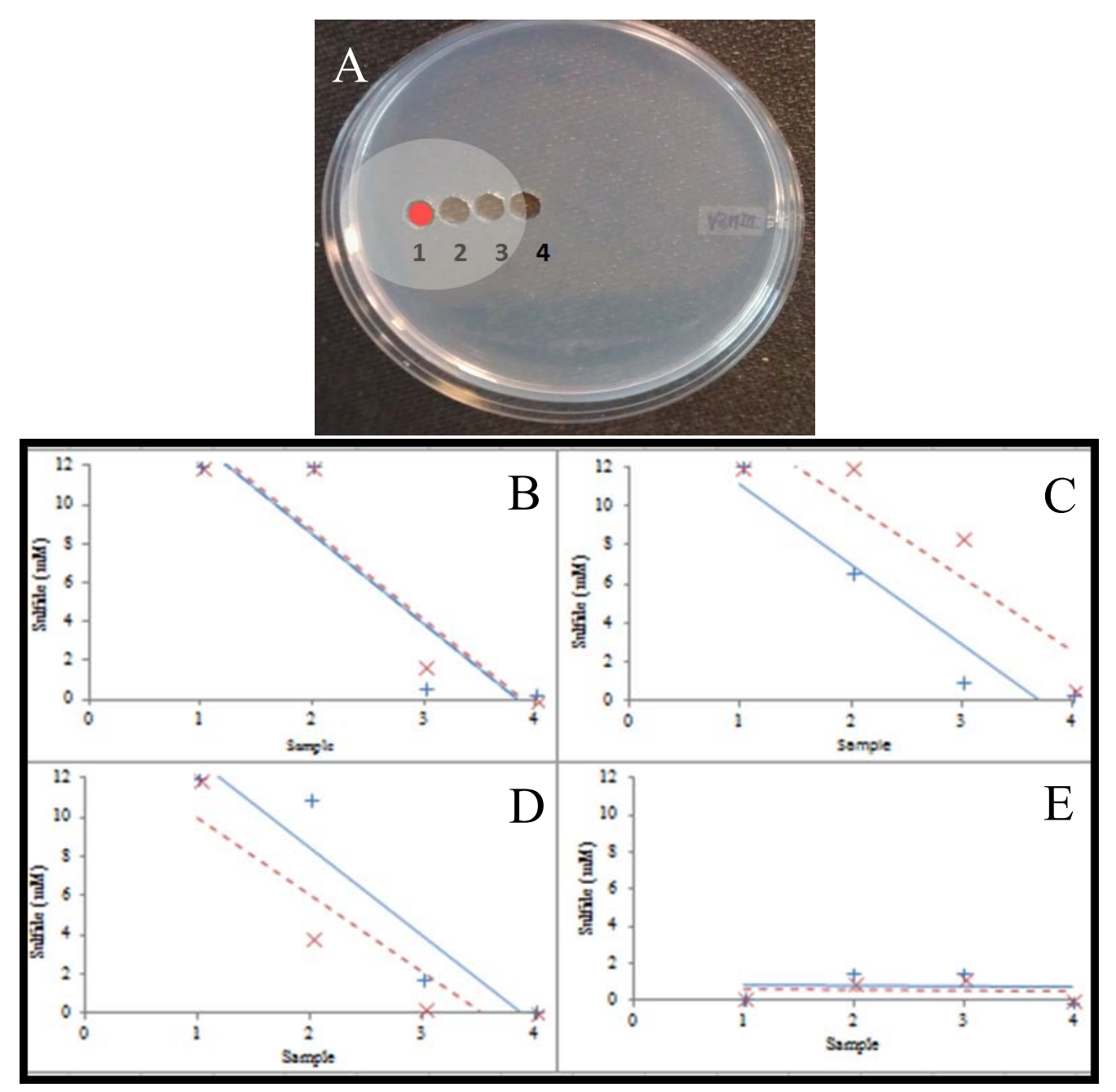

Figure 2. A) Sample collection for the Pachmayr Assay to document the sulfide gradient in the horizontal sulfide chemotaxis experiments. The red circle indicates where $25 \mathrm{mg}$ of sodium-sulfide nonahydrate crystals were originally plated. The opaque area is indicative of the sulfide-ring. Four samples, as designated by the black numbers, were taken from each plate over time (see text). B - E) Changes in the sulfide gradient over time. Sulfide concentrations within the sulfide-ring of ASN-III (red +, dotted line) and BG-11 (blue ×, solid line) agar plates. Trendlines show the gradient change in sulfide between the center of the sulfide ring and the edge. Graph $B$ ) $t=1$ hour, C) $t=12$ hours, D) $t=1$ day, E) $t=$ 4 days. (Photograph by AC Brownell) 


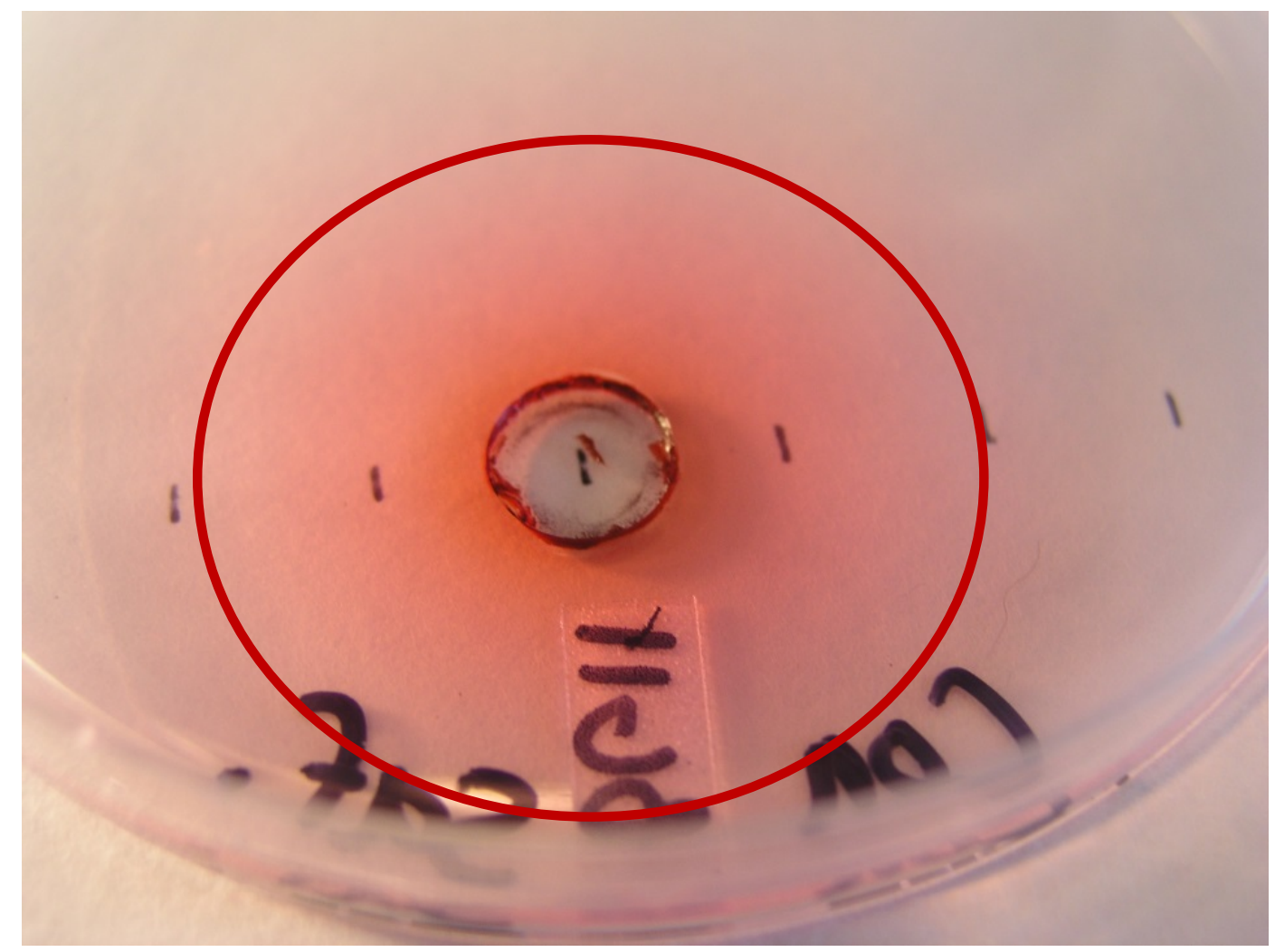

Figure 3. Diffusion of a mixture of microcystin and safranin dye into agar. The pink hue denotes the area of diffused solution in the agar. The red circle depicts the extent of the microcystin-ring. The diameter of the ring was approximately four inches. (Photograph by AC Brownell) 


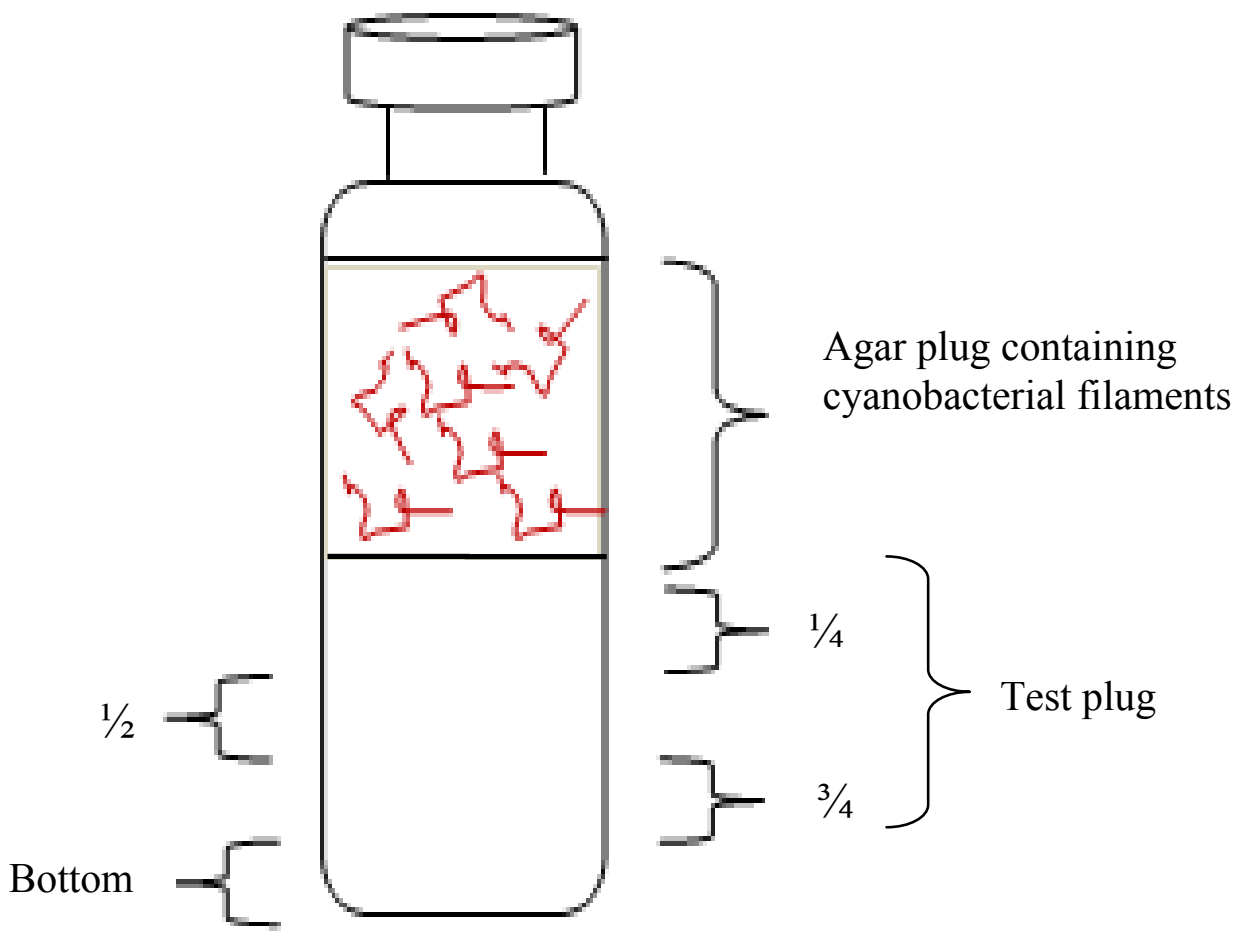

Figure 4. Depiction of the vertical chemotaxis experiment. The test substances were added to the test plug. The distance each filament travelled into the test plug is indicated by $1 / 4,1 / 2,3 / 4$, or to the bottom, representing distances of $0.625,1.25,1.875$ and $2.5 \mathrm{~cm}$. 


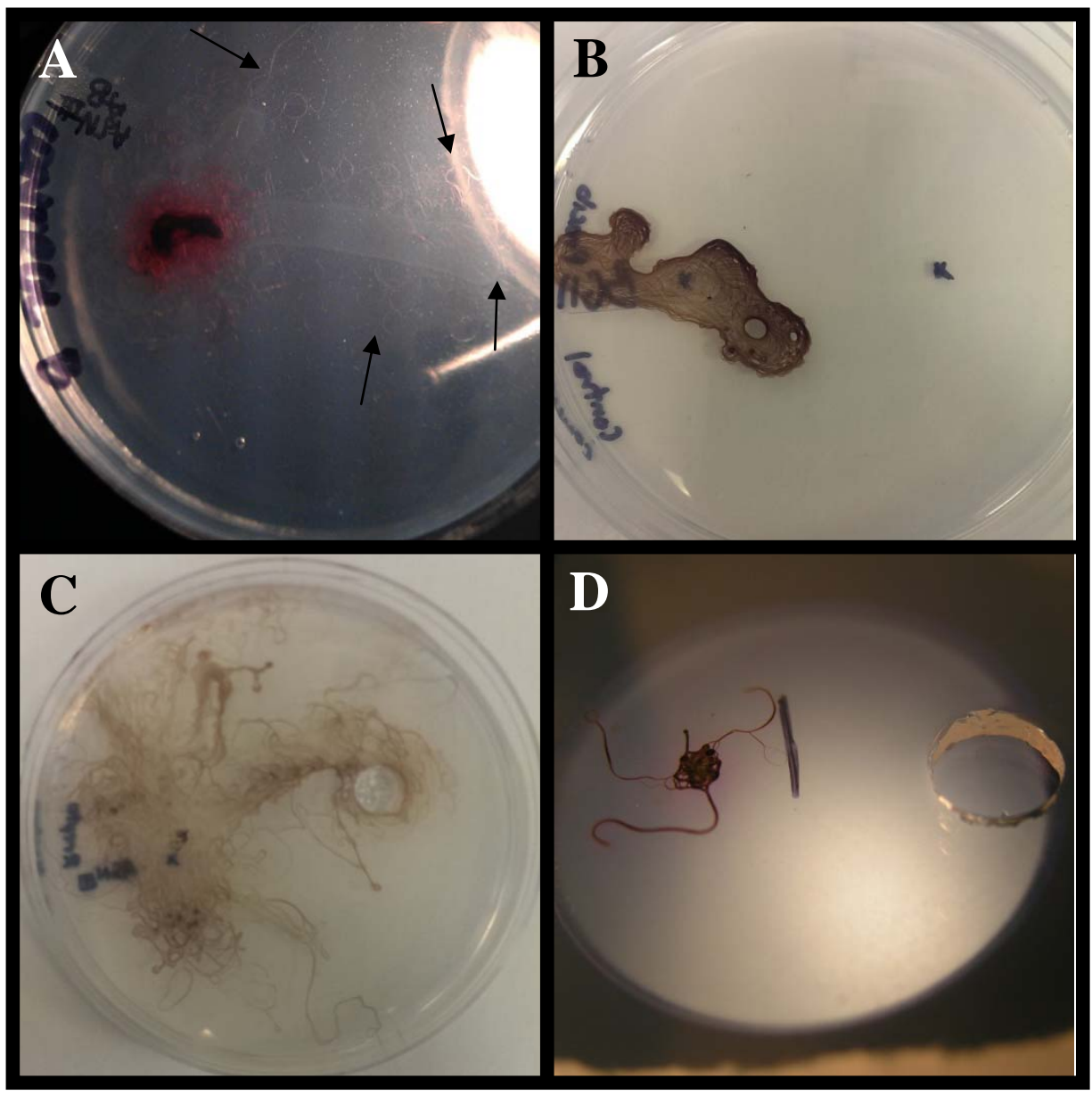

Figure 5. Comparison of Roseofilum reptotaenium (A and C) and Planktothricoides raciborskii (B and D) control plates in the sulfide (top) and microcystin (bottom) chemotaxis experiments. Toxins were not present in the control plates. When incubated, the light source would have been to the right of the plates. Filaments of $R$. reptotaenium travelled across the plate towards the light source. Filaments of $P$. raciborskii did not have a strong phototactic response to light. Black arrows highlight filaments that are difficult to visualize. (Photograph by AC Brownell) 


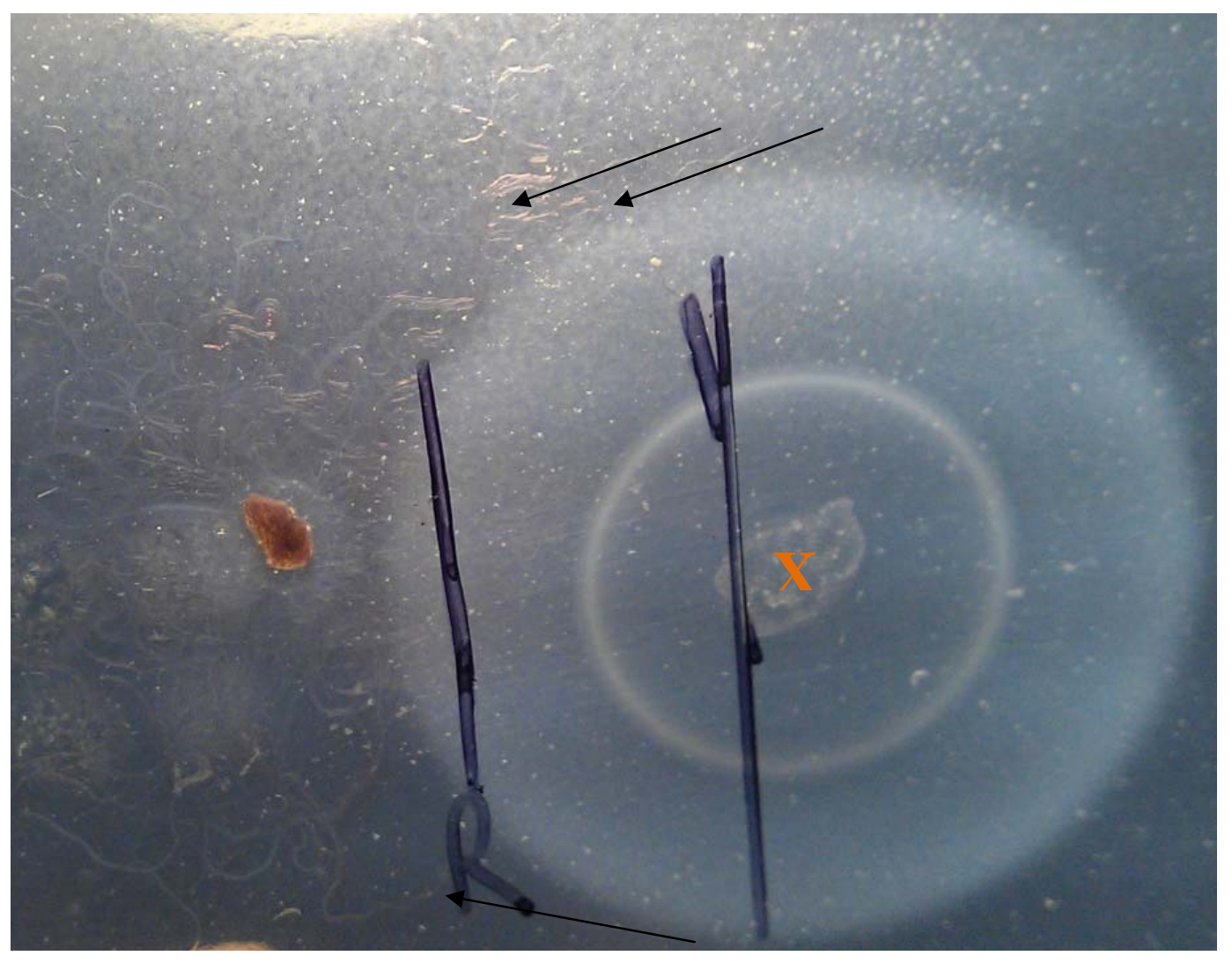

Figure 6. Movement of Roseofilum reptotaenium filaments around the sulfide-ring (opaque area). Arrows highlight filaments that are moving along the edge of the sulfidering. The orange $\mathrm{X}$ denotes the area in which sulfide crystals were plated. (Photograph by AC Brownell) 


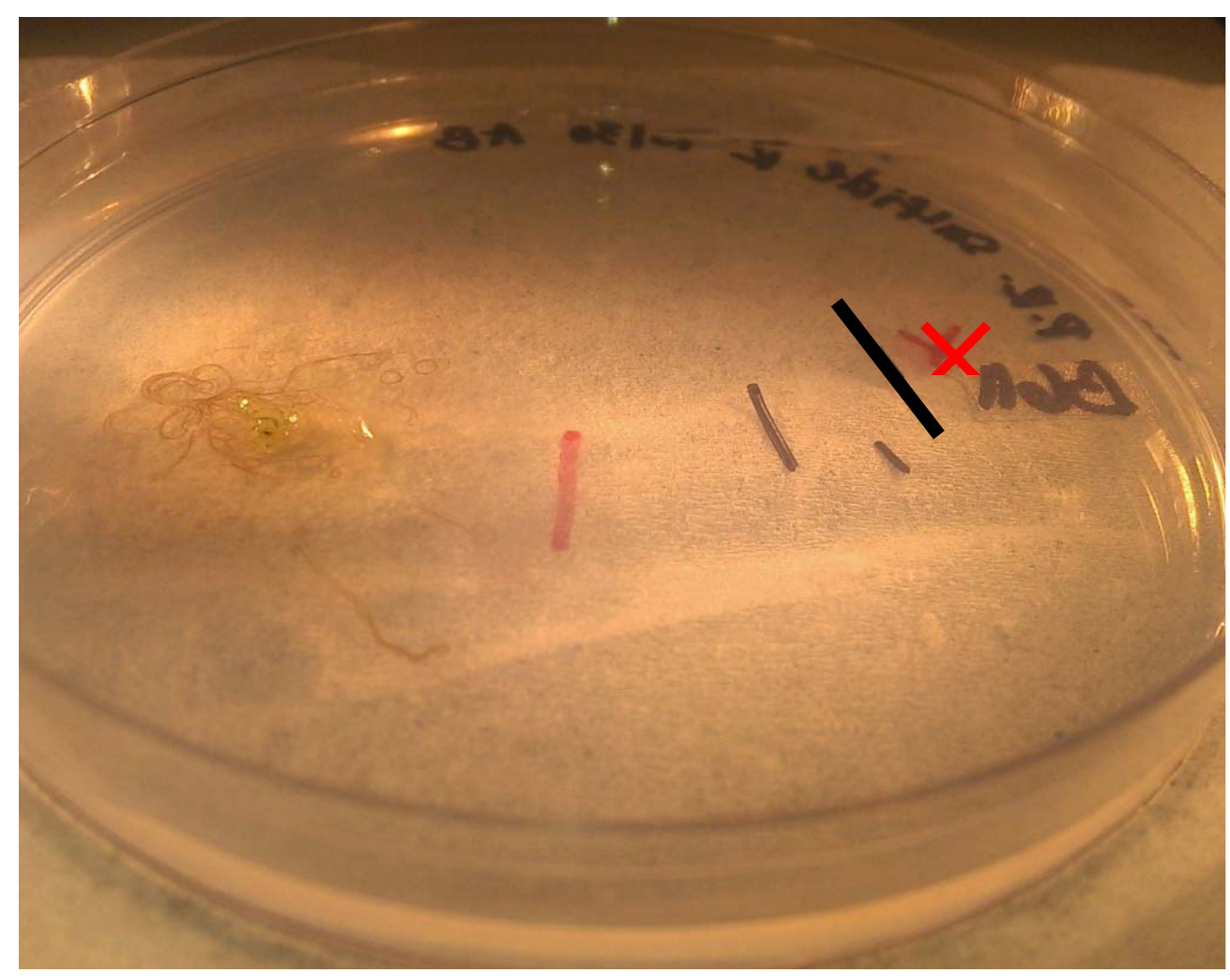

Figure 7. Chemotaxis of Planktothricoides raciborskii filaments into the area of high sulfide concentration. A sulfide-ring is not visible on BG-11 agar; the red $\times$ denotes the area where the sulfide crystals were plated. The heavy black line indicates the furthest that filaments travelled. (Photograph by AC Brownell) 


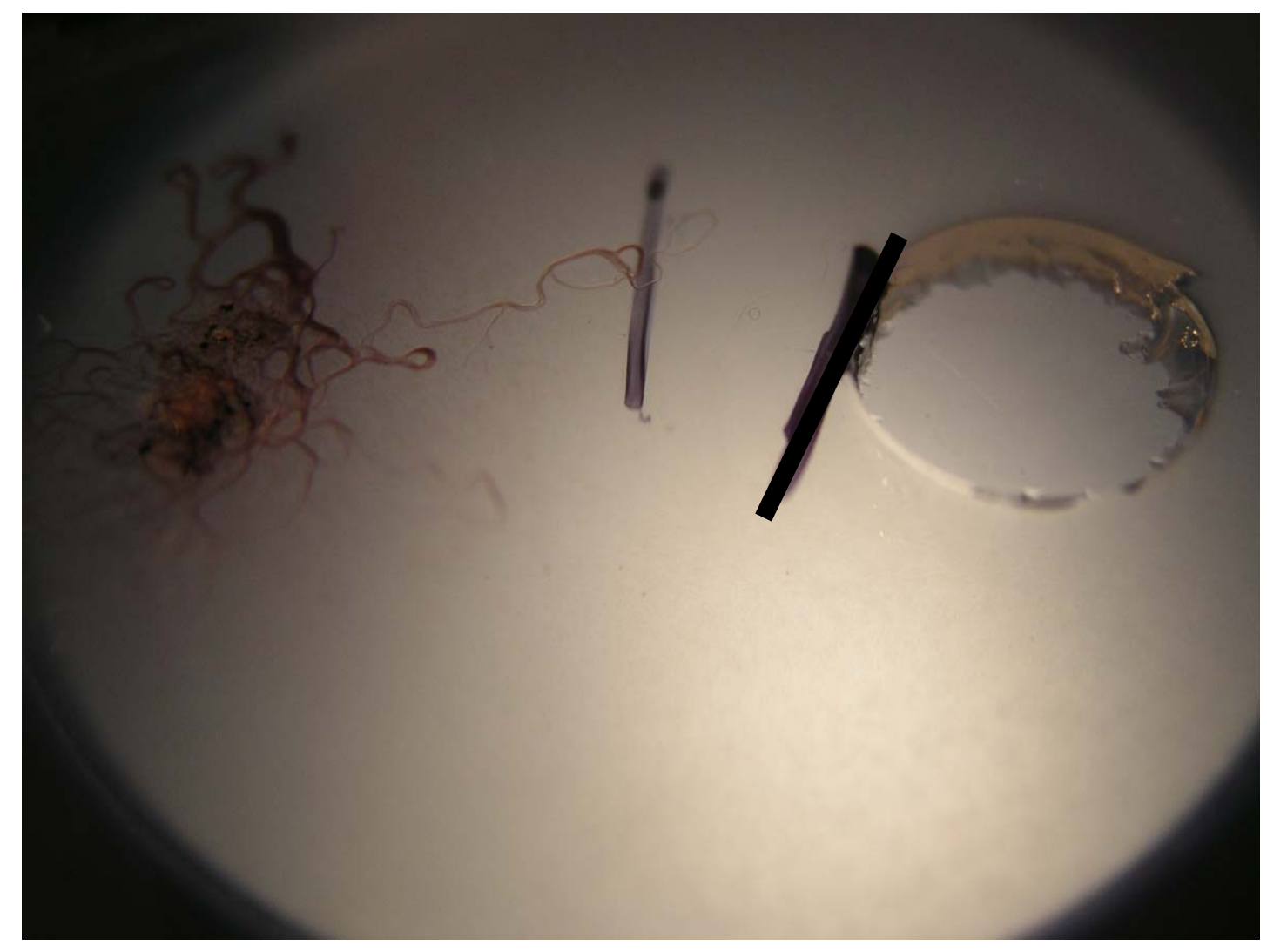

Figure 8: Chemotactic response of Roseofilum reptotaenium to microcystin. The heavy

black line indicates the furthest distance travelled by the filaments. The filaments travelled up to the edge of the challenge well containing MC. (Photograph by AC Brownell) 


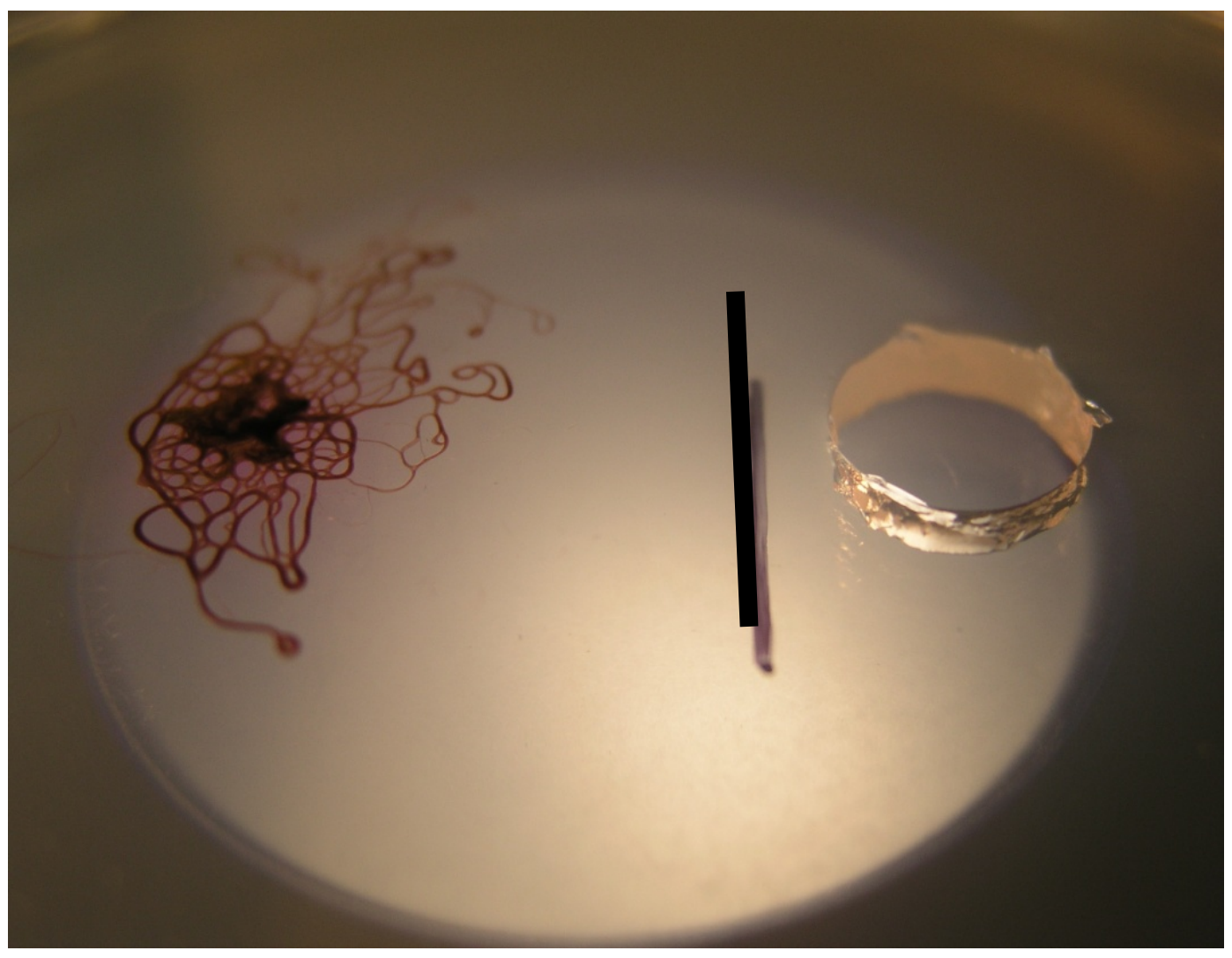

Figure 9: Chemotactic response of Planktothricoides raciborskii to microcystin. The heavy black line depicts the distance travelled by the filaments. The challenge well is visible on the right. (Photograph by AC Brownell) 


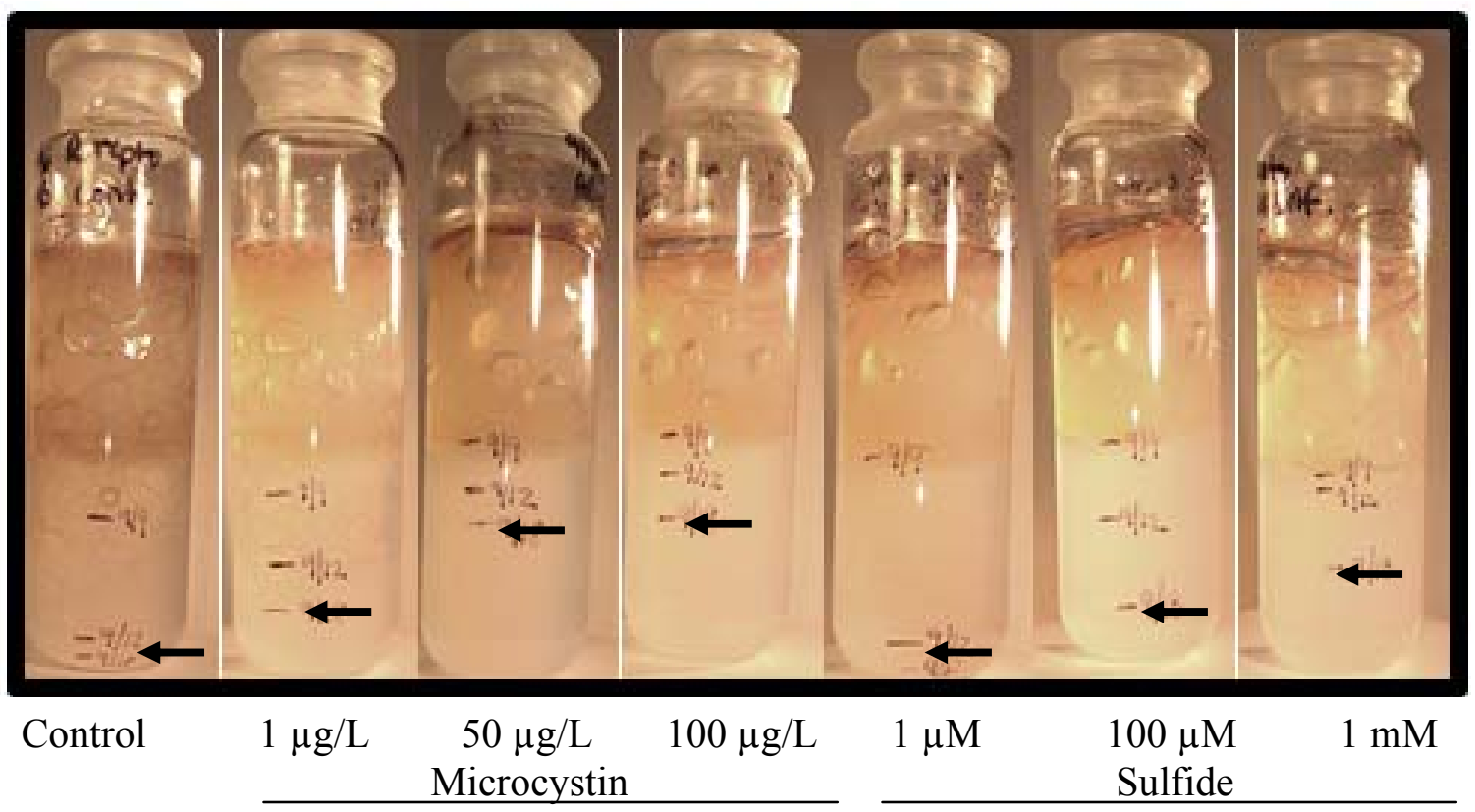

Figure 10. Response of Roseofilum reptotaenium to artificial gradients of microcystin and sulfide in the vertical chemotaxis experiment. Black arrows indicate depth to which filaments travelled within each vial. (Photographs by AC Brownell) 


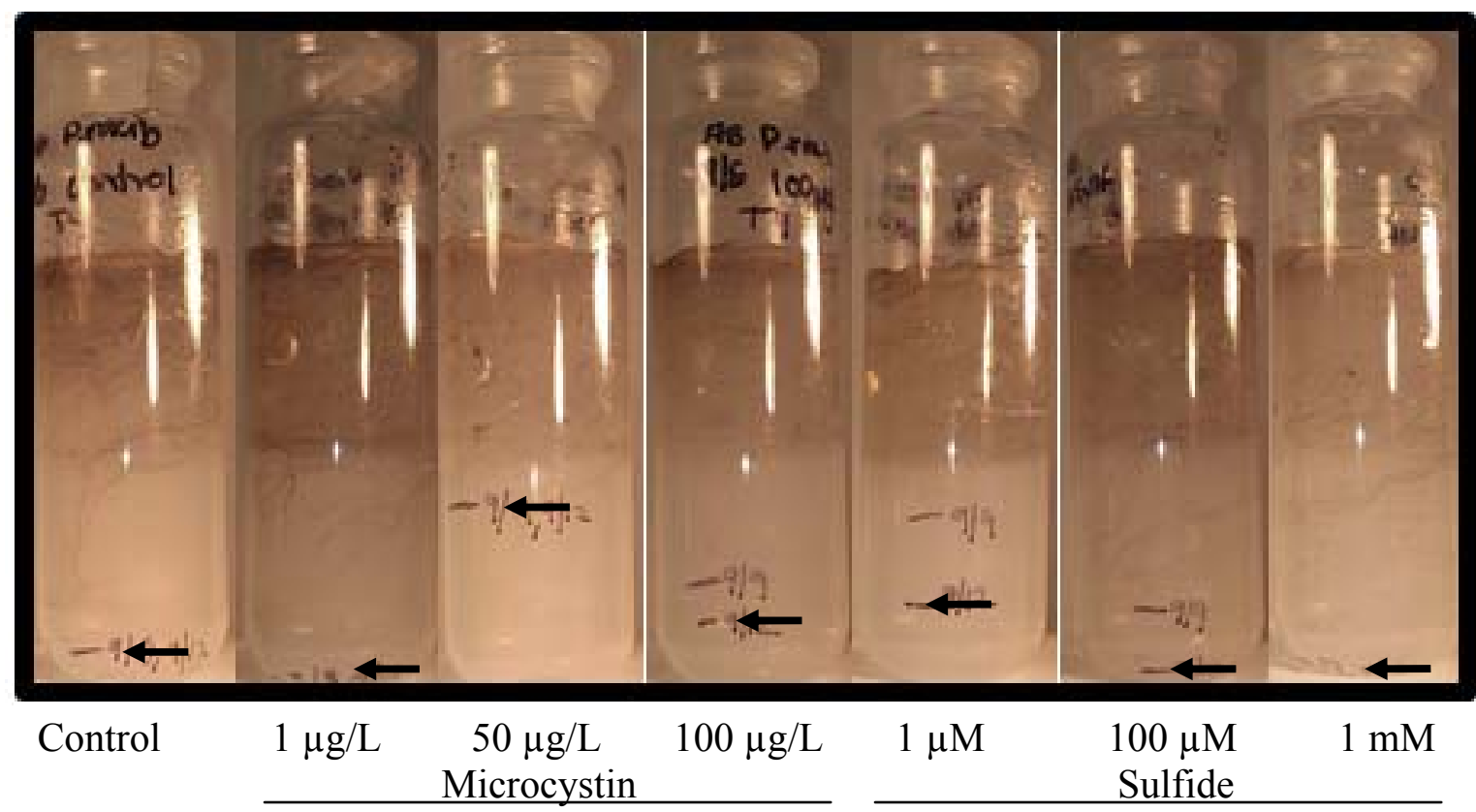

Figure 11. Response of Planktothricoides raciborskii to artificial gradients of microcystin and sulfide in a vertical chemotaxis trial. Black arrows indicate depth to which filaments travelled within each vial. (Photographs by AC Brownell) 


\section{CHAPTER V}

\section{CONCLUSIONS}

The two cyanobacterial species that were the subjects of my study share morphological and physiological characteristics, yet they form cyanobacterial mats in ecologically distinct systems. Roseofilum reptotaenium is the dominant cyanobacterium in black band disease (BBD) of coral, whereas Planktothricoides raciborskii is part of a non-pathogenic, photoautotrophically-based cyanobacterial mat in a sulfidic hot spring outflow. Comparing the roles of these cyanobacteria provides insights into cyanobacterial mat communities in terms of pathogenic versus non-pathogenic systems. The objectives of my thesis were to: (i) investigate the role of sulfide in black band disease pathogenesis, (ii) elucidate the impact of microcystin and sulfide on pathogenicity of these cyanobacteria, (iii) compare the effects of environmental factors on microcystin production by these cyanobacteria, and (iv) determine the tactic response of these cyanobacteria to two toxic compounds.

Results from chapter II further elucidate the role of primary and secondary pathogens in BBD. Sulfate reducing bacteria (SRB) produce toxic concentrations of sulfide within the BBD mat (Carlton and Richardson, 1995; Glas et al., 2012).

Richardson et al. (2009) found that sodium molybdate (a metabolic inhibitor of sulfate reduction) prevented freshly collected BBD inoculum from infecting healthy coral fragments. Their results suggested that $\mathrm{SRB}$ are required for $\mathrm{BBD}$ pathogenesis when the complete pathogenic consortium is present (Richardson et al., 2009). Stanić (2010) identified $R$. reptotaenium as the potential primary pathogen of BBD. In her work a unialgal culture of the cyanobacterium infected and caused a BBD-like lesion on healthy 
coral fragments. In my study, I sought to clarify the roles of $R$. reptotaenium and SRB as primary and secondary pathogens of the complex, polymicrobial disease. I found that the unialgal inoculum of $R$. reptotaenium was unable to infect healthy coral fragments in the presence of sodium molybdate. My results show that SRB are required in the initial stages of BBD mat formation. I propose that BBD infection is induced by a sequential community of pathogens that includes $R$. reptotaenium as the primary pathogen and SRB as the secondary pathogens. The cyanobacterium is required for initial colonization of coral tissue at the site of infection (Stanić 2010; Chapter II); as the cyanobacterial biomass increases, an anaerobic environment is created at the mat-coral interface (Carlton and Richardson, 1995). Anaerobic conditions select for SRB from the seawater (Richardson and Kuta, 2003). Sulfate reduction by SRB leads to an accumulation of hydrogen sulfide within the band which is toxic to coral tissue and causes tissue degradation (Miller and Richardson, 2012). Further work is necessary to determine the sequence of infection by other pathogenic members of the BBD consortium. My work presented in chapter II provides evidence for SRB as secondary and necessary pathogens in BBD.

Results presented in chapter III demonstrate the cyanotoxin production potential of both P. raciborskii and $R$. reptotaenium. Microcystin production varied in response to environmental factors (temperature, $\mathrm{pH}$, trace metals, and nitrate). Microcystin production by $P$. raciborskii was stable when exposed to $35^{\circ} \mathrm{C}$ but $\mathrm{MC}$ production decreased in response to 7.0 and $9.0 \mathrm{pH}, 40^{\circ} \mathrm{C}, 10 \mu \mathrm{M} \mathrm{FeCl}$, and $10 \mu \mathrm{M} \mathrm{NaNO}$. The decrease was significant $(\mathrm{P}<0.05)$ in response to excess $\mathrm{FeCl}(10 \mu \mathrm{M})$ and $\mathrm{NaNO}_{3}(10$ $\mu \mathrm{M})$. In this experiment, $R$ reptotaenium decreased production in response to $10 \mu \mathrm{M}$ 
FeCl. Overall, $R$. reptotaenium produced significantly more $(\mathrm{p}<0.05) \mathrm{MC}$ than $P$. raciborskii. Results published by Stanić (2010) showed that $R$. reptotaenium decreased $\mathrm{MC}$ production in response to increased temperatures, but was unaffected by $\mathrm{pH}$ changes. The difference in toxicity is in agreement with the pathogenic versus non-pathogenic nature of the cyanobacteria in relation to their respective environments. In BBD, MC production by $R$. reptotaenium plays a central role in coral tissue degradation and disease pathogenesis (Richardson et al., 2009; Miller and Richardson, 2012). At this time, no studies have documented a pathogenic role of $P$. raciborskii in Hunters Hot Springs.

Chapter IV focused on documenting chemotactic responses of $R$. reptotaenium and $P$. raciborskii to $\mathrm{MC}$ and sulfide. Both toxins are present in $\mathrm{BBD}$ and Hunters Hot Springs cyanobacterial mats. Microcystin is produced by R. reptotaenium and other disease consortium cyanobacteria in BBD (Gantar et al., 2009; Stanić et al., 2011), and by P. raciborskii in Hunter's Hot Springs (Chapter III). Future studies should be conducted to determine whether the other cyanobacteria within Hunter's Hot Springs produce MC. Populations of sulfate reducing bacteria cause high concentrations of sulfide ( $\sim .7 \mathrm{mM}$ ) to develop below the surface of the BBD, whereas sulfide is present in the source water in Hunter's Hot Springs (Richardson and Castenholz, 1987; Carlton and Richardson, 1995; Glas et al., 2012). Sulfide concentrations as low as $0.1 \mathrm{mM}$ can poison Photosystem II of photosynthetic electron transport in cyanobacteria (Cohen et al., 1986). However, both $P$. raciborskii and $R$. reptotaenium conduct sulfide-insensitive oxygenic photosynthesis, which is a rare cyanobacterial attribute (Castenholz, 1977; Myers et al., 2008). The chemotactic responses to sulfide and MC were determined using chemotaxis assay. Results showed that filaments of $R$. reptotaenium were negatively chemotactic to 
sulfide. Conversely, P. raciborskii did not respond chemotactically to sulfide. Neither test organisms did not exhibited a chemotactic response to MC. I concluded that sulfide is a chemorepellant to R. reptotaenium in the BBD cyanobacterial mat, in support of the "escaped convict hypothesis". The difference in chemotactic reaction to sulfide by $R$. reptotaenium and $P$. raciborskii may reflect the pathogenic status of each cyanobacterium. A lack of chemotactic response to $\mathrm{MC}$ indicates that the toxin does not affect migration of the cyanobacteria within their respective systems. 


\section{References}

Carlton, R, and LL Richardson. Oxygen and sulfide dynamics in a horizontally migrating cyanobacterial mat - black band disease of corals. FEMS Microbiol Ecol (1995) 18: 155162.

Castenholz, RW. The effect of sulfide on the blue-green algae of hot springs II. Yellowstone National Park. Microb Ecol (1977) 3: 79-105.

Cohen, Y, B Jørgensen, N Revsbech, and R Poplawski. Adaptation to hydrogen-sulfide of oxygenic and anoxygenic photosynthesis among cyanobacteria. Appl Environ Microbiol (1986) 51: 398-407.

Gantar, M, R Sekar, and LL Richardson. Cyanotoxins from black band disease of corals and from other coral reef environments. Microb Ecol (2009) 58: 856-864.

Glas, MS, Y Sato, KE Ulstrup, and DG Bourne. Biogeochemical conditions determine virulence of black band disease in corals. The ISME J (2012) 6: 1526-1534.

Miller, AW, and LL Richardson. Fine structure analysis of black band disease (BBD) infected coral and coral exposed to the BBD toxins microcystin and sulfide. $J$ Invertebr Pathol (2012) 109: 27-33.

Myers, JL, and LL Richardson. Adaptations of cyanobacteria to the sulfide-rich microenvironment of black band disease of coral. Microb Ecol (2008) 67: 242-251.

Richardson, LL, and RW Castenholz. Diel vertical movements of the cyanobacterium Oscillatoria terebriformis in a sulfide-rich hot spring microbial mat. Appl Environ Microbiol (1987) 53: 2142-2150.

Richardson, LL, and KG Kuta. Ecological physiology of the black band disease cyanobacterium Phormidium corallyticum. FEMS Microb Ecol (2003) 43: 287-298.

Richardson, LL, AW Miller, E Broderick, L Kaczmarsky, M Gantar, D Stanić, and R Sekar. Sulfide, microcystin, and the etiology of black band disease. Dis Aquat Organ (2009) 87: 79-90.

Stanić, D. Characterization of Oscillatoria spp. and their role in black band disease of coral. M. S. Thesis, Florida International University, Miami, Florida. (2010) 103 pp.

Stanić, D, S Oehrle, M Gantar, and LL Richardson. Microcystin production and ecology physiology of Caribbean black band disease cyanobacteria. Environ Microbiol (2011) 13: 900-910. 